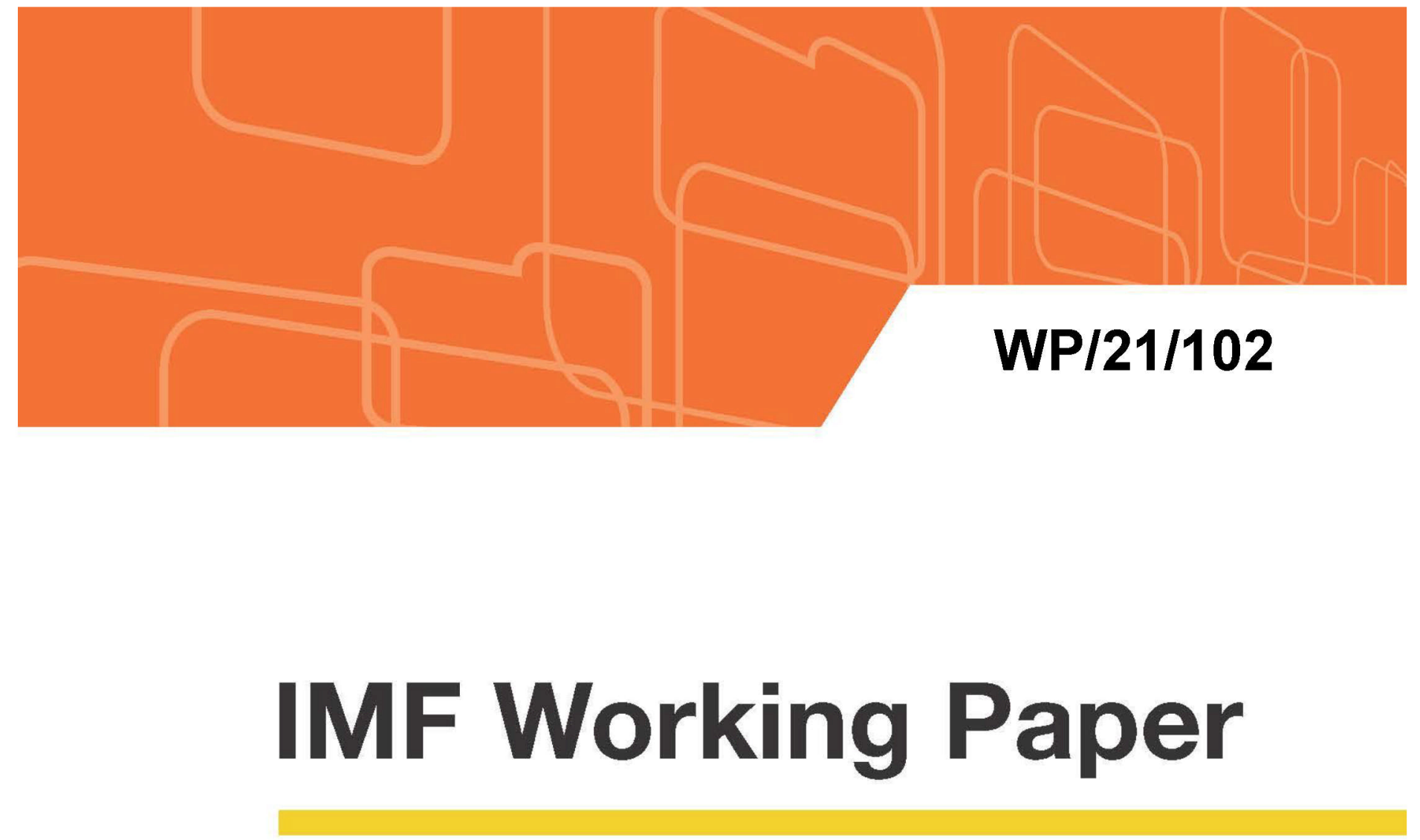

\title{
Competition vs. Stability: Oligopolistic Banking System with Run Risk
}

by Damien Capelle

IMF Working Papers describe research in progress by the author(s) and are published to elicit comments and to encourage debate. The views expressed in IMF Working Papers are those of the author(s) and do not necessarily represent the views of the IMF, its Executive Board, or IMF management.

$$
\text { I N T E R N A T I O N A L M O N E T A R Y F U N D }
$$




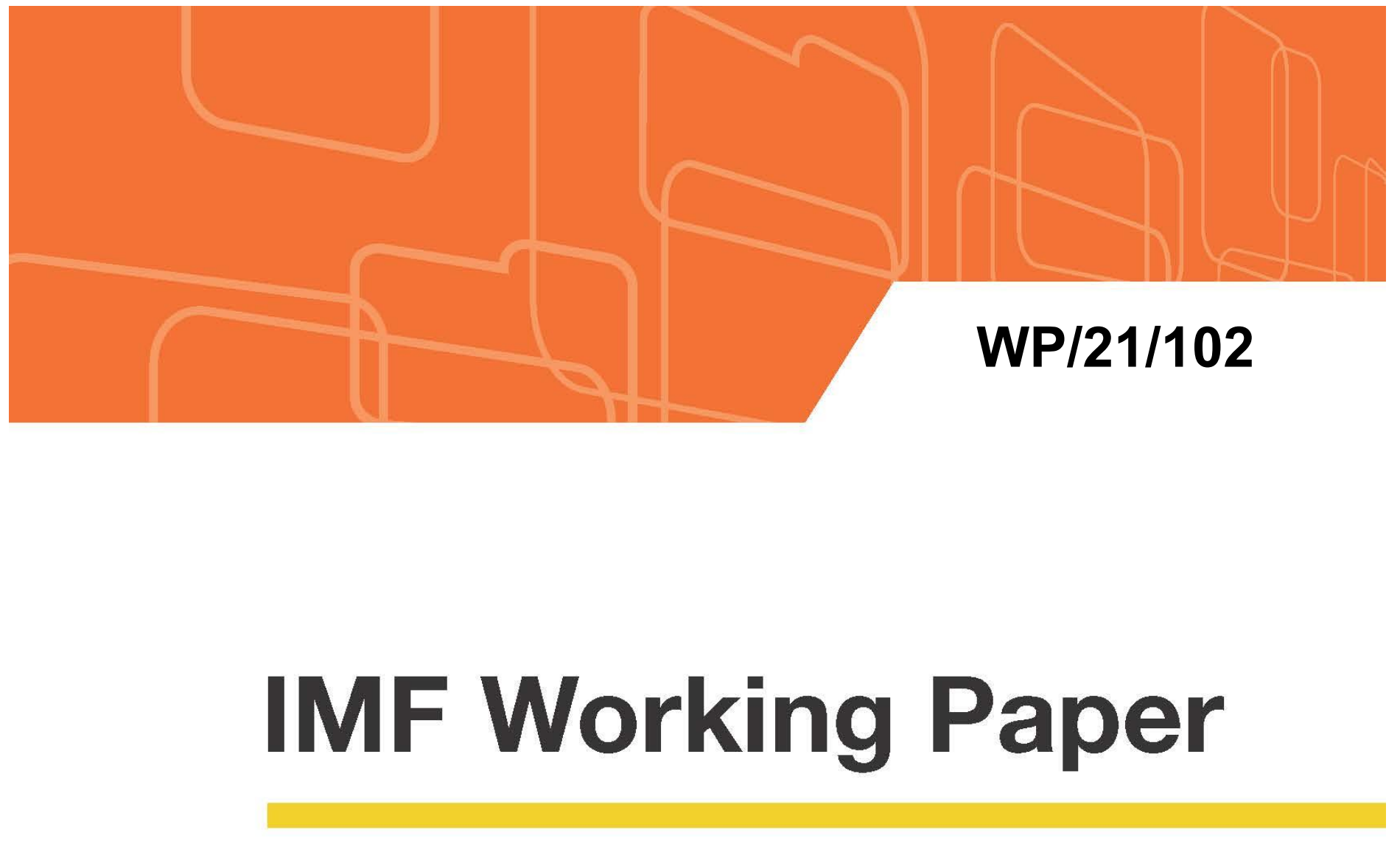

\section{Competition vs. Stability: Oligopolistic Banking System with Run Risk}

by Damien Capelle

IMF Working Papers describe research in progress by the author(s) and are published to elicit comments and to encourage debate. The views expressed in IMF Working Papers are those of the author(s) and do not necessarily represent the views of the IMF, its Executive Board, or IMF management.

$$
\text { I N T E R N A T I O N A L M O N E T A R Y F U N D }
$$




\title{
IMF Working Paper
}

\author{
Research Department
}

\section{Competition vs. Stability: Oligopolistic Banking System with Run Risk ${ }^{1}$ \\ Prepared by Damien Capelle}

Authorized for distribution by Maria Soledad Martinez Peria

April 2021

\section{IMF Working Papers describe research in progress by the author(s) and are published to elicit comments and to encourage debate. The views expressed in IMF Working Papers are those of the author(s) and do not necessarily represent the views of the IMF, its Executive Board, or IMF management.}

\begin{abstract}
This paper develops a model where large financial intermediaries subject to systemic runs internalize the effect of their leverage on aggregate risk, returns and asset prices. Near the steady-state, they restrict leverage to avoid the risk of a run which gives rise to an accelerator effect. For large adverse shocks, the system enters a zone with high leverage and possibly runs. The length of time the system remains in this zone depends on the degree of concentration through a franchise value, price-drop and recapitalization channels. The speed of entry of new banks after a collapse has a stabilizing effect.
\end{abstract}

JEL Classification Numbers: Bank runs, oligopolistic competition, shadow banks

Keywords: E32, E44, G01, G21, G33, L13

Author's E-Mail Address: dcapelle@imf.org

\footnotetext{
${ }^{1}$ I am grateful to Nobuhiro Kiyotaki for his continued and invaluable support in this project. I thank the participants of the Princeton macro lunch seminar, Divya Kirti and Maria Soledad Martinez Peria for helpful comments. All errors are my own. The views expressed therein are those of the author and do not necessarily represent the views of the IMF, its Executive Board, or IMF management.
} 


\section{Introduction}

Does the degree of competition among financial intermediaries increase instability? Compared to the U.S. banking system, the stability of the Canadian system whose three largest banks total three fourth of total bank asset is often cited as the example that an oligopolistic banking system enhances financial stability. This paper revisits this question in the context of the shadow banking system. ${ }^{1}$ As the Great Recession has shown, it is much more subject to the risk of systemic runs than traditional banks, for three main reasons: i) shadow banks rely heavily on wholesale short-term funding (Pozsar et al., 2010), ii) their assets are continuously and freely traded on financial markets which makes shadow banks' assets more liquid but also their value more volatile, and iii) they operate in a different regulatory framework and are not covered by public deposit insurance. How does the level of competition among unregulated financial intermediaries shape the likelihood of systemic runs and what are the implications for macroeconomic stability and welfare?

The competition vs. stability debate has a long history. Building on the traditional bank run framework (Diamond and Dybvig, 1983; Morris and Shin, 1998), Vives (2016) studies the role of non-competitive profits in increasing the ability of banks to repay running depositors ex post - which share some similarities with what I call the recapitalization channel - and Matutes and Vives (2000) study the role of noncompetitive profits in incentivizing intermediaries to lower their risk exposure ex ante to protect their future profits, what is known as the charter or franchise value channel. In addition, the fact that lower competition leads to higher franchise value also implies cheaper cost of funding, which incentivizes risk-taking. Finally, it has also been shown that lower competition could lead to more risk-taking through the adverse selection of borrowers implied by higher loan rate (Nicolo and Boyd, 2003; Corbae and D'Erasmo, 2014). This mechanism relies on information frictions from which I abstract. Carletti and Hartmann (2003) and Vives (2016) provide an overview of the literature. These results have been obtained in static and partial equilibrium frameworks.

This paper revisits the competition-stability debate in a dynamic and general equilibrium framework. I build a stylized macroeconomic stochastic general equilibrium model that features atomistic households and a finite number of large leveraged financial

\footnotetext{
${ }^{1}$ The unregulated financial intermediaries total more than a third of total intermediation in the US (Board, 2017). Herfindhal indexes range from .05 to .5 across different segments of financial markets, corresponding to an average of 20 to 2 actors (Cetorelli et al., 2007).
} 
intermediaries ("banks" hereafter) investing in a freely traded asset. ${ }^{2}$ I assume that households are less efficient than banks at managing capital. At any instant, households can decide to withdraw their deposits, which makes the system subject to run in some part of the state-space. Multiple equilibria exist whenever otherwise solvent banks are insolvent at the run price. The run price is a macroeconomic endogenous object, that depends on how inefficient households are at managing capital and how much of the capital stock they have to absorb.

I depart from the macrofinance literature in two important ways. First, in contrast with a framework in which banks are atomistic, large banks internalize their impact on the aggregate likelihood of a run, asset prices and excess returns when choosing their capital investment, the composition of their liability, and their exposure to risk. ${ }^{3}$ Second, I do not assume that banks have to abide by a collateral constraint originating in a moral hazard friction, as in Mendoza (2010), Gertler and Kiyotaki (2015) or Gertler et al. (2017) (hereafter GK), that there is a fixed amount of equity and an occasionally binding constraint as in Brunnermeier and Sannikov (2014) (hereafter BS), or that banks face a value-at-risk constraint as in Adrian and Shin (2014) and Coimbra and Rey (2017). Like these papers, I assume that there are frictions in the issuance of equity. Despite the absence of constraints on leverage, banks' net worth matter for the size of their investment because banks understand that a higher leverage increases the exposure of the financial system to runs. While the main focus of the literature has been on how risk builds up over time, I focus on the time of crisis itself and the recovery that follows, which is when runs happen.

The first contribution is the analysis of the equilibrium path of the economy. In the aftermath of an adverse aggregate productivity shock, banks experience a drop in net worth. The economy lands in the run zone where banks choose to take on high leverage, by investing in the interior solution of the Cournot game and where runs might happen with positive probability. In the run zone, banks restrict dividend payments. After finite time, banks have accumulated enough net worth and the system enters the safe zone. In the safe zone, banks optimally choose to restrict their level of

\footnotetext{
${ }^{2}$ It is a model of an unregulated or shadow banking system. "Banks" should be understood as shadow banks. In an extension, I analyze a model of a dual banking system in which regulated and unregulated banks co-exist.

${ }^{3}$ This paper relates to a recent literature that investigates the stability implications of departures from the price-taking assumption in general equilibrium (Dávila and Walther, 2020; Eisenbach and Phelan, 2020; Neuhann and Sockin, 2019).
} 
investment to a multiplier of their net worth to avoid the risk of runs. In this zone, the system is characterized by a positive relationship between banks' net worth, asset prices and capital investment. The novelty is that leverage is a function of the drop in prices should a run occur: the larger the potential drop, the smaller the leverage. In this zone, banks continue to save until they reach the level of net worth that allows them to invest at the interior solution of the Cournot game without taking the risk of a systemic run. The endogenous amplification of the initial adverse macroeconomic shock is therefore of a very different nature in the run zone where it comes from the possibility of a run, and in the safe zone, where it comes from the traditional financial accelerator.

The second contribution is to shed light on the mechanisms through which concentration as well as the speed at which new banks enter after a systemic run shape stability. I highlight three channels through which the level of competition shapes stability. Firstly the franchise value channel, already present in the older static and partial equilibrium literature, makes large firms less willing to take on the risk of runs because they have more to lose from liquidation. Secondly, the price-drop channel, the most novel of all, is the focus of the next paragraph and will also influence the time spent in the run zone. Thirdly the recapitalization channel makes a more concentrated market more stable by increasing the speed at which they can accumulate net worth and escape the zone in which runs may happen. Finally, the speed of entry also influences the stability of the system: the faster the entry of new banks after a run, the less likely a run happens ex ante, what I label the entry channel. In the limit where entry happens infinitely fast, there is no run in equilibrium. This is because the expectation of new entrants raises the run price to the point that eliminates the possibility of a run.

The price-drop channel makes more concentrated systems safer by decreasing the size of the drop in asset prices when a run occurs. More competitive financial systems are more efficient: the size of intermediation is larger, the gap between the returns on capital and on deposits is lower and asset prices are higher. But this also implies a larger drop in asset prices when a systemic run occurs because more capital has to be liquidated and absorbed by households, who are less efficient at managing capital. The larger the potential drop in prices, the smaller the leverage banks can afford if they want to avoid the risk of a run. This gives them incentives to play a highly leveraged investment strategy rather than engaging in a safe one, thereby increasing 
the likelihood of a run. This finding is in sharp contrast with what happens when runs are not systemic but on individual banks, which makes this channel maybe surprising and controversial. ${ }^{4}$

The net worth dynamics interact with the price-drop channel in three ways that matter for stability. First, financial stability depends on both the size of the run zone, which depends crucially on the size of the price-drop, and the speed at which banks travel through it, which depends on the recapitalization channel. Second, asset prices depend on the path of banks net worth going forward. An important implication is that in a highly competitive environment, where the accumulation of net worth is relatively slow, the expectation that banks will coordinate on a safe equilibrium with low leverage and high output losses in the future depresses asset prices in the present, which makes the safe strategy relatively more attractive. The recapitalization channel mitigates the price-drop channel. Third, the stabilizing effects of low competition are mitigated by the net worth accumulation behavior of banks in the medium-run. After a long period without adverse shocks, banks operating in a concentrated sector do not have as much net worth on aggregate relative to their assets compared to banks in a more competitive sector because they understand that the drop in asset prices is also lower, should a run occur. This makes the system vulnerable to adverse exogenous shocks. This paradox of safety echoes the paradox of volatility in Brunnermeier and Sannikov (2014) where low fundamental volatility may actually lead to high endogenous volatility.

Finally, I extend the model to a framework where shadow and traditional banks coexist. ${ }^{5}$ I analyze the implications for stability of competition and macroprudential policies affecting the traditional banking sector. Even if regulated banks are insulated from the risk of runs thanks to the deposit insurance scheme and their access to the lender of last resort, changes in the concentration of the regulated banking system or in the macro-prudential policies affecting them have implications for stability because they affect the shadow banking system. Increasing concentration in the regulated sector has a positive effect on stability through the franchise value and recapitalization channels but a negative effect through the price-drop effect, by decreasing the absorption capacity of assets by the regulated banking system, the net effect being ambiguous.

\footnotetext{
${ }^{4}$ When runs are on individual banks, the failure of large institutions imply large price-drops which impair the balance-sheet of surviving banks paving the way for contagion. But this Too-Big-To-Fail argument doesn't apply in the case of systemic runs.

${ }^{5}$ This analysis can be found in appendix D.
} 
Tighter capital requirements on regulated banks have in general a stabilizing effect because regulated banks are better capitalized which implies that they have a higher absorption capacity of assets should shadow banks experience a run and liquidate their assets.

A complete welfare analysis weighs the potential stabilizing advantages of lower competition with the output costs introduced by market power: more competition increases output because the system as a whole intermediates a larger proportion of the capital stock. A social planner should balance a potentially more efficient system in the long-run with less stability. And this trade-off is all the more acute as entry takes time.

The qualitative findings are consistent with empirical evidence on the dynamics of financial systems in the aftermath of an adverse shock and on the effect of concentration on stability. Regarding the former, the equilibrium transition features a period of low franchise value, high leverage and deleveraging after an adverse macroeconomic shock, during which the risk of runs is high. Regarding the relationship between concentration and stability, I do find an a priori ambiguous relationship, although more forces work in the sense of more concentration implying more stability. Most papers find indeed a positive relationship using many different methodologies and measure of risk and concentration (Beck et al., 2003, 2013; Keeley, 1990) and more recently Degl'Innocenti et al. (2018) for investment banks. Contestability is shown to have a positive effect on stability Beck et al. (2013) consistent with the entry channel. Table 3 in Freixas and Ma (2015) provides a summary of the empirical findings and Zigraiova and Havranek (2016) provides a meta-analysis of the literature.

The model gives rise to several new testable predictions. The first contribution highlights the limits of empirical analyses that do not take into account the statedependency of banks' behaviors. A key prediction of the analysis is indeed that the optimal capital investment of banks remains an endogenous multiplier of net worth for small shocks around the steady-state but for large shocks, they take on a higher leverage and runs may occur until they have accumulated enough net worth and reached the safe zone. The second contribution highlights the importance of three channels that have been overlooked by the current literature: the recapitalization channel according to which more concentrated markets have the ability to recapitalize more quickly and escape the run zone; the price-drop channels according to which concentration influences the size of the drop in asset prices when a run occurs and the 
entry channel.

The rest of the paper is organized as follows. In section 2, I present a static model with an oligopoly of intermediaries and systemic runs to isolate the franchise value and the price-drop channels. In section 3, I extend the model to a dynamic setting which allows for endogenous net worth accumulation, entry of banks and run at every period. I analyze the properties of the equilibrium and solve for the transition path following an aggregate productivity shock which depletes banks' net worth. This section focuses on two additional channels: the recapitalization and the entry channels. In section 4, I illustrate the working of the model with numerical examples allowing for stochastic productivity shocks. Section 5 concludes.

\section{A Static Model of Oligopolistic Banks with Sys- temic Runs}

In this section, I present a static model of a finite number of banks deciding how much deposits to issue and real assets to buy given their exogenous net worth and a continuum of households choosing how much of their wealth to hold in deposits and in real assets and in which there is a risk of a system-wide run. This section formalizes two channels through which concentration affects stability: the franchise value and the price-drop channels.

\subsection{The Model}

Environment. There are two stages. In the first stage, the two types of agents, bankers and households, make their portfolio decision. There is a fixed supply of a real asset called capital, denoted $\bar{K}$, freely tradable at price $q$ on a centralized market. Each unit of capital provides a flow $z$ of good. Banks borrow by issuing deposits. In the second stage, a run game among households takes place.

There is only one source of uncertainty: the endogenous risk of a run. I restrict attention to systemic runs, which is a run on the entire financial system. I posit that in equilibrium a systemic run occurs with probability $\lambda$, which will be determined endogenously. Figure 1 summarizes the different actors, their balance-sheet and their financial relationships. 


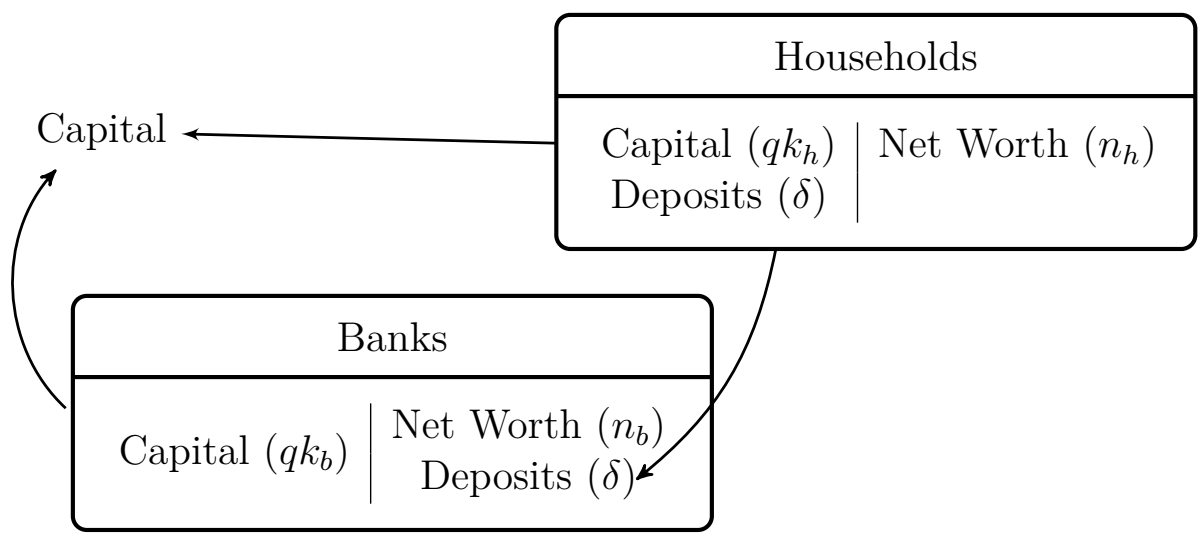

Figure 1: Schema of financial system

Households. There is a mass one of identical households. In the first stage, they can invest their net worth $n_{h}$ in two kinds of assets, the real asset $k_{h}$ and deposits at all banks $b \in\{1, \ldots, \mathscr{B}\}, \delta_{b}$ :

$$
n_{h}=q k_{h}+\sum_{b} \delta_{b} .
$$

Each unit of capital generates a stream of income $z$ and capital gains $d q$ per unit of capital. Each unit of deposit generates interest income $r_{b}$. If the bank has to be liquidated because of a run, the household recovers a proportion $\psi_{b}$ of its deposits at bank $b$, determined endogenously. Households are subject to a convex cost of managing capital in terms of good as in GK. The convex cost implies that it is increasingly costly at the margin for households to manage capital directly. This cost ensures that financial institutions have a meaningful role in the intermediation of funds without forbidding households from directly investing in real assets.

$$
f\left(k_{h}\right)=\frac{\alpha}{2}\left(k_{h}\right)^{2}
$$

If no systemic run occurs, the net worth of the household at the end of the second period is the sum of its deposits at all banks augmented by the interest rate and of the market value of the real asset, $q^{N R}=q+d q$, augmented with the income from the real assets, $z$

$$
\sum_{b}\left(1+r_{b}\right) \delta_{b}+\left(q^{N R}+z\right) k_{h}-f\left(k_{h}\right)
$$

If a systemic run occurs, the households' net worth is equal to the sum of the recovered 
deposits after liquidation of the banks, the market value of the stock of capital at the run price, and the stream of income:

$$
\sum_{b} \delta_{b, h} \psi_{b}+\left(q^{R}+z\right) k_{h}-f\left(k_{h}\right)
$$

where $\psi_{b}$ is the recovery rate per unit of deposit at bank $b$ when a systemic run occurs.

The objective of the households is to maximize the discounted sum of consumption in the first and second stage. I assume households have linear utility and discount rate $\rho$. This assumption of linearity is meant to ensure the tractability of the bank's problem. Recall that the probability of a run is denoted $\lambda$. Taking the price of the asset $q$ as given, the representative household solves

$$
\begin{aligned}
\max _{\{\delta\}_{b=1}^{\mathscr{B}}, k_{h}} & -n_{h}+\frac{1}{1+\rho}\left[(1-\lambda) c+\lambda c^{R}\right] \\
\text { with } \quad c & =\sum_{b}\left(1+r_{b}\right) \delta_{b}+\left(q^{N R}+z\right) k_{h}-f\left(k_{h}\right) \\
\text { and } \quad c^{R} & =\sum_{b} \delta_{b, h} \psi_{b}+\left(q^{R}+z\right) k_{h}-f\left(k_{h}\right) \\
\text { such that } \quad n_{h} & =\sum_{b} \delta_{b, h}+q k_{h}
\end{aligned}
$$

Run Game. In the second stage, all household play a run game. Taking the behavior of others as given, a household decides whether to withdraw all of their deposits from all banks. Since I focus on symmetric equilibria where all households take the same action, I describe payoffs only for individual departures from the (symmetric) equilibrium behavior. Assume first that no one runs. An atomistic individual is able to withdraw their funds from all banks because the required sale of real assets by banks in order to honor their creditor will not move the asset price at all. Doing so has a cost for the individual: they have to give up the interest payment on their deposits. Assume now that everyone runs. Banks have to liquidate sufficient amount of real asset to reimburse their creditors and this moves the asset price. Either they can honor all of their deposits, despite the decline in the value of their asset caused by the drop in asset prices, in which case, not running has a benefit for households: it saves them the interest payments delivered at the next instant. Or banks can't honor their debt, in which case they are liquidated and I assume that the liquidation value of the banks is shared only among households who ran. A household who didn't run would lose all 
of their deposits.

Banks. There is a finite number $\mathscr{B}$ of banks indexed by $b \in\{1, \ldots, \mathscr{B}\}$. They are owned by a banker, who maximizes the dividends received at the end of the second period. Instantaneous utility is denoted $u_{b}($.$) , which we assume to be bounded from$ below, increasing and concave. I will assume in this section that it takes a CRRA form

$$
u_{b}(d)=\frac{d^{1-\gamma}}{1-\gamma} \quad \text { with } \quad \gamma \in[0,1)
$$

The assumption that utility is concave in dividends implies that equity issuance is costly. It is indeed a necessary condition for net worth to matter, otherwise a bank would issue equity to jump directly to the unconstrained optimal investment.

A bank chooses its investment in real assets, $k_{b}$. They behave a la Cournot, i.e. they make their investment in capital decisions taking others' investment as given but internalizing their impact on returns to capital, on asset prices and on the probability of a run. Contrary to households, they are financial experts and do not face capital management costs. They can issue deposits to households without any exogenous limit. They enter the first stage with some net worth denoted $n_{b}$.

If there is no run, the net worth at the end of the second stage is given by

$$
(q+z) k_{b}-\left(1+r_{b}\right) \delta_{b}
$$

When there is a run, prices drop and the net worth at the end of the second stage is

$$
n_{b}-k_{b}\left(q-q^{R}\right) .
$$

After a successful run, all banks are liquidated. Each banker is forced to exit and gets $v^{R}$. One should think of $v^{R}$ as the value from the point of view of a banker to go back to the population of households and in the rest of the section I set $v_{R}=0$. 
The problem of a bank is therefore to solve

$$
\begin{aligned}
\max _{\{\delta, k\}} & (1-\lambda) v\left(d_{b}\right)+\lambda v_{R} \\
\text { with } \quad d_{b} & =\left(q^{\prime}+z\right) k_{b}-\left(1+r_{b}\right) \delta_{b} \\
\text { such that } q k_{b} & =n_{b}+\delta_{b}
\end{aligned}
$$

When choosing capital investment, a bank will internalize the impact of their action on asset prices $q$, on the interest rates paid on deposits $r_{b}$ as well as on the equilibrium probability of a run $\lambda$.

Recovery rate. The recovery rate of deposits at bank $b$ is the amount that depositors get back after liquidation of the bank per unit of deposits plus the stream of income. It is given by

$$
\psi_{b}=\max \left(\frac{q^{R} k_{b}}{\delta_{b}}, 1\right)+\frac{z k_{b}}{\delta_{b}}
$$

Market clearing. The deposits and capital markets in the first stage and the goods market in the second stage must clear. By Walras' law, it is sufficient that the deposits and capital market clear:

$$
\begin{aligned}
\forall b \in\{1, \ldots, \mathscr{B}\} \quad \int \delta_{b, h} d h & =\delta_{b} \\
\sum_{b=1}^{\mathscr{B}} k_{b}+\int k_{h} d h & =\bar{K}
\end{aligned}
$$

Asset prices at the end of the second stage. At the end of the second stage, I assume that the price of the asset (i) when there is a run, $q^{R}$, is equal to the value of the asset should households operate all the capital stock forever

$$
q^{R}=\frac{z-\frac{\alpha}{2} \bar{K}^{2}}{\rho}
$$


and (ii) when there isn't a run, $q^{N R}$, is equal to the value of the asset if the financial system operates without the risk of a run forever:

$$
q^{N R}=\frac{z-\frac{\alpha}{2}\left(\frac{\bar{K}}{\mathscr{B}+1}\right)^{2}}{\rho} .
$$

While these prices are exogenous in this section, I show in the next one that they are the equilibrium prices of the fully dynamic model in the case where there is no entry of banks after a systemic run and where there is a risk of runs only in the current period.

\subsection{Properties of the Static Equilibrium}

I now solve for the optimal behaviors of intermediaries, the equilibrium and analyze how the risk of a systemic run depends on the degree of competition, $\mathscr{B}$. Proofs can be found in appendix.

Run Game and Probability of a Run I first solve for the equilibria of the run game happening in the second stage. The existence of multiple equilibria is a function of the aggregate level of equity should the entire system be liquidated. A run might occur whenever the system is solvent if there is no run and insolvent if there is a run. Denote $\Delta$ the sum of deposits of all banks, $q^{R}, N^{R}, K^{R}$ and $q, N, K$ the price of the asset, the sum of net worth of all banks, the sum of capital investment of all banks just after and before the systemic run. There are multiple equilibria whenever

$$
N^{R} \equiv N+\left(q^{R}-q\right) K<0
$$

Denoting $\Psi$ the aggregate recovery rate, the second inequality becomes

$$
\Psi=\frac{q^{R} K}{q K-N}=\frac{q^{R} K}{\Delta}<1
$$

The lower the equity over capital ratio, the more leveraged the system, the more likely the existence of multiple equilibria. Whenever there are multiple equilibria, I as- 
sume that a sunspot with probability $\bar{\lambda}$ coordinates depositors on the run equilibrium. ${ }^{6}$ The unconditional probability of a run is therefore given by $\lambda=\bar{\lambda} \mathbb{1}_{\Psi<1}$.

From the point of view of an individual bank $b$ taking others' bank net worth and capital as given, when all other banks are symmetric, this condition is:

$$
\lambda\left(k, \mathbf{k}_{-b}, n, \mathbf{n}_{-b}\right)=\bar{\lambda} \mathbb{1}_{\left((\mathscr{B}-1) n_{-b}+n_{b}+\left(q^{R}-q\right)\left((\mathscr{B}-1) k_{-b}+k_{b}\right)\right)<0}
$$

where I have dropped the dependence of $\lambda($.$) on \mathscr{B}$ and $z$.

Households Optimal Decisions and Pricing Equations The dynamics of asset prices and the interest rate on deposits at bank $b$ should be consistent with the households optimal portfolio and intertemporal allocation. The F.O.C. of households are given by

$$
\begin{gathered}
q^{N R}-q+z-f^{\prime}\left(k_{h}\right)=-\lambda\left(q^{R}-q^{N R}\right)+\rho q \\
\forall b \in\{1, \ldots, \mathscr{B}\} \quad r_{b}=\lambda\left(1+r_{b}-\psi_{b}\right)+\rho
\end{gathered}
$$

where the first condition is the asset pricing equation and the second is the traditional Euler equation for deposits adjusted for the probability of a run and the recovery rate. In contrast with an environment in which banks are atomistic and take the rate of deposits and asset prices as given, bankers in this model internalize the impact of their decisions on prices and returns implied by (6) and (7).

Bank's Capital Investment and Deposit Decisions I now solve for the optimal choice of capital investment and deposit of a bank taking other banks' capital investments as given.

Rewriting the bank's problem. Using the F.O.C. of the households 6 and 7, and the definition of the recovery rate (2), one can rewrite dividends at the end of the second

\footnotetext{
${ }^{6}$ Should $\bar{\lambda}$ be related to fundamentals? There isn't a consensus in the literature regarding the best way to model the likelihood of runs arising from coordination failure among depositors. Some papers choose to make the sunspot probability independent of any endogenous variables, e.g. Gertler et al. (2016, 2017), while others make the probability of a run an increasing function of some measure of risk in an ad-hoc manner, usually leverage (Gertler and Kiyotaki, 2015). The former is obviously an extreme case of the latter, but it has the advantage of being transparent and simple and to avoid having to take a stand on the exogenous relationship between the probability of a run and the fundamentals of the system. In one of the numerical exercise, 4 , I show that my results are qualitatively similar when the arrival rate is a smooth function of the fundamentals.
} 
stage of a bank in case of no run shock, given by equation (1), as

$$
d=\frac{1}{1-\lambda(\mathbf{k}, \mathbf{n})}\left[(1+\rho) n+f^{\prime}\left(\bar{K}-\sum_{j=1}^{\mathscr{B}} k_{j}\right) k_{b}\right]
$$

This shows how the net excess return on capital depends on the choice of capital by the individual banker through the aggregate capital investment of banks $K=\sum_{j=1}^{\mathscr{B}} k_{j}$. $\lambda$ also depends on $k_{b}$, in a discontinuous fashion, as shown in 5 .

Given the normalization that $v^{R}=0$, the optimal capital investment is solution to

$$
\max _{k}\left(1-\lambda\left(k, \mathbf{k}_{-b}, n, \mathbf{n}_{-b}\right)\right) v\left(\frac{1}{1-\lambda\left(k, \mathbf{k}_{-b}, n, \mathbf{n}_{-b}\right)}\left[(1+\rho) n+f^{\prime}\left(\bar{K}-\sum_{j}^{\mathscr{B}} k_{j}\right) k_{b}\right]\right)
$$

Given the non-linearities introduced by $\lambda$, the objective function of a bank at a given instant is piece-wise concave with respect to capital, with a downward step at the point where $\lambda$ jumps up. There are therefore two candidates for optimality. Figure 2 illustrates the optimal capital investment for two different levels of $n$. The optimal investment can be the interior point as in the gray curve or at the corner as in the black curve.

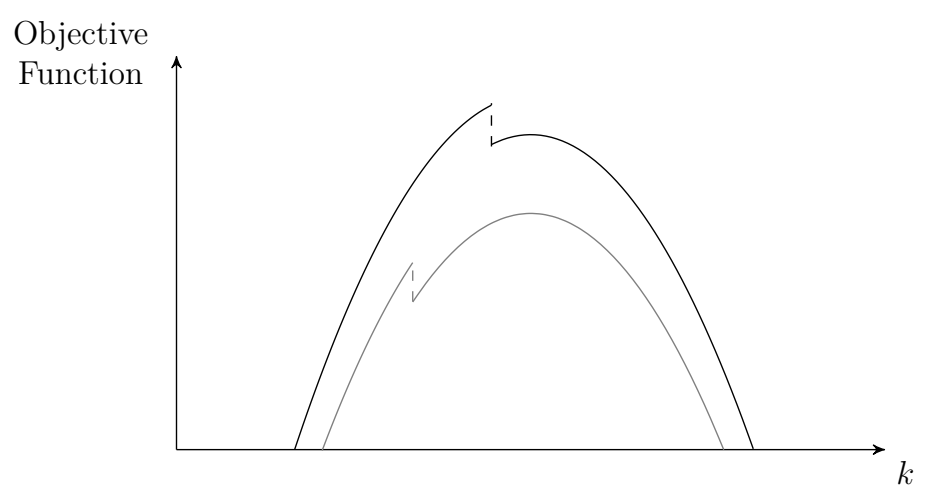

Figure 2: Stylized drawing of the objective function

Legend: The black line corresponds to a high net worth, the gray line to a low net worth

Interior and corner solutions. The interior solution, denoted $k^{I}$, is solution to the 
following F.O.C.:

$$
f^{\prime}\left(\bar{K}-\sum_{j=1}^{\mathscr{B}} k_{j}\right)-f^{\prime \prime}\left(\bar{K}-\sum_{j=1}^{\mathscr{B}} k_{j}\right) k_{b}=0
$$

In a symmetric equilibrium of the Cournot game, and using the assumed functional form for $f, 10$ is

$$
k^{I}=\frac{\bar{K}}{\mathscr{B}+1}
$$

Each bank holds a fraction $\frac{1}{\mathscr{B}+1}$ of the capital stock and the remaining fraction is held by households. $k^{I}$ is independent of the vector of banks' net worth. When I extend the model to allow for productivity shocks, $k^{I}$ will depend on the vector of banks' net worth.

The corner solution, denoted $k^{C}$, is given by the highest capital investment such that $\lambda=0$. It is not only a function of one's net worth but also a function of the other banks' net worth and capital investment

$$
k^{C}\left(n, \mathbf{n}_{-b}, \mathbf{k}_{-b}\right)=\frac{1}{q-q^{R}}\left(\sum_{j \neq b} n_{j}+n\right)-\sum_{j \neq b} k_{j}=\frac{N}{q-q^{R}}-\sum_{j \neq b} k_{j}
$$

where $N$ is the sum of banks' net worth as defined above. In a symmetric equilibrium in which all banks have the same net worth $n$ and invest the same amount, it is given by

$$
k^{C}=\frac{n}{q-q^{R}} .
$$

The corner investment is a decreasing function of the difference between the current price and the price in a run. In the limit where the recovery rate is $1, q^{R}-q \rightarrow 0$, capital investment and leverage can be infinite without banks taking the risk of a run. The ratio $\frac{q^{R}}{q}$ therefore measures the degree of illiquidity of the financial system aggregate balance sheet. The closer it is to 1 , the higher the aggregate liquidity of the financial sector and the less risky high leverage is. Crucially asset prices are endogenous to the actions of banks, which I analyze in the next paragraph. In the dynamic setting, asset prices will also depend on the entire future path of banks' actions. 
Choosing between the interior and the corner strategy amounts to choosing the one that brings the highest flow of utility. Denoting the net return on capital

$$
R\left(k_{b}, \mathbf{k}_{-b}\right)=f^{\prime}\left(\bar{K}-\sum_{j \neq b}^{\mathscr{B}} k_{j}-k_{b}\right)
$$

the global optimum for capital investment is solution to the following comparison

$$
\begin{aligned}
& \max \left[v\left((1+\rho) n+R\left(k^{C}\left(n, \mathbf{n}_{-b}, \mathbf{k}_{-b}\right), \mathbf{k}_{-b}\right) k^{C}\left(n, \mathbf{n}_{-b}, \mathbf{k}_{-b}\right)\right)\right. \\
&\left.\left(1-\lambda\left(k, \mathbf{k}_{-b}, n, \mathbf{n}_{-b}, z, \mathscr{B}\right)\right)^{\gamma} v\left((1+\rho) n+R\left(k^{I}, \mathbf{k}_{-b}\right) k^{I}\right)\right]
\end{aligned}
$$

The decision amounts to a comparison between higher profits and risk-taking. At the interior point, a bank enjoys more profit

$$
R\left(k^{I}, \mathbf{k}_{-b}\right) k^{I}>R\left(k^{C}\left(n, \mathbf{n}_{-b}, \mathbf{k}_{-b}\right), \mathbf{k}_{-b}\right) k^{C}\left(n, \mathbf{n}_{-b}, \mathbf{k}_{-b}\right)
$$

which gives it an incentive to take on more risks. But by doing so, it also runs the risk of losing their franchise value.

\subsection{Symmetric Cournot Equilibria}

I focus on symmetric Cournot equilibria, in which either all banks simultaneously play the corner solution - a "corner" equilibrium - or all play the interior solution - the "interior" equilibrium. I assume that all banks have the same exogenous amount of net worth.

Asset prices and size of price drop. Asset prices in the first stage are the discounted sum of today's flow of income and tomorrow's asset prices. From the F.O.C. of the households, given by (6), the price of the asset when banks all play 
interior or all play corner is given by

$$
\begin{aligned}
q^{I} & =\frac{z+\lambda q^{R}+(1-\lambda) q^{N R}-\frac{\alpha}{2}\left(\frac{\bar{K}}{\mathscr{B}+1}\right)^{2}}{1+\rho} \\
\text { and } \quad q^{C}(n) & =\frac{z+q^{N R}-\frac{\alpha}{2}\left(\bar{K}-\mathscr{B} \frac{n}{q^{C}(n)-q^{R}}\right)^{2}}{1+\rho}
\end{aligned}
$$

where the second equation defines $q^{C}$ implicitly as a function of $n$.

From the two expressions (13) and (14), one can derive an important result that underlies the price-drop channel: the price drop in case of a systemic run is larger for less concentrated system.

Lemma 1. The current price of the real asset minus the run price, $q^{I}-q^{R}$ and $q^{C}-q^{R}$, is increasing in the number of banks, $\mathscr{B}$.

The intuition for this lemma is as follows. More competitive financial systems are more efficient: the size of intermediation is larger, the gap between the returns on capital and on deposits is lower and asset prices are higher. Asset prices in both types of equilibria, (13) and (14), are indeed increasing in the number of banks. Given that the price in case of a run, $q^{R}$, is independent of the level of competition in this static version of the model, it in turn implies that the drop in asset prices is increasing in the number of intermediaries. In other words, when more capital has to be liquidated and absorbed by households who are less efficient at managing capital, asset prices have to drop more. This has important implications for the risk-taking behavior of intermediaries, which I analyze in the rest of the section.

Equilibria as a function of net worth. The following proposition characterizes the set of symmetric Cournot equilibria for every level of equity of a bank. It establishes that for low levels of equity, only the interior equilibrium is supported, and for high levels of equity, only a corner equilibrium is supported. For intermediate levels of equity, the two types of equilibria are possible.

Proposition 2.1. There exists a unique $\left\{n_{1}^{C}, n_{1}^{I}\right\}$ and $n^{S S}$ with $n_{1}^{C} \leq n_{1}^{I}<n^{S S}$ such that

- If $0 \leq n<n_{1}^{C}$, the only symmetric Cournot equilibrium is one in which all banks play the interior solution, $k^{I}$. 
- If $n_{1}^{C} \leq n<n_{1}^{I}$, all banks playing the interior investment, $k^{I}$, or all banks playing the corner solution, $k^{C}(n)$, are two possible symmetric equilibria

- If $n_{1}^{I} \leq n \leq n^{S S}$ the only symmetric Cournot equilibrium is one in which all banks play the corner solution, $k^{C}(n)$

Figure 3 illustrates the best response functions of a bank when all other banks play the corner solution (black line) or the interior solution (gray line) for all values of net worth. For low levels of net worth, banks have a strong incentive to play the risky strategy while for high levels of net worth they prefer to play safe. This stems from the fact that the franchise value is increasing in net worth: the higher its equity, the stronger the incentives to play safely and avoid the risk of runs. In between the two thresholds both equilibria are sustainable. If all banks play safe, it is optimal to play safe and if all banks play interior and risky it is optimal to play interior as well. This interesting complementarity among banks' actions stems from the fact that the probability of run depends on the system-wide leverage and not on individual leverage. If all banks have a low leverage, an individual bank can eliminate the risk of runs without restricting its investment as much as it would have to in a situation where all other banks have a high leverage. In the remainder of the paper, whenever there is multiplicity, I choose an arbitrary $n_{1} \in\left[n_{1}^{C}, n_{1}^{I}\right]$ as the threshold value below which I assume all banks play interior and above which all banks play corner. ${ }^{7}$

Corollary 1. There exists $n_{1} \in\left[n_{1}^{C}, n_{1}^{I}\right]$ with $n_{1}>0$ such that the capital investment function $\left.k^{(} n\right)$ given by

$$
k(n)=\left\{\begin{array}{l}
k^{I} \quad \text { if } n<n_{1} \quad \text { Run zone } \\
k^{C}(n) \quad \text { if } n_{1} \leq n<n^{S S} \quad \text { Safe zone } \\
k^{I} \quad \text { if } n^{S S} \leq n \quad \text { Steady-state zone }
\end{array}\right.
$$

is compatible with an outcome of a Cournot game. Furthermore, the probability of

\footnotetext{
${ }^{7}$ The existence of multiple equilibria between $n_{1}^{C}$ and $n_{1}^{I}$ implies that coordination failures might occur whenever the two equilibria are ranked. It is a priori unclear which equilibrium is most efficient. If banks coordinate on the corner equilibrium, intermediation and hence output is lower in the current period. If banks coordinate on the interior equilibrium, intermediation is maximized (although still too low due to the oligopolistic ineffiency) but there is a risk that banks will be wiped out in a systemic run which would imply output losses in all future periods. Although this coordination failure is a feature of the equilibrium, it is independent of the level of competition and for that reason I do not discuss it further.
} 


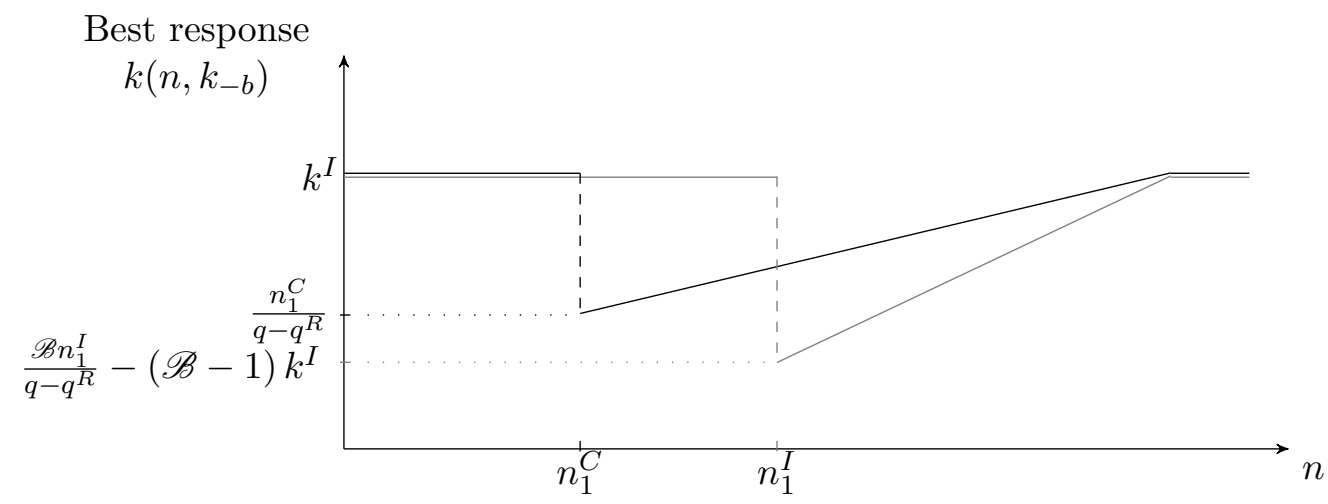

Figure 3: Stylized drawing best response functions

Legend: The black line displays the best response of a bank when all other banks play corner.

The gray line displays the best response of a bank when all other banks play interior.

a systemic run $\lambda(n)$ is given by

$$
\lambda(n)=\left\{\begin{array}{lll}
\bar{\lambda} & \text { if } & n<n_{1} \\
0 & \text { if } & n \geq n_{1}
\end{array}\right.
$$

Concentration and stability: franchise value and the price-drop channels. The degree of concentration, $\mathscr{B}$, decreases the risk of a run through two channels: the franchise value and the price-drop channels. To make this statement more precise, I show now that the total amount of net worth across the financial system required to i) avoid the risk of a run, $\mathscr{B} n_{1}^{I}$, and to ii) make it avoidable, $\mathscr{B} n_{1}^{C}$, increase as the number of banks $\mathscr{B}$ increases. If the degree of concentration were irrelevant for stability, then these two aggregate thresholds should be independent of $\mathscr{B}$, the number of banks.

To isolate the franchise value, I consider first the partial effect of $\mathscr{B}$ on $\mathscr{B} n_{1}^{C}$ and $\mathscr{B} n_{1}^{I}$ holding asset prices, $q^{C}-q^{R}$, fixed. To isolate the price-drop channel, I then consider the total effect. The following proposition formalizes the key finding of this section: both the franchise value and the price-drop channel imply that a system with more intermediaries requires more aggregate equity to avoid the risk of a run. I first introduce the following notations: the price drop $d q(\mathscr{B})=q^{C}(\mathscr{B})-q^{R}(\mathscr{B})$, the required aggregate net worth for the safe equilibrium to be sustainable, $N_{1}^{C}(\mathscr{B}, d q)=$ $\mathscr{B} n_{1}^{C}(\mathscr{B}, d q)$ and the required aggregate net worth for the safe equilibrium to be necessary, $N_{1}^{I}(\mathscr{B}, d q)=\mathscr{B} n_{1}^{I}(\mathscr{B}, d q)$. 
Proposition 2.2. $\quad$ 1. Franchise value channel. Holding $d q=d q(\mathscr{B})$ fixed, the aggregate thresholds are increasing in the number of intermediaries. If $\mathscr{B}^{\prime}>\mathscr{B}$ then

$$
N_{1}^{C}\left(\mathscr{B}^{\prime}, d q(\mathscr{B})\right)>N_{1}^{C}(\mathscr{B}, d q(\mathscr{B})) \quad \text { and } \quad N_{1}^{I}\left(\mathscr{B}^{\prime}, d q\right)>N_{1}^{I}(\mathscr{B}, d q(\mathscr{B}))
$$

2. Price-drop channel. The aggregate thresholds further increase when asset prices are allowed to change. If $\mathscr{B}^{\prime}>\mathscr{B}$ then

$$
N_{1}^{C}\left(\mathscr{B}^{\prime}, d q\left(\mathscr{B}^{\prime}\right)\right)>N_{1}^{C}\left(\mathscr{B}^{\prime}, d q(\mathscr{B})\right) \quad \text { and } \quad N_{1}^{I}\left(\mathscr{B}^{\prime}, d q\left(\mathscr{B}^{\prime}\right)\right)>N_{1}^{I}\left(\mathscr{B}^{\prime}, d q(\mathscr{B})\right)
$$

Franchise value channel. Larger and more profitable banks enjoy a higher franchise value and are therefore willing to take on less risk. This channel implies that as concentration increases, the total amount of equity in the financial system required to keep banks in the safe zone decreases. The run zone shrinks with concentration.

Price-drop channel. Lower concentration in the banking sector a implies larger price drop when a run occurs because asset prices in normal times are higher, as the financial system intermediates a larger fraction of the capital stock. Consequently, banks find it less appealing to play the interior investment strategy because it requires more net worth to reach a given level of capital investment. This channel implies that as concentration increases, the total amount of equity in the financial system required to keep banks in the safe zone decreases. This makes the run zone shrink with concentration.

An Efficiency - Stability Trade-off. A highly concentrated shadow banking section is stabilizing but it is also less efficient when it invests at the interior solution of the Cournot game because large banks restrict their capital investment which lowers output. In the run zone, where banks coordinate on the interior Cournot equilibrium, total output per unit of time net of management cost is

$$
\bar{K} z-f\left(\bar{K}-\mathscr{B} k^{I}\right)=\bar{K} z-\frac{\alpha}{2}\left(\frac{\bar{K}}{\mathscr{B}+1}\right)^{2} .
$$

Total output is increasing in the number of banks: the more banks there are, the more competition and the less the distortion from market power. Total output is also decreasing in $\alpha$, the degree convexity of the households' cost function: the higher $\alpha$, 
the more costly it is at the margin for households to manage capital, the higher the output loss for a given amount of capital holding.

\section{A Dynamic Model of Oligopolistic Banks with Systemic Runs}

The first section assumed that banks' net worth was exogenous, that systemic runs could happen only in the current period and that there was no entry of banks after a run. In this section, I extend the previous framework to a dynamic setting in which households and banks decide how much net worth to consume at each instant, in which run can happen in the current as well as in future periods and in which entry of new banks eventually occurs after a systemic run. A dynamic setting allows us to analyze how the risk of runs in the future feeds back into current asset prices and run risk, how the accumulation of net worth which depends on endogenous dividends choices shapes the time the system spent in the run zone, which in turn determines the franchise value and asset prices. This section focuses on two additional channels: the recapitalization and the entry channels. The model also allows for productivity shocks and the analysis will focus on the transition path following a productivity shock that depletes banks' net worth.

\subsection{The Model}

Environment Time is continuous. There are two stages within an instant. These two stages are the same as in the static setting of the previous section. There are two sources of uncertainty. Productivity $z$ can take two values, $\underline{z}<\bar{z}$. When it is low (resp. high), it switches to low (resp. high) with arrival rate $\underline{\zeta}(\bar{\zeta}) \cdot{ }^{8}$ I define the function $\zeta$ as follows $\zeta(z)=\underline{\zeta}$ if $z=\underline{z}$ and $\zeta(z)=\bar{\zeta}$ if $z=\bar{z}$. The second source of uncertainty is the endogenous risk of a run, explained in the previous section. Systemic runs follow a Poisson process with arrival rate $\lambda$ per unit of time, which will be determined endogenously.

\footnotetext{
${ }^{8}$ Discrete jumps in TFP are needed to trigger discrete jump in asset prices and in banks net worth in order for the economy to experience runs. If the exogenous process were continuous in time, like most of the macrofinance literature assumes, banks would continuously adjust their net worth to avoid the crisis zone.
} 
Households Law of motion of net worth. When neither productivity nor run shocks occur, the net worth $n_{h}$ of a household $h$ evolves according to

$$
\dot{n}_{h}=(\dot{q}+z) k_{h}+\sum_{b} \delta_{b} r_{b}-f\left(k_{h}\right)-c_{h}
$$

where $c_{h}$ denotes household consumption. In case of a discrete productivity change $\Delta z$, asset prices and net worth discontinuously jump. Denoting $q^{z}$ the post $z$-shock asset price, $\Delta n_{h}=\Delta q^{z} k_{h}$ with $\Delta q^{z}=q^{z}-q$. And the post $z$-shock net worth is: $q^{z} k_{h}+\sum_{b} \delta_{b, h}$

When a systemic run occurs, households experience a change of net worth stemming from both the change in asset prices and the loss on deposits at all banks:

$$
\Delta n_{h}=\Delta q^{R} k_{h}+\sum_{b} \delta_{b, h}\left(\psi_{b}-1\right)
$$

where $\Delta q^{R}=q^{R}-q$ is the discontinuous drop in asset prices at the time of the run and $\psi_{b}$ is the recovery rate per unit of deposit at bank $b$ when a systemic run occurs.

Hamilton-Jacobi-Bellman equation. The aggregate state variables of this economy are the vector of banks net worth $\mathbf{n}$, the value of productivity $z$ and the number of banks $\mathscr{B}$. Taking the asset price $q$, the intensity of run risk $\lambda^{*}$ in equilibrium, ${ }^{9}$ and the aggregate state variables as given, the following HJB is solution to the household's problem

$$
\begin{aligned}
\rho H\left(n_{h}, \mathbf{n}, z, \mathscr{B}\right)= & \max _{c,\{\delta\}_{b=1}^{\mathscr{B}}, k_{h}} h(c)+H_{n}\left((\dot{q}+z) k_{h}+\sum_{b} \delta_{b} r_{b}-f\left(k^{h}\right)-c\right) \\
& +\lambda^{*}(\mathbf{n}, z, \mathscr{B})\left[H\left(n_{h}+\Delta q^{R} k_{h}+\sum_{b} \delta_{b, h}\left(\psi_{b}-1\right), 0, z, 0\right)-H\left(n_{h}, \mathbf{n}, z, \mathscr{B}\right)\right] \\
& +\zeta(z)\left(H\left(n_{h}+\Delta q^{z} k_{h}, \mathbf{n}+\Delta q^{z} \mathbf{k}, z^{\prime}, \mathscr{B}\right)-H\left(n_{h}, \mathbf{n}, z, \mathscr{B}\right)\right) \\
& +\sum_{b} H_{n_{b}} \dot{n}_{b} \\
& +\eta\left(H\left(n_{h}, \mathbf{n}_{E}, z, \mathscr{B}^{\prime}\right)-H\left(n_{h}, 0, z, 0\right)\right) \mathbb{1}_{\mathscr{B}=0} \\
\text { with } n^{h}= & q k^{h}+\sum_{b} \delta_{b}
\end{aligned}
$$

\footnotetext{
${ }^{9}$ The star superscript on $\lambda^{*}$ distinguishes the equilibrium arrival rate which is only a function of the state variables $(\mathbf{n}, z, \mathscr{B})$ from the general arrival rate $\lambda$, which is also a function of banks portfolio decisions.
} 
The first term is the flow utility of consumption. The second term corresponds to the deterministic drift in net worth. The third corresponds to the run shock. In case of a run, all banks fail, hence $\mathscr{B}=0$. The fourth term corresponds to the productivity shock. The fifth to the deterministic drift in the vector of banks net worth. The last term corresponds to the entrance of new banks after a run, which I explain later in this section.

Banks Instanteneous utility is denoted $u_{b}($.$) and is assumed to be HARA with$ parameters $\gamma, \theta:^{10}$

$$
u_{b}(d)=\xi \frac{(d-\gamma \theta)^{1-\gamma}}{1-\gamma} \quad \text { with } \quad d>0, \gamma \in[0,1), \xi>0 . \theta \geq 0
$$

A bank chooses dividends $d_{b}$ and investment in real asset $k_{b}$, thereby a path of net worth $n_{b}$ and an issuance of deposits $\delta_{b}$. As before, they behave à la Cournot. In this dynamic setting, they not only internalize the effect of their investment in capital but also the effect of their accumulation of equity on the returns to capital, on asset prices and on the probability of a run, taking others' investment and accumulation decisions as given.

Law of motion of banks' net worth. Real asset holdings, $q k_{b}$ are financed either by deposits, $\delta_{b}$, or by net worth, $n_{b}$. I omit banks indexes when no confusion results.

$$
n=q k-\delta
$$

As for the household, the general law of motion of equity

$$
d n=(d q+z) k-r \delta-d
$$

can be rewritten separately for the case without shock and the cases with shock. If neither run nor productivity shocks occurs, the law of motion is deterministic

$$
\dot{n}=(\dot{q}+z) k-r \delta-d
$$

\footnotetext{
${ }^{10} \gamma \rightarrow+\infty$ gives the CARA case, $\theta=0$ gives the usual CRRA case and $\theta>0, \theta<+\infty$ is the decreasing relative risk aversion case.
} 
When there is a run, prices jump discretely and net worth evolves according to

$$
\Delta n=k \Delta q^{R}
$$

where $\Delta q^{R}$ denotes the discrete jump in asset price when all banks experience a run. After a successful run - and all runs are successful in equilibrium -, all banks are liquidated. Each banker is forced to exit and gets $v^{R}$. I think of $v^{R}$ as the value of becoming an atomistic household, which is essentially $v^{R}=0$ from the point of a banker who is a large agent in the economy. In the calibration, I set it to 0 .

Hamilton-Jacobi-Bellman equation. The state of the economy is summarized by the vectors of banks' net worth $\mathbf{n}$, the level of productivity $z$ and the number of banks $\mathscr{B}$. Denote $\mathbf{n}_{-b}, \mathbf{k}_{-b}, \dot{\mathbf{n}}_{-b}$ the vector of net worth, capital investment and change of net worth of all other banks except $b$. Taking these three vectors as given, a bank's $b$ value function solves the following HJB equation

$$
\begin{aligned}
\rho v\left(n, \mathbf{n}_{-b}, z, \mathscr{B}\right) & =\max _{d, k} u(d)+v_{n}((\dot{q}+z) k-r \delta-d)+\sum_{j \neq b} v_{n_{-j}} \dot{n}_{-j} \\
& +\lambda\left(k, \mathbf{k}_{-b}, n, \mathbf{n}_{-b}, z, \mathscr{B}\right)\left(v^{R}-v\left(n, \mathbf{n}_{-b}, z, \mathscr{B}\right)\right) \\
& +\zeta(z)\left[v\left(n+\Delta q^{z} k, \mathbf{n}_{-b}+\Delta q^{z} \mathbf{k}_{-b}, z^{\prime}, \mathscr{B}\right)-v\left(n, \mathbf{n}_{-b}, z, \mathscr{B}\right)\right]
\end{aligned}
$$

The first term is the flow utility of dividends. The second term corresponds to the deterministic drift in net worth. When choosing dividends and capital investment, a bank will internalize the impact of their action on the returns $\dot{q}$ and the interest rates paid on deposits $r$. The third corresponds to the deterministic drift in the vector of other banks' net worth, which bank $b$ takes as given. The fourth corresponds to the run shock where $\lambda\left(k, \mathbf{k}_{-b}, n, \mathbf{n}_{-b}, z, \mathscr{B}\right)$ is the arrival rate of a systemic run. It depends on the aggregate state variables of the economy and on the banks' capital investments. $\lambda^{*}\left(n, \mathbf{n}_{-b}, z, \mathscr{B}\right)$ which I used in the households problem, is the equilibrium arrival rate, once banks have chosen their optimal capital investment. In case of a run, a banker gets $v^{R}$. The assumption that utility is bounded from below and that $v^{R}-v\left(n, \mathbf{n}_{-b}, z, \mathscr{B}\right)<0$ everywhere in the state-space ensures that a banker would never want to voluntarily leave banking to get the outside value $v^{R}$. The fifth term corresponds to the productivity shock. 
General Equilibrium Conditions Recovery rate. The recovery rate of deposits at bank $b$ is given by ${ }^{11}$

$$
\psi_{b}=\max \left(\frac{q^{R} k_{b}}{\delta_{b}}, 1\right)
$$

Market clearing. The good, deposits and capital markets must clear.

Entry and run price. After a run has occurred, $\mathscr{B}^{\prime}$ households are simultaneously and randomly drawn with intensity $\eta$ per unit of time to become the new bankers. $\eta$ and $\mathscr{B}^{\prime}$ are parameters. Entry occurs only after a run. In normal times, the number of banks remains constant. I further assume that $\mathscr{B}^{\prime}=\mathscr{B}$, i.e. the number of new banks randomly created at some point after a run is the same as the number of banks prevailing before the run. ${ }^{12}$ I assume that, whenever banks enter, they are exogenously endowed with a level of equity equal to $n_{E}=0$, with $E$ stands for entry.

In addition, I call "immediate entry", the special case corresponding to $\eta \rightarrow+\infty$, in which the new banks enter immediately after the liquidation of the incumbants, and "no entry", the special case corresponding to $\eta=0$, in which no bank never enters after a run.

Finally, the run price should be consistent with the post-run macroeconomic conditions, which is:

$$
q^{R}(\mathbf{n}, z, \mathscr{B})=q(0, z, 0)
$$

where I use the convention that banks' net worth is zero whenever there is no banks currently operating. In the aftermath of a run, and as long as the random draw of new bankers hasn't occurred, all the capital stock is held by households.

\footnotetext{
${ }^{11}$ In the dynamic continuous time setting, the recovery rate doesn't include the stream of income, in contrast with the static formulation of the previous section.

${ }^{12}$ The timing and the number of entrants are exogenous. Introducing a free-entry condition would be a natural way to make both the timing and the number of entrants endogenous. It turns out to be rather complicated to deal with in a dynamic setting with a finite number of banks because there is no reason why banks should enter at the same time, which breaks the symmetry among banks needed for tractability. The assumption of exogeneity amounts to assuming that a) once $\mathscr{B}$ banks are operating, at no point of the state-space would an additional bank be willing to enter ; b)the cost of entry is such that $\mathscr{B}$ simultaneously entering is optimal for private agents ; c)opportunity to enter occurs randomly over time. These two assumptions keep the framework tractable while capturing the main mechanisms. Regarding the assumption that $\mathscr{B}^{\prime}=\mathscr{B}$, the analysis could easily be extended to the more general case where $\mathscr{B}^{\prime}$ is different from $\mathscr{B}$. This is beyond the scope of this paper.
} 
Equilibrium Definition An equilibrium is a collection of functions $H\left(n_{h}, \mathbf{n}, z, \mathscr{B}\right)$, $\left\{\delta_{b, h}\left(n_{h}, \mathbf{n}, z, \mathscr{B}\right)\right\}_{b=1}^{\mathscr{B}}, c\left(n_{h}, \mathbf{n}, z, \mathscr{B}\right) k_{h}\left(n_{h}, \mathbf{n}, z, \mathscr{B}\right), v\left(n, \mathbf{n}_{-b}, z, \mathscr{B}\right), k\left(n_{b}, \mathbf{n}_{-b}, z, \mathscr{B}\right)$,

$\delta\left(n_{b}, \mathbf{n}_{-b}, z, \mathscr{B}\right), d\left(n_{b}, \mathbf{n}_{-b}, z, \mathscr{B}\right), \lambda^{*}(\mathbf{n}, z, \mathscr{B}), q(\mathbf{n}, z, \mathscr{B})$ such that i) taking prices as given, $H\left(n_{h}, \mathbf{n}, z, \mathscr{B}\right), c\left(n_{h}, \mathbf{n}, z, \mathscr{B}\right), k_{h}\left(n_{h}, \mathbf{n}, z, \mathscr{B}\right),\left\{\delta_{b, h}\left(n_{h}, \mathbf{n}, z, \mathscr{B}\right)\right\}_{b=1}^{\mathscr{B}}$ are solutions to the households' problem, ii) taking other bank's behavior as given, $v\left(n, \mathbf{n}_{-b}, z, \mathscr{B}\right)$, $k\left(n_{b}, \mathbf{n}_{-b}, z, \mathscr{B}\right), d\left(n_{b}, \mathbf{n}_{-b}, z, \mathscr{B}\right), \delta\left(n_{b}, \mathbf{n}_{-b}, z, \mathscr{B}\right)$ are solutions to the bank's problem, iii) the deposits, asset and goods markets clear, iv) the run price is given by 16 is compatible with the post-run equilibrium conditions and $\mathrm{v}) \lambda^{*}(\mathbf{n}, z, \mathscr{B})$ is consistent with the equilibrium of the run game.

\subsection{A Symmetric Equilibrium with Systemic Runs}

In this section, I solve for the equilibrium of the model assuming that banks have the same amount of net worth at every point in time. I abstract from productivity shock and come back to the case with productivity risk in the numerical examples. The restriction to symmetric path of net worth is for tractability. It allows us to derive the main intuitions and mechanisms through which the degree of concentration influences the likelihood of bank runs. All proofs can be found in appendix.

Run Game and Arrival Rate of Run The run game is exactly the same as in the static framework. $\lambda$ denotes the arrival rate of a run.

Households Optimal Decisions and Pricing Equations The dynamics of asset prices and the interest rate on deposits at bank $b$ should be consistent with the households optimal portfolio and intertemporal allocation.

Pricing equations. Assuming that households are risk neutral and no productivity shock $\zeta()=$.0 , their F.O.C. are

$$
\begin{aligned}
\dot{q}+z-f^{\prime}\left(k_{h}\right) & =-\lambda \Delta q^{R}+\rho q \\
\forall b \in\{1, \ldots, \mathscr{B}\} \quad r_{b} & =\lambda\left(1-\psi_{b}\right)+\rho
\end{aligned}
$$

where the first condition is the asset pricing equation and the second is the traditional Euler equation for deposits adjusted for the probability of a run and the recovery rate. Through these equations, the bankers will internalize the impact of its choices on prices and returns. 
Bank's Capital Investment and Deposit Decisions I now solve for the optimal choice of capital investment and deposit of a bank. I fix the vectors of banks' net worth, $\mathbf{n}$, and solve for the static problem of a bank taking other banks capital investments as given.

Law of motion of a bank's net worth. Using the F.O.C. of the households 17 and 18 , one can rewrite the law of motion of a bank in case of no run shock as

$$
\dot{n}=(\lambda(\mathbf{k}, \mathbf{n})+\rho) n+f^{\prime}\left(\bar{K}-\sum_{j=1}^{\mathscr{B}} k_{j}\right) k_{b}-d
$$

In the rest of section 3.2, I restrict attention to equilibrium paths that satisfy the following properties:

Assumption 1. (Equilibrium Restrictions) I restrict attention to equilibrium paths where the following is true

1. All banks have the same amount of net worth.

2. $F^{*}(n)$ is differentiable with $\left(F^{*}\right)^{\prime}>0$.

3. There exists $\varepsilon>0$ such that $k^{C^{*}}(n)$ is differentiable with $\frac{\partial k^{C *}}{\partial n}>\varepsilon$.

4. Banks' capital investment strategies are Markovian, symmetric and stationary.

The restriction to symmetric path of net worth keeps the framework tractable while allowing us to derive the main mechanisms. Under assumption 1, I show in appendix that proposition 2.1 still holds, i.e. that there exists two thresholds $n_{1}^{C}, n_{1}^{I}$ such that if banks' net worth is lower than $n_{1}^{C}$ only the interior equilibrium is sustainable, if banks' net worth is higher than $n_{1}^{I}$ only the corner equilibrium is sustainable and both are sustainable for intermediate levels of net worth. It is not obvious that this proposition should also hold in a dynamic setting because asset prices and the value function also depend on the future path of the economy. In the rest of the section, I focus on the dynamics of the system.

Steady-State, Dividend and Accumulation Policy I start by deriving the accumulation and dividends policies of banks. I first characterize the steady-state of the model.

Steady-State. In steady-state, banks invest at the optimal interior, $k^{I}$, and their net worth is such that this investment is also safe given the price-drop. 
Lemma 2. The interior steady-state with positive net worth is given by ${ }^{13}$

$$
\begin{array}{rlrl}
k^{S S} & =\frac{\bar{K}}{\mathscr{B}+1} & n^{S S}=k^{S S}\left(q^{S S}-q^{R}\right) \\
q^{S S}=\frac{z-f^{\prime}\left(\bar{K}-\mathscr{B} k^{S S}\right)}{\rho} & d^{S S}=\rho n^{S S}+f^{\prime}\left(\bar{K}-\mathscr{B} k^{S S}\right) k^{S S}
\end{array}
$$

Notice that lemma 2 provides steady-state expressions as a function of primitives only when $q^{R}$ is exogenous which is the case only when there is no-entry after a systemic run $(\eta=0), q^{R}=\frac{z-\frac{\alpha}{2} \bar{K}^{2}}{z} . q^{R}$ is in general an endogenous object, which is the focus of a later section.

Dividends and saving policy. Along the equilibrium path, dividends are constant is the run zone, then increasing is the safe zone until the steady-state has been reached. Denoting $k_{1}^{*}(n), q_{1}^{*}(n)$ the derivative of $k^{C}\left(n_{b}, \mathbf{n}_{-b}\right), q\left(n_{b}, \mathbf{n}_{-b}\right)$ respectively, with respect to their first argument, along the equilibrium path, the following lemma characterizes the path of dividends and accumulation decisions

Lemma 3. With utility 15, along the symmetric equilibrium path, if the path of capital investment, $k^{*}(n)$, is of the form described in corollary 1, dividends are given by

- For all $n \in\left[0, \max \left(n_{-1}, 0\right)\right], \dot{d}=0$ and $d(n)=(\rho+\bar{\lambda}) n+R\left(\boldsymbol{k}^{I}\right) k^{I}$ where $n_{-1}=\frac{d\left(n_{1}\right)-R\left(\boldsymbol{k}^{I}\right) k^{I}}{\rho+\bar{\lambda}}$

- For all $n \in\left(\max \left(n_{-1}, 0\right), n_{1}\right), \dot{d}=0$ and $d(n)=d\left(n_{1}\right)$

- For all $n \in\left[n_{1}, n^{S S}\right)$, d solves

$$
\begin{aligned}
\gamma \frac{\dot{d}}{d-\gamma \theta} & =k_{1}^{C *}(n) \alpha\left(\bar{K}-(\mathscr{B}+1) k^{C *}(n)\right) \\
\text { with } \quad k^{C *}(n) & =\frac{n}{q(n)-q^{R}}, \quad k_{1}^{C *}(n)=\frac{1-k^{C *}(n) q_{1}^{*}(n)}{q(n)-q^{R}}
\end{aligned}
$$

- For all $n \geq n^{S S}, d(n)=d^{S S}$

- For all $n$, the path of saving is given by

$$
\dot{n}=\left(\rho+\lambda^{*}(n)\right) n+\alpha\left(\bar{K}-\mathscr{B} k^{*}(n)\right) k^{*}(n)-d
$$

\footnotetext{
${ }^{13}$ One needs to specify that this steady-state is the one with positive net worth because there may also exist an (unstable) steady-state with negative net worth, from which I abstract.
} 
Below $n_{1}$, in the run zone, banks understand that keeping dividend payments low accelerates the accumulation of net worth and the exit of the run zone. The level of dividend payments is constant and equal to $d\left(n_{1}\right)$ everywhere between $n_{-1}$ and $n_{1}$ because their current investment - the interior Cournot - is disconnected from their current level of net worth, which implies that locally banks do not have any incentive to tilt the time path of dividends either in an increasing or decreasing fashion. From the concavity of the utility function, the path of dividends has to be continuous at $n_{1}$, which pins down $d\left(n_{1}\right)$.

For low enough net worth - below $n_{-1}$ - the constant level of dividends $d\left(n_{1}\right)$ would imply a decrease in net worth, i.e. $d\left(n_{1}\right)>(\rho+\bar{\lambda}) n+R\left(\mathbf{k}^{I}\right) k^{I}$. In this zone, banks will also decide to set their dividends constant, but they are not constrained to set it to $d\left(n_{1}\right)$ by the same continuity at $n_{1}$ argument because it will turn out that in equilibrium, they will never reach $n_{1}$. In that zone, banks set the level of dividends to keep net worth constant. This part of the state-space isn't empty if and only if $d\left(n_{1}\right)<(\rho+\bar{\lambda}) n+R\left(\mathbf{k}^{I}\right) k^{I}$.

Dividends are increasing in the safe zone because $\left(\bar{K}-(\mathscr{B}+1) k^{C *}(n)\right)>0$. In this zone, the marginal value of net worth is strictly positive: postponing dividend payments and building net worth allow banks to increase their investment capacity in the future and eventually reach the level of net worth for which it is safe to invest at the interior Cournot capital investment. At this point dividends stop increasing.

The Euler equation for dividends in the safe zone, given by equation 21, also features the derivative of the corner capital investment with respect to a bank own net worth, $k_{1}^{C *}(n)$. The latter is also positive and depends negatively on the size of the price drop $q(n)-q^{R}$. The larger the price drop, the smaller the amount of additional capital a marginal increase in net worth permits and the slower the increase in dividends over time should be. It also depends negatively on the derivative of asset prices with respect to a bank own net worth, $q_{1}^{*}(n)$ : this is because they take into account the positive impact the accumulation of their net worth has on asset prices in equilibrium, which tempers the increase in capital investment that an additional unit of net worth can buy. This derivative has to be consistent with the equilibrium asset price function which is the focus of the next paragraph.

Transition Path I analyze the transition path in two steps. I first analyze the dynamics in the safe zone, when $n \in\left[n_{1}, n^{S S}\right]$. The dynamics are characterized by a 
system of differential equations. I provide an existence and uniqueness result for a linear approximation around the steady-state. In a second step, I characterize the full transition path, including the run zone. For tractability, I look at the case with no entry after a run, $\eta \rightarrow 0$, which implies that the run price is exogenous. The intuitions go through in the more general case and I discuss the implications of $\eta>0$ in subsection 3.2.

Transition path in the safe zone. In the safe zone, when $n \in\left[n_{1}, n^{S S}\right]$, capital investment is given by $k^{C *}(n)$. The dynamics of the system is characterized by the following system of coupled differential equations for net worth, dividends and asset prices

$$
\begin{aligned}
\dot{n} & =\rho n+\alpha\left(\bar{K}-\mathscr{B} k^{C *}(n)\right) k^{C *}(n)-d \\
\dot{q} & =\rho q-z+\alpha\left(\bar{K}-\mathscr{B} k^{C *}(n)\right) \\
\gamma \frac{\dot{d}}{d-\gamma \theta} & =k_{1}^{C *}(n) \alpha\left(\bar{K}-(\mathscr{B}+1) k^{C *}(n)\right) \\
\text { with } \quad k^{C *}(n) & =\frac{n}{q-q^{R}}, \quad k_{1}^{C *}(n)=\frac{1-k^{C *}(n) q_{1}^{*}(n)}{q-q^{R}}, \quad q_{1}^{*}(n)=\frac{\dot{q}}{\mathscr{B} \dot{n}}
\end{aligned}
$$

and initial condition $n\left(t_{0}\right)=n_{1}$ and terminal conditions

$k^{S S}=\frac{\bar{K}}{\mathscr{B}+1} \quad q^{S S}=\frac{z-\alpha\left(\bar{K}-\mathscr{B} k^{S S}\right)}{\rho} \quad d^{S S}=\rho n^{S S}+\alpha\left(\bar{K}-\mathscr{B} k^{S S}\right) k^{S S}$

The following lemma establishes that in the safe zone, dividends, prices, capital and net worth increase over time. It also establishes existence and uniqueness for the solution to the linearized model around the steady-state which gives us confidence for the existence and uniqueness of the non-linear solution. I finally give an expression for the speed of convergence whose dependence on the level of competition is discussed later.

Lemma 4. 1. Along any transition path solution to the initial-terminal value problem 22, all variables, $\left(d(t), n(t), k^{C}(t), q(t)\right)$, are increasing.

2. There exists a unique solution $(d(t), n(t), k(t), q(t))$ to the linear approximation of the system 22 around $\left(d^{S S}, n^{S S}, k^{S S}, q^{S S}\right)$ and the (negative of the) rate of 
convergence of capital to its steady-state is given by:

$$
\ell_{-}=\frac{z-\rho q^{R}-\sqrt{\left(z-\rho q^{R}\right)^{2}+\frac{4}{\gamma}\left(1-k^{S S} q_{1}^{S S}\right)\left(d^{S S}-\theta \gamma\right)(\mathscr{B}+1) \alpha}}{2\left(q^{S S}-q^{R}\right)}
$$

Figure 4 represents the system 22 in the $(k, \tilde{q})$ plane with $\tilde{q}=q-q^{R}$. In black I draw the line corresponding to the locus of $(k, \tilde{q})$ compatible with $\dot{\tilde{q}}=0$. The dotted black line represents the locus of $(k, \tilde{q})$ compatible with the initial condition. Capital is always increasing in the safe zone, so all horizontal arrows point to the right. Asset prices decrease if they start below the black line and increase if they start above it. The system has to start at some point on the dotted black line. It is immediate from the phase diagram why capital and asset prices should be increasing along any transition path. The grey line represents one possible path.

It is not straightforward at all to obtain general conditions over the parameter space such that the forward-backward system of differential equations 22 admits one and only one solution. Lemma 4 establishes existence and uniqueness only for the linear approximation of the system. I check numerically that for my parametrization, a solution to the non-linear system exists and is unique. I discuss further this issue in the proof of lemma 4 .

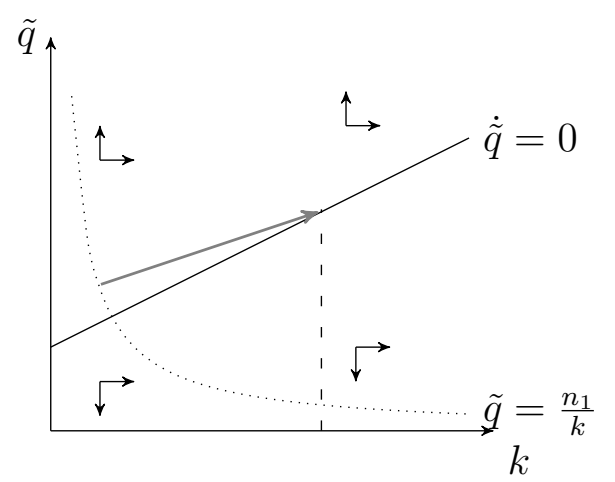

$k^{S S}$

Figure 4: Phase diagram of system in safe zone

Full transition path. I are now ready to characterize the equilibrium path of the system. 
Proposition 3.1. Any transition path starting at $n_{0} \geq 0$ and satisfying assumption 1 is characterized by:

1. (Run zone with certain death). If $n_{0} \in\left[0, \max \left(n_{-1}, 0\right)\right], k^{*}(n)=k^{I}$, the system operates in the run zone, $\lambda^{*}(n)=\bar{\lambda}, n$ is constant over time, the system is in steady-state, banks eventually experience a run.

2. (Run zone with escape). If $n_{0} \in\left(\max \left(n_{-1}, 0\right), n_{1}\right), k^{*}(n)=k^{I}$, the system operates in the run zone, $\lambda^{*}(n)=\bar{\lambda}, n$ increases and reaches in finite time $n_{1}$, at which point the system enters the safe zone

3. (Safe zone). If $n_{0} \in\left[n_{1}, n^{S S}\right)$, then all variables increase and converge to their steady-state value: $k^{*}(n)=k^{C *}(n) \rightarrow k^{S S}$ and $n \rightarrow n^{S S}, q \rightarrow q^{S S}$ and the system is not subject to run.

4. (Safe Steady-State) If $n_{0} \geq n^{S S}$, then $k=k^{S S}$ and $n=n_{0}$ forever. It is a steady-state.

Moreover, all assumptions in 1 hold.

On the equilibrium path, the capital investment jumps at $n_{1}$ from $k^{S S}$ to $k^{C *}\left(n_{1}\right)<$ $k^{S S}$.

Financial accelerator in the safe zone. The financial accelerator describes the amplification coming from the decrease in intermediation by banks after a shock that depletes their net worth. There are three main ways the literature relates banks' net worth to their lending behavior. Kiyotaki and Moore (1997); Gertler and Kiyotaki (2015); Mendoza (2010) use a collateral constraint originating in moral hazard, Brunnermeier and Sannikov (2014); He and Krishnamurthy (2013) assumes a fixed amount of equity and therefore occasionally binding constraint and Adrian and Shin (2014); Coimbra and Rey (2017) use Value-at-Risk constraints. My model gives rise to a fourth one: the willingness of banks to optimally restrict their leverage to avoid the risk of a run when they are sufficiently capitalized implies the following rule for leverage:

$$
k^{C *}(n)=\frac{n}{q-q^{R}} \Longleftrightarrow \frac{q k^{C *}(n)}{n}=\frac{1}{1-\frac{q^{R}}{q}}
$$

While the multiplier of leverage in Gertler and Kiyotaki (2015) is constant over the entire state-space, mine depends on the endogenous difference between asset prices and run prices. 
Around the steady-state, for small enough shocks to net worth, the economy remains within the safe zone and features a traditional financial accelerator. The amplification mechanism in this zone comes from the voluntary restrictions on capital investment by banks who find it more profitable to protect their franchise value from the risk of a run. But a large adverse shock throws the economy into the run zone where the relationship between net worth and banks' investment endogenously breaks down because banks find it more profitable to keep their leverage high. The endogenous amplification from the financial sector therefore takes two different forms over time: in the run zone it comes from the possibility of a run which could further lower output, in the safe zone it comes from the traditional accelerator effect. The latter only kicks in with a delay. The model provides a testable explanation for the fact that during the Great Recession, runs happened between 2007 and 2009 and restriction of lending happened later, in 2009-2010 (Gorton and Metrick, 2009; Kacperczyk and Schnabl, 2009; Covitz et al., 2013).

Recapitalization channel. Banks operating in more concentrated systems earn higher profits. One implication is that they can potentially recapitalize more quickly. Whether they will or not depends on their dividends policy and ultimately on the specification on the utility function.

In order to get a sense of how the strength of the recapitalization channel depends on the parameters of the bank's utility function, I look at the speed of convergence around the steady-state (given in lemma 4) which is the speed at which capital approaches its steady-state value. To get more intuition, I consider the special case where $\eta=0$ for which one has (quasi) analytical solutions. Denoting $\tilde{z}=z-\rho q^{R}$, the expression for the speed of convergence is given by:

$$
\ell=\frac{\tilde{z}-\sqrt{\tilde{z}^{2}+\frac{4}{\gamma}\left(1-k^{S S} q_{1}^{S S}\right)\left(\bar{K}^{2} \alpha-\theta \gamma(\mathscr{B}+1)\right) \alpha}}{2 \frac{\alpha \mathscr{B} \bar{K}}{\rho(\mathscr{B}+1)}}
$$

The speed of convergence depends on the number of banks through three channels. First, increasing the number of banks increases the denominator which slows down convergence. This is an implication of the price-drop effect: because the drop in asset prices is larger in more competitive systems, each additional unit of net worth buys less additional capital in the safe zone. Secondly, increasing $\mathscr{B}$ increases the speed of 
convergence through the term $k^{S S} q_{1}^{S S}$ in the numerator: more competitive banks have more incentive to accumulate net worth because they don't move asset prices as much with their actions. Thirdly, the term $\theta \gamma(\mathscr{B}+1)$ reflects the fact that banks in more concentrated markets make higher profits and, if they do not distribute dividends "too early", converges more quickly.

The third mechanism is really what drives the recapitalization channel. However, it depends crucially on the parameters of the utility function. In the case where banks have linear utility, $\gamma=0$, and a non-negativity constraint on dividends, dividends are zero until the steady-state is reached and the speed of convergence would vary one for one with the level of profits and therefore one for one with the level of competition. When banks want to smooth dividends, $\gamma>0$, whether the recapitalization channel is strong, weak or negative, depends on $\theta$, which governs how quickly the intertemporal elasticity (relative risk aversion) increases (decreases) with the level of dividends. When $\theta=0$, corresponding to a CRRA utility function, banks distribute dividends in proportion to their income and the recapitalization channel has no effect on the speed of convergence in the neighborhood of the steady-state. But in general, the higher $\theta$, the stronger the negative effect that increasing the number of banks has on the speed of convergence.

How fast banks distribute dividends as they recapitalize is ultimately an empirical question. And it is an important question, as the recapitalization channel governs the speed at which the system escapes the run zone in which banks might experience run and governs the speed at which the system converges towards the steady-state once in the safe zone, and therefore the output cost along the path through the safe zone. It is unfortunately a question that hasn't received much attention in the empirical (and theoretical) literature.

Run Price and Entry Channel In this section, I show how the speed of entry determines the size of the price-drop and thereby influences the stability of the financial system. The main take-away is the entry channel: increasing the speed of entry of new banks raise the run-price and stabilizes the system by shortening the run zone.

Let's first consider the extreme case with immediate entry. The following proposition shows that when $\eta \rightarrow+\infty$, runs don't happen in equilibrium and banks play the interior solution without taking any risk of runs.

Proposition 3.2. If $\eta \rightarrow+\infty$, then $\left(n_{1}, n^{S S}\right) \rightarrow(0,0)$ and for all $n \in[0,+\infty)$ 


$$
\lambda^{*}(n)=0 \quad k^{*}(n)=k^{S S} \quad q^{*}(n)=q^{S S} \quad d(n)=\rho n+\alpha\left(k^{I}\right)^{2}
$$

Intuitively, expectations of very fast entry after a run raise the run price, $q^{R}$, to the point that eliminates the possibility of a drop in asset prices and therefore of runs. Banks always invest at the interior $k^{S S}$ and asset prices remain stable at their steady-state level. This is a version of contestable markets in which the existence of potential entrants eliminates the inefficiency caused by a small number of actors. I am not the first one to notice this effect, see for example Gertler and Kiyotaki (2015). This theoretical result is consistent with the finding of Beck et al. (2003) and Beck et al. (2013) that contestability increases stability.

The speed of entry, $\eta$, could also be reinterpreted in terms of availability of public fund for recapitalization of distressed institutions: by standing ready to recapitalize any institution experiencing a run, the government decreases the likelihood of runs by raising the run price.

I now discuss heuristically why the idea that faster entry reduces the size of the run zone is also true for $\eta<\infty$. Since after a run $\mathscr{B}$ banks enter at some arrival rate $\eta$, the run price is given by $q^{R}=\frac{\eta}{\rho+\eta} q^{*}(0)+\frac{z-\alpha \bar{K}}{\rho+\eta}$. A first order approximation of the price-drop at $n=0$ is $q^{*}(0)-q^{R}=\frac{\rho}{\rho+\eta} q^{*}(0)-\frac{z-\alpha \bar{K}}{\rho+\eta}$. Hence a first order approximation of the corner strategy is $\frac{n}{q^{*}(n)-q^{R}} \simeq_{n=0} \frac{n}{q^{*}(0)-q^{R}}=\frac{(\rho+\eta) n}{q^{*}(0) \rho-(z-\alpha \bar{K})} \cdot{ }^{14}$ As $\eta$ increases, the price-drop decreases and the interior investment increases. The required amount of net worth to make the interior Cournot strategy safe decrease and banks switch all the more quickly to the safe strategy. ${ }^{15}$

Concentration and stability: recapitalization and entry channels. In the first section, I analyzed the price-drop and the franchise value channels. I now highlight the entry and recapitalization channels. First note that there are two dimensions to competition: the level of competition as well as the speed of entry of new banks. The recapitalization channel, like the price-drop and the franchise value channels, refers to the first dimension while the entry channel refers to the second dimension.

${ }^{14}$ The derivative of the safe strategy around $n=n_{0}$ is

$$
\frac{\partial \frac{n}{q(n)-q^{R}}}{\partial n}=\frac{1}{q\left(n_{0}\right)-q^{R}}\left(1-\frac{n_{0} q_{n}\left(n_{0}\right)}{q\left(n_{0}\right)-q^{R}}\right)
$$

${ }^{15}$ Although $q(0)$ also moves with $\eta$, it converges to some finite value $\frac{z-\alpha \frac{\bar{K}}{\rho \mathcal{B}+1}}{\rho}$ as $\eta$ increases. 
Entry channel. I have seen in section 3.2 that the faster the entry of banks after a run - or the more available public funds for recapitalization of distressed banks the smaller the price-drop, the smaller the run zone and the more stable the system. In the extreme case of immediate entry, the run zone disappears, the system never experiences runs and banks always invest at their interior optimum because potential entrants make large drop in asset prices impossible.

Recapitalization channel. A more concentrated system recapitalizes more quickly because it makes higher profits. It can therefore not only escape the run zone more quickly making the system more stable but it also converges to the steady-state with interior investment faster which is good from an efficiency point of view since in the safe zone output is depressed. The strength - and even the sign - of this channel is however dependent on the dividends policy of banks and ultimately the parameters characterizing the banks' preferences.

Market-power distorsion and entry channel. Finally, as in the static setting, a welfare analysis should also take into account the efficiency losses implied by the oligopolistic distortion. A more concentrated system will generate greater output loss because of its intermediates less capital. Interestingly, the trade-off depends on the entry channel in the following way. In the extreme case with immediate entry, since concentration has no effect on stability, a social planner should focus on increasing competition to reduce the oligopolistic distorsion. When entry happens slowly, financial stability makes competition less appealing.

\section{Numerical Examples}

In this section I provide some suggestive numerical examples to illustrate the mechanisms of the model. Given that households have linear utility, a natural measure of welfare that puts zero weight on bankers, is expected discounted lifetime income. It turns out that the price of the asset is exactly the expected discounted sum of future flow of output. A direct corollary is that with zero weight on bankers, the price of the asset is a sufficient statistics for welfare. The measure of instability is the cumulative probability of a run, the probability that a run happens by the end of the transition.

Parameter Choices Table 1 lists the parameters values in the benchmark calibration assigned to $\rho, \gamma, \theta, z, \bar{\lambda}, \bar{K}, \alpha, v^{R}$. A period is a year. I set the discount rate, $\rho$, to 
$5 \%$, a standard value in the literature and $\gamma$ the risk-aversion parameter of bankers to 0 in absence of clear estimates from the literature. I calibrate $\alpha$ to match a $2 \%$ interest margin. I set the benchmark number of banks to 5 to match a HHI of 2000: which is on the higher end of the range of HHI reported by Cetorelli et al. (2007), but consistent with my focus on concentrated markets. Incidentally 5 is also the number of the largest US investment banks before the crisis, the main broker-dealers of the US shadow banking (Adrian and Shin, 2010). I set $v^{R}$ to 0 to capture the fact that if a banker is forced to liquidation and becomes an household, their payoff will be of an order of magnitude smaller. I set $\bar{\lambda}$ to $3 \%$ to get a cumulative probability of run at the beginning of the transition path of $55 \%$ consistent with the finding of Valencia and Laeven (2008).

\begin{tabular}{c|c|c|c|c|c|c|c|c}
\hline Parameters & $\rho$ & $\gamma$ & $\theta$ & $\bar{\lambda}$ & $\alpha$ & $\bar{K}$ & $\mathscr{B}$ & $v^{R}$ \\
\hline Value & .05 & .5 & 0 & .03 & .02 & 10 & 5 & 0 \\
\hline
\end{tabular}

Table 1: Parameters

\section{Increasing Concentration: $\mathscr{B}$}

Policy rules. Figure 10 in appendix displays the policy rule for the individual bank capital investment, the total capital investment of all banks and saving together with the equilibrium asset price and implied leverage for the set of relevant level of net worth, for three different degrees of concentration, $\mathscr{B}=1,3,5$. My benchmark is in black, and the lightest gray corresponds to the monopoly case. The three zones of the state-space are easiest to see on the capital investment figure, (a). For low levels of net worth, the optimal capital investment is interior and high, and the bank is taking on the risk of runs. In this zone leverage is high and decreasing. When $n$ passes the threshold $n_{1}$, capital investment optimally and discontinuously drops to a safe level. For high levels of net worth, the interior investment becomes safe. The optimal saving policy is to save all profits until the steady-state has been reached. The discontinuity in the saving policy at the point $n_{1}$ corresponds to the drop in profits when the system enters the safe zone.

In this example, the threshold net worth $n_{1}$ at which the system switches to the safe zone is similar across different level of concentration. The fact that banks in less 
concentrated systems, despite having a smaller balance sheet, switch at the same level of net worth as banks in more concentrated systems stems from 1-the price-drop effect that makes it more costly in terms of net worth for a bank to reach the same level of capital investment 2-the franchise value effect. These two effects are enough to keep the net worth similar across degrees of concentration. This obviously has far reaching consequences for stability along the transition path.

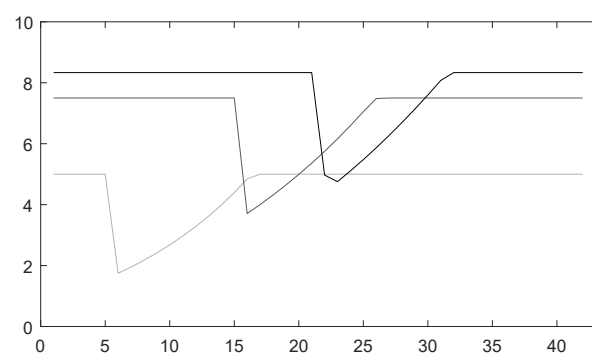

(a) All Bank Investment

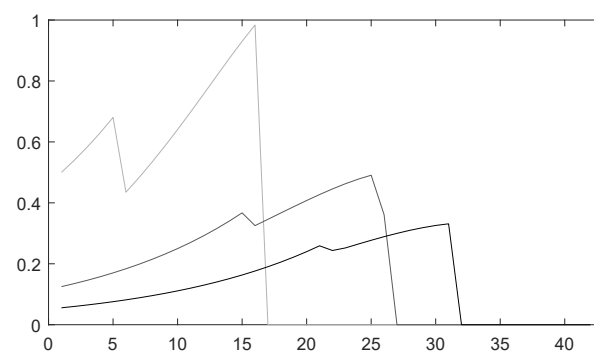

(c) Saving

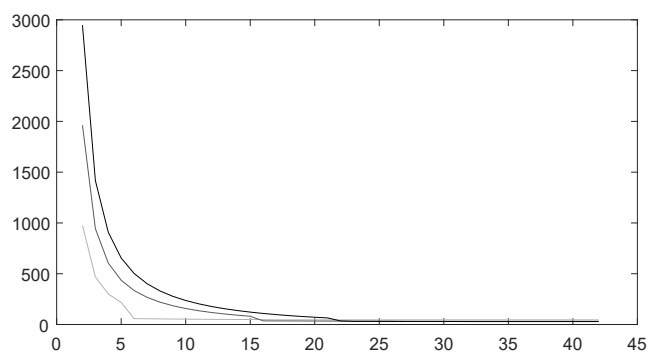

(b) Leverage

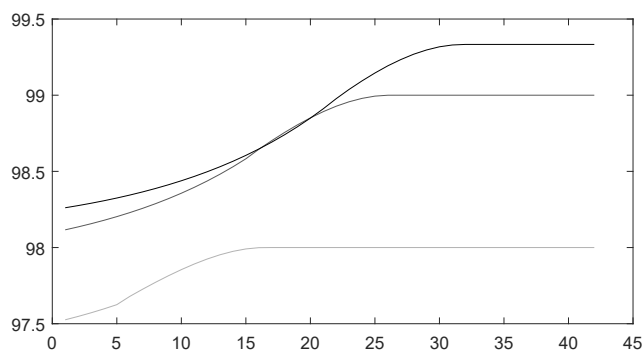

(d) Asset Price

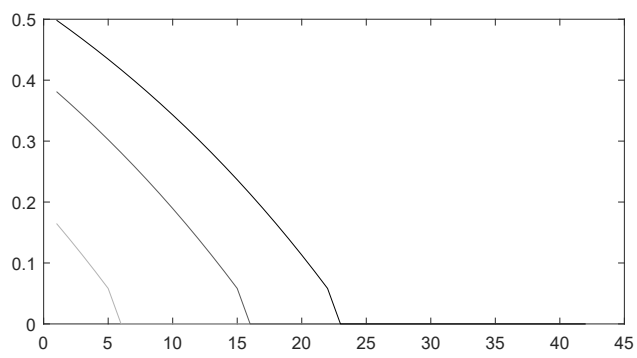

(e) CumProbRun

Figure 5: Transition path as a function of time for $\mathscr{B}=1,3,5$

Transition path. Figure 5 displays the transition path through time of the total amount of capital intermediated by banks, leverage, saving, asset prices and the cumulative probability of a run, defined as the probability that a run occurs by the end of time. Given that the threshold $n_{1}$ is similar across systems, the length of their 
respective run zone is comparable, hence the amount of time spent in it depends only on the speed at which banks travel through it, i.e. on the recapitalization effect. which is determined by their saving and in turn by their profits. A more concentrated system reaches the safe zone, and then its steady-state, much faster than my benchmark specification. In this example, looking at $5 \mathrm{c}$ and $5 \mathrm{e}$, going from $\mathscr{B}=5$ to 1 implies a reduction of the time spent in the crisis by a factor 4 and of the cumulative probability of a run by a factor 3 .

Increasing the Speed of Entry: $\eta$ To illustrate the effect of the speed of entry, figure 6 displays the transition path for the total amount of intermediated capital, asset prices and the cumulative probability of a run for three different values of $\eta$. The black line corresponds the benchmark $\eta=0$, the middle gray to $\eta=.05$ and the lighter gray to $\eta=.1$ which corresponds to an average time before entry of 10 years. To compute the transition path, I assume that the entry level of net worth is $n_{E}=0$.

As the speed of entry $\eta$ increases, the run price, given by

$$
q^{R}=\frac{\eta}{\rho+\eta} q(0)+\frac{z-\alpha \bar{K}}{\rho+\eta}
$$

increases, through a direct effect - the weight on $q(0)$ increases relative to the weight on $\frac{z-\alpha \bar{K}}{\rho+\eta}$ but also through an indirect effect coming from a higher $q(0)$, which can be seen on figure $6 \mathrm{~b}$. The latter effect stems from the fact that in general equilibrium the run zone is smaller, and the convergence to the safe zone and then to the steady-state occurs more quickly, which raises the $q(0)$. The higher run price, $q^{R}$ implies a smaller price-drop, which makes bank willing to switch more quickly to the safe investment strategy, as displayed in figure 6a. The run zone becomes smaller as well as the safe zone: the system travels faster to the steady-state. Consequently, welfare (figure 6b) increases with $\eta$, and instability (figure 6c) decreases.

Dividends Policy and the Recapitalization Channel: $\gamma$ In the example shown so far, I had assumed linear utility $(\gamma=0)$ and a non-negative dividend constraint $(d>0)$ so that banks didn't distribute dividends until the marginal utility had reached $\xi$. Assuming $\gamma=0$ implies that the recapitalization channel will be very strong because all profits - which increase with concentration - are being kept for the accumulation of equity. Allowing for a higher $\gamma$ tempers the recapitalization channel. Figure 11 


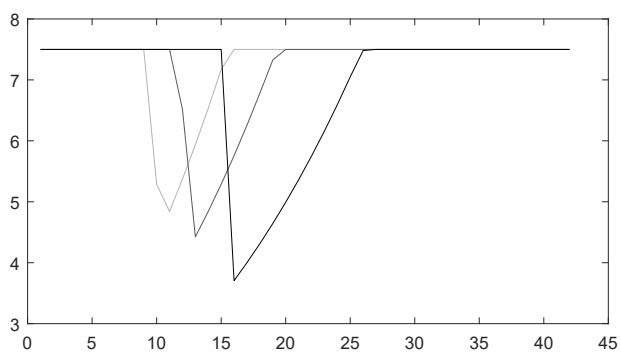

(a) All Bank Investment

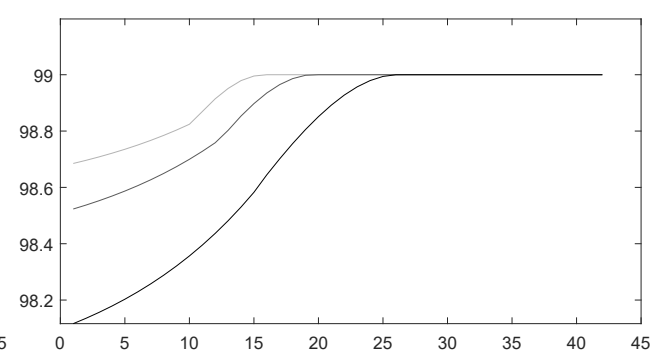

(b) Asset Price

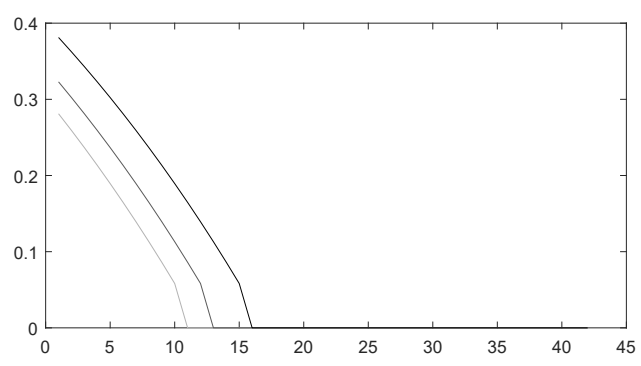

(c) CumProbRun

Figure 6: Transition path as a function of time for $\eta=0, .05$, and .1

displays the transition path through time of the total amount of capital intermediated by banks, leverage, saving, asset prices, dividends and the cumulative probability of a run, for $\gamma=.1$.

Compared to the transition path when $\gamma=0$ displayed in figure 5, it takes much more time for the economy to escape the run zone, travel through the safe zone and reach their steady-state because banks distribute dividends and do not save all their profits along the transition path as can be seen on figure 11e and 11c in appendix. This affects dis-proportionally systems with higher level of competition. At time 0 , the probability of a run in the system with five banks increases from $50 \%$ to $80 \%$ while it remains unchanged for the monopoly, as shown in figure $11 f$.

A Smooth Functional Form for $\lambda$ One may wonder how much of the previous results rely on the assumption that the arrival rate of a run is a step function. I show in this section that making $\lambda$ a smooth function of fundamentals doesn't change qualitatively the results. The following functional form for the arrival rate proves 
tractable

$$
\lambda=\frac{\bar{\lambda}}{2}\left(\max \left(\sum_{b} k_{b}-\frac{\sum_{b} n_{b}}{\left(q-q^{R}\right)}, 0\right)\right)^{2}
$$

with $\bar{\lambda}=.002 . \lambda($.$) is (weakly) increasing in k$ with $\frac{\partial \lambda}{\partial k}=\sqrt{2 \lambda \bar{\lambda}} \geq 0$ and decreasing in $n$. Figure 12 reports the transition path for three different levels of concentration, $\mathscr{B}=1,3,5$. The panel showing the probability of a run $12 \mathrm{f}$ is not the cumulative probability of a run but the instantaneous probability of a run (the cumulative probability isn't well defined because the lower bound of $\lambda($.$) is strictly positive). It$ decreases over time because as they accumulate net worth, the franchise value of banks increases and they find the safe strategy increasingly appealing. The patterns for dividends, asset prices, saving and leverage are very similar to the previous case except for investment that doesn't feature a downward jump at the entrance of the safe zone.

As can be seen on panel 12f, a more concentrated system will tend to restrict more its investment and play more safely for low levels of net worth and will exit more quickly the zone with high risk of runs. Also note that the intuition that more competitive sector have more incentive to take on risks carries to the long-run as well: more competitive systems have a higher risk of runs in the steady-state. This reflects a force that one couldn't see previously because there was no intensive margin to risk-taking: when deciding upon how much net worth to accumulate, a monopoly understands that the marginal dollar reduce the risk of a run by a greater extent than the marginal dollar accumulated by a bank in a more competitive sector since the the risk depends on the aggregate amount of net worth. This free-rider problem becomes more and more acute as the number of banks increases.

Exogenous Risk: the Paradox of Safety I now reintroduce exogenous productivity uncertainty. I solve the model with two productivity levels. I calibrate $\underline{z}, \bar{z}, \underline{\zeta}$ and $\bar{\zeta}$ as follows. I set $\bar{z}=5$ and $\underline{z}=4.25$ for the GDP drop to be of $15 \%$ in recession. I choose the transition rates between productivity states, $\bar{\zeta}=.02, \underline{\zeta}=.08$ so that the average time spent in the low state is 12 years and in the high state 50 years. This is consistent with the size and frequency of large and rare macroeconomic recessions.

Figure 7 displays the stationary distribution of this economy where the x-axis represents the sum of banks' net worth for $\mathscr{B}=1,3$ and 5 where I keep the same 
color convention as before. The solid (resp. dotted) line represents the distribution in the high (resp. low) state. The plotted densities are conditional on having effectively banks operating on financial markets; after a run, the system will operate without banks for a while.

The fact that the distribution of net worth is shifted to the left in normal and in bad times suggests that the stabilizing effects of low competition are mitigated by the net worth accumulation behavior of banks in the medium-run. After a long period without adverse shocks, banks operating in a concentrated sector do not have as much net worth on aggregate relative to their assets compared to banks in a more competitive sector because they understand that the drop in asset prices is also lower, should a run occur. This makes the system vulnerable to adverse exogenous shocks. This paradox of safety echoes the paradox of volatility in Brunnermeier and Sannikov (2014) where low fundamental volatility may actually lead to high endogenous volatility.

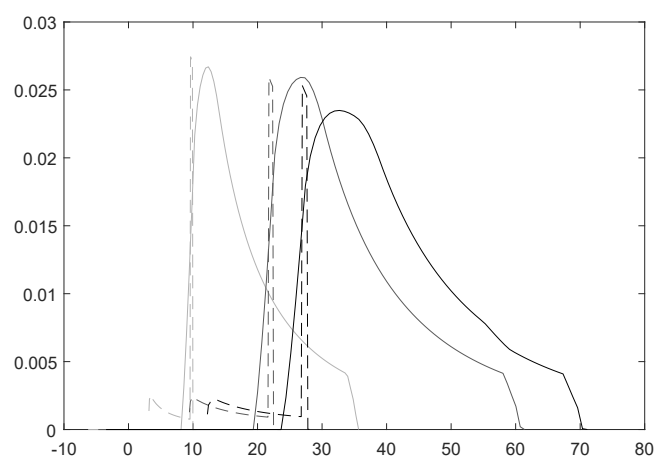

Figure 7: Stationary distributions as a function of net worth for $\mathscr{B}=1,3$ and 5

\section{Conclusion}

This paper has developed a dynamic general equilibrium model with a finite number of large financial intermediaries subject to endogenous - systemic and idiosyncratic run risk and playing $\grave{a}$ la Cournot, internalizing the effect of their action on aggregate risk, returns and asset prices. In the neighborhood of the steady-state, they optimally restrict their investment to be a function of their net worth to avoid the risk of a run which gives rise to an accelerator effect. For a large adverse shock, the financial system enters a run zone characterized by high leverage, deleveraging over time and risk of runs from which it may escape in finite time. The instability of the system is a 
function of how long it stays in this zone. This depends on the level of competition through three channels: the franchise value channel, the price-drop channel and the recapitalization channel. I also show that contestability - the speed of entry - has a significant stabilizing effect, what I call the entry channel.

By highlighting a new general equilibrium channel - the price-drop channel -, the paper has the following policy implications. First, it brings into question the idea that more competition among financial intermediaries, in the sense of lower concentration, is welfare-improving, especially in an environment where intermediaries are subject to runs and where assets are freely traded, which is exactly the environment in which the shadow banking system operates. The acuteness of the trade-off between efficiency and stability depends on other characteristics of the environment: if entry of new intermediaries after a systemic run is fast or if government steps in quickly to recapitalize failing intermediaries in case of a run, it eliminates the risk and procompetitive policies are always beneficial. Second, it provides support to the idea that shadow banks should be regulated the same way as banks and enjoy the same access to the lender of last resort. Indeed, if shadow banks were subject to the same macro-prudential regulations and were granted the same access to the discount window or to the deposit insurance scheme as ordinary banks, increasing competition would always be welfare-improving. Third, in a dual system where banks and shadow banks co-exist, increasing competition in the regulated sector or toughening capital requirements may increase the likelihood of runs by changing the degree of competition or the size of the unregulated sector.

The qualitative findings are consistent with empirical evidence of the dynamics of the financial system in the aftermath of a adverse shock as well as with the findings of the effect of concentration on stability. My analysis gives rise to several new testable predictions and areas for further empirical research. I highlight the limits of empirical analyses that do not take into account the state-dependency of banks' behaviors. For small shocks, banks behavior is characterized by a safe strategy while after a large shock, runs may occur in the short run and the decline in intermediation happens with a delay, once the banks have reached the safe zone. I also highlight the importance of two channels that have been overlooked by the current literature: the recapitalization channel according to which more concentrated markets have the ability to recapitalize more quickly and escape the run zone and the price-drop channels according to which concentration influences the size of the drop in asset prices when a run occur. 


\section{References}

T. Adrian and H. S. Shin. Liquidity and leverage. Journal of Financial Intermediation, 19(3):418-437, July 2010.

T. Adrian and H. S. Shin. Procyclical Leverage and Value-at-Risk. Review of Financial Studies, 27(2):373-403, 2014.

T. Beck, A. Demirguc-Kunt, and R. Levine. Bank Concentration and Crises. NBER Working Papers 9921, National Bureau of Economic Research, Inc, Aug. 2003.

T. Beck, O. De Jonghe, and G. Schepens. Bank competition and stability: Crosscountry heterogeneity. Journal of Financial Intermediation, 22(2):218-244, 2013.

F. S. Board. Global shadow banking monitoring report 2016. Technical report, May 2017.

M. K. Brunnermeier and Y. Sannikov. A Macroeconomic Model with a Financial Sector. American Economic Review, 104(2):379-421, February 2014.

E. Carletti and P. Hartmann. Competition and stability: what's special about banking? In Monetary History, Exchange Rates and Financial Markets, Chapters, chapter 8. Edward Elgar Publishing, 2003.

N. Cetorelli, B. Hirtle, and D. Morgan. Trends in financial market concentration and their implications for market stability. FRBNY Economic Policy Review, 13(1), Mar. 2007.

N. Coimbra and H. Rey. Financial Cycles with Heterogeneous Intermediaries. NBER Working Papers 23245, National Bureau of Economic Research, Inc, Mar. 2017.

D. Corbae and P. D'Erasmo. Capital requirements in a quantitative model of banking industry dynamics. Working Papers 14-13, Federal Reserve Bank of Philadelphia, Apr. 2014.

D. Covitz, N. Liang, and G. A. Suarez. The Evolution of a Financial Crisis: Collapse of the Asset-Backed Commercial Paper Market. Journal of Finance, 68(3):815-848, June 2013.

M. Degl'Innocenti, F. Fiordelisi, C. Girardone, and N. Radić. Competition and Risk-Taking in Investment banking. Essex Finance Centre Working Papers 21268, University of Essex, Essex Business School, Jan. 2018.

D. W. Diamond and P. H. Dybvig. Bank Runs, Deposit Insurance, and Liquidity. Journal of Political Economy, 91(3):401-419, June 1983.

E. Dávila and A. Walther. Does size matter? Bailouts with large and small banks. 
Journal of Financial Economics, 136(1):1-22, 2020.

T. M. Eisenbach and G. Phelan. Cournot Fire Sales. Department of Economics Working Papers 2020-10, Department of Economics, Williams College, Oct. 2020.

X. Freixas and K. Ma. Banking Competition and Stability: The Role of Leverage. Working Papers 781, Barcelona Graduate School of Economics, Oct. 2015.

M. Gertler and N. Kiyotaki. Banking, Liquidity, and Bank Runs in an Infinite Horizon Economy. American Economic Review, 105(7):2011-2043, July 2015.

M. Gertler, N. Kiyotaki, and A. Prestipino. Anticipated Banking Panics. American Economic Review, 106(5):554-559, May 2016.

M. Gertler, N. Kiyotaki, and A. Prestipino. A Macroeconomic Model with Financial Panics. NBER Working Papers 24126, National Bureau of Economic Research, Inc, Dec. 2017.

G. B. Gorton and A. Metrick. Securitized Banking and the Run on Repo. NBER Working Papers 15223, National Bureau of Economic Research, Inc, Aug. 2009.

Z. He and A. Krishnamurthy. Intermediary Asset Pricing. American Economic Review, 103(2):732-770, April 2013.

M. Kacperczyk and P. Schnabl. When Safe Proved Risky: Commercial Paper During the Financial Crisis of 2007-2009. NBER Working Papers 15538, National Bureau of Economic Research, Inc, Nov. 2009.

M. C. Keeley. Deposit Insurance, Risk, and Market Power in Banking. American Economic Review, 80(5):1183-1200, December 1990.

N. Kiyotaki and J. Moore. Credit Cycles. Journal of Political Economy, 105(2): 211-248, April 1997.

C. Matutes and X. Vives. Imperfect competition, risk taking, and regulation in banking. European Economic Review, 44(1):1-34, January 2000.

E. G. Mendoza. Sudden Stops, Financial Crises, and Leverage. American Economic Review, 100(5):1941-1966, December 2010.

S. Morris and H. S. Shin. Unique Equilibrium in a Model of Self-Fulfilling Currency Attacks. American Economic Review, 88(3):587-597, June 1998.

D. Neuhann and M. Sockin. Risk-Sharing and Investment in Concentrated Markets. 2019 Meeting Papers 118, Society for Economic Dynamics, 2019.

G. D. Nicolo and J. H. Boyd. Bank Risk-Taking and Competition Revisited. IMF Working Papers 03/114, International Monetary Fund, June 2003.

Z. Pozsar, T. Adrian, A. B. Ashcraft, and H. Boesky. Shadow banking. Staff Reports 
458, Federal Reserve Bank of New York, 2010.

F. Valencia and L. Laeven. Systemic Banking Crises; A New Database. IMF Working Papers 08/224, International Monetary Fund, Sept. 2008.

X. Vives. Competition and Stability in Banking: The Role of Regulation and Competition Policy. Princeton University Press, 2016.

D. Zigraiova and T. Havranek. Bank Competition And Financial Stability: Much Ado About Nothing? Journal of Economic Surveys, 30(5):944-981, December 2016. 


\section{For Online Publication}

\section{Competition vs. Stability: Oligopolistic Banking System with Run Risk Damien Capelle}

\section{A Static Model}

Pricing equation. Denoting the lagrange multiplier on the net worth constraint $\mu$, substituting for $c$ and $c^{R}$, and taking the F.O.C. with respect to $\delta_{b}, n$ and $k$ gives

$$
\begin{aligned}
\frac{1}{1+\rho}\left[(1-\lambda)\left(1+r_{b}\right)+\lambda \psi_{b}\right] & =\mu \\
\frac{1}{1+\rho}\left[(1-\lambda)\left(q^{\prime}+z-f^{\prime}(k)\right)+\lambda\left(q^{R}+z-f^{\prime}(k)\right)\right] & =\mu q \\
\mu & =1
\end{aligned}
$$

which can be rewritten as

$$
\begin{gathered}
q^{N R}-q+z-f^{\prime}\left(k_{h}\right)=-\lambda\left(q^{R}-q^{N R}\right)+\rho q \\
\forall b \in\{1, \ldots, \mathscr{B}\} \quad r_{b}=\lambda\left(1+r_{b}-\psi_{b}\right)+\rho
\end{gathered}
$$

Lemma $1 q^{N R}$ is increasing in $\mathscr{B}$ since its last term $-\frac{\bar{K}}{\mathscr{B}+1}$ increases in $\mathscr{B}$. $q^{R}$ is independent of $\mathscr{B} . q^{I}$ is an increasing function of $\mathscr{B}$ both directly through its last term $-\frac{\bar{K}}{\mathscr{B}+1}$ and $q^{N R}$ which I just showed was also increasing.

First I show that the function $q^{C}(n)$ is well defined for every $n>0$ and increasing in $n$. The LHS of equation (14) is continuous, strictly increasing and linear in $q^{C}$. The RHS of equation (14) is also continuous and strictly decreasing in $q^{C}$ for $q^{C} \in\left(q^{R}+\mathscr{B} n / \bar{K}, q^{N} R\right]$. In addition, denoting $R H S\left(q^{C}\right)=\frac{z+q^{N R}-\frac{\alpha}{2}\left(\bar{K}-\mathscr{B} \frac{n}{q^{C}-q^{R}}\right)^{2}}{1+\rho}$, it is easy to see that $R H S\left(q^{R}+\mathscr{B} n / \bar{K}\right)>\frac{z+q^{N R}}{1+\rho}>q^{N R}>q^{R}+\mathscr{B} n / \bar{K}$. Hence there exists a unique $q^{C}$ solution to the equation (14). In addition, since $R H S\left(q^{C}\right)$ is strictly increasing in $n$, the function $q^{C}(n)$ is also continuous and strictly increasing in $n$. Finally, since $\operatorname{RHS}\left(q^{C}\right)$ is strictly increasing in $\mathscr{B}$ both directly through its last term $\frac{\alpha}{2}\left(\bar{K}-\mathscr{B} \frac{n}{q^{C}(n)-q^{R}}\right)^{2}$ and through $q^{N R}$, the function $q^{C}(n)$ is also strictly increasing in $\mathscr{B}$. 
Existence and uniqueness of the thresholds $n_{1}^{C}, n_{1}^{I}$. I now study the best responses of an individual bank in a symmetric cournot game for a given level of net worth $n$ common across all banks. I define four functions: the first one corresponds to the payoffs of playing safe when all other banks play the safe strategy, the second one to the payoffs of playing risky when all other banks play the safe strategy (i.e. of deviating), the third one to the payoffs of playing safe when all other banks play risky, and the last one of playing risky when all other banks play risky:

$$
\begin{aligned}
S S\left(n, k^{C}\right) & =u\left[(1+\rho) n+\alpha \cdot *\left(\bar{K}-\mathscr{B} \cdot * k^{C}\right) * k^{C}\right] \\
R S\left(n, k^{C}\right) & =(1-\lambda)^{\gamma} u\left[(1+\rho) n+\alpha \cdot *\left(\frac{\bar{K}-(\mathscr{B}-1) \cdot * k^{C}}{2}\right)^{2}\right] \\
S R\left(n, k^{C}\right) & =u\left[(1+\rho) n+\alpha \cdot *\left(\bar{K}-\mathscr{B} \cdot * k^{C}\right) *\left(\mathscr{B} k^{C}-(\mathscr{B}-1) k^{I}\right)\right] \\
R R(n) & =(1-\lambda)^{\gamma} u\left[(1+\rho) n+\alpha \cdot *\left(\frac{\bar{K}}{\mathscr{B}+1}\right)^{2}\right]
\end{aligned}
$$

Now define the net payoff of playing safe when all the other banks play safe and risky respectively

$$
\begin{aligned}
& N S\left(n, k^{C}\right)=S S\left(n, k^{C}\right)-R S\left(n, k^{C}\right) \\
& N R\left(n, k^{C}\right)=S R\left(n, k^{C}\right)-R R
\end{aligned}
$$

I also define the following

$$
\begin{aligned}
S S p\left(k^{C}\right) & =\alpha \cdot *\left(\bar{K}-\mathscr{B} \cdot * k^{C}\right) * k^{C} \\
R S p\left(k^{C}\right) & =\alpha \cdot *\left(\frac{\bar{K}-(\mathscr{B}-1) \cdot * k^{C}}{2}\right)^{2} \\
S R p\left(k^{C}\right) & =\alpha \cdot *\left(\bar{K}-\mathscr{B} \cdot * k^{C}\right) *\left(\mathscr{B} k^{C}-(\mathscr{B}-1) k^{I}\right) \\
R R p & =\alpha \cdot *\left(\frac{\bar{K}}{\mathscr{B}+1}\right)^{2}
\end{aligned}
$$

$S R\left(n, k^{C}\right)$ is increasing in $n$ on $[0,+\infty)$ and in $k^{C}$ on $\left(0, k^{I}\right] \cdot S R\left(n, k^{C}(n)\right)$ is thus increasing in $n$. $R R$ is independent of $k^{C}$. It is increasing in $n$. I now show that $N R(n)$ is increasing in $n$. It directly stems from the comparison of the derivative of $S R$ and $R R$ : 


$$
\begin{aligned}
& S R_{n}\left(n, k^{C}\right)-R R_{n}(n) \\
& =(1+\rho) u^{\prime}\left[(1+\rho) n+\alpha \cdot *\left(\bar{K}-\mathscr{B} \cdot * k^{C}\right) *\left(\mathscr{B} k^{C}-(\mathscr{B}-1) k^{I}\right)\right] \\
& -(1-\lambda)^{\gamma}(1+\rho) u^{\prime}\left[(1+\rho) n+\alpha \cdot *\left(\frac{\bar{K}}{\mathscr{B}+1}\right)^{2}\right] \\
& =(1+\rho) u^{\prime}\left[(1+\rho) n+\alpha \cdot *\left(\bar{K}-\mathscr{B} \cdot * k^{C}\right) *\left(\mathscr{B} k^{C}-(\mathscr{B}-1) k^{I}\right)\right] \\
& \quad \times[1-(1-\lambda)^{\gamma} \underbrace{u^{\prime}\left[(1+\rho) n+\alpha\left(\frac{\bar{K}}{\mathscr{B}+1}\right)^{2}\right]}_{<1}]
\end{aligned}
$$

where we used the concavity of $u$ and the fact that $\left(\bar{K}-\mathscr{B} . * k^{C}\right) *\left(\mathscr{B} k^{C}-(\mathscr{B}-1) k^{I}\right)$ is bounded above by $\frac{\bar{K}}{\mathscr{B}+1}$ for $k^{C}$ below $\frac{\bar{K}}{\mathscr{B}+1}$, in the last line. This shows that $N R\left(n, k^{C}\right)$ is increasing in $n$.

Since $N R$ is increasing in $n$ and in $k^{C}$ and $k^{C}$ is increasing in $n$, the function $N R\left(n, k^{C}(n)\right)$ is increasing in $n$.

I now turn to $N S$. First $S S\left(n, k^{C}\right)$ is increasing in $n$ on $[0,+\infty)$ and in $k^{C}$ on $\left(0, k^{I}\right] . S S\left(n, k^{C}(n)\right)$ is thus increasing in $n$. $R S$ is decreasing in $k^{C}$. It is increasing in $n$. Hence $N R$ is increasing in $k^{C}$. I now show it is also increasing in $n$. Using the exact same line of argument as before, the concavity of $u$ and the fact that $\left(\bar{K}-\mathscr{B} . * k^{C}\right) * k^{C}$ is bounded above by $\left(\frac{\bar{K}-(\mathscr{B}-1) \cdot * k^{C}}{2}\right)^{2}$ for $k^{C}$ below $k^{I}$, one can show that $N S\left(n, k^{C}\right)$ is increasing in $n$.

Since $N S$ is increasing in $n$ and in $k^{C}$ and $k^{C}$ is increasing in $n$, the function $N S\left(n, k^{C}(n)\right)$ is increasing in $n$.

In addition, both $N S$ and $N R$ are negative at the lower bound of the interval of $n$, $N S(0)<0$ and $N R(0)<0$. They are both positive at the upper of the interval of $n$ : it is easy to see that $S S p\left(k^{I}\right)=R S p\left(k^{I}\right)$ and $S R p\left(k^{I}\right)=R R p\left(k^{I}\right)$; given that $\lambda>0$, one directly gets that for the level of net worth such that $k^{C}=k^{I}$, which I denote $n=n^{S S}$, and for $k^{C}=k^{I}$, one has $N S\left(n^{S S}, k^{I}\right)>0$ and $N R\left(n^{S S}, k^{I}\right)>0$.

Finally, given that $N S$ and $N R$ are strictly increasing over the relevant domain $\left[0, n^{S S}\right]$, and are continuous over this domain, there exists a unique pair $\left(n_{1}^{C}, n_{1}^{I}\right) \in$ $\left[0, n^{S S}\right]^{2}$ such that $N S\left(n_{1}^{C}\right)=0$ and $N R\left(n_{1}^{I}\right)=0$. 
Concentration and Risk Channels. I now show that risk increases when $\mathscr{B}$ increases. To do so, I will show that both $\mathscr{B} n_{1}^{C}$ and $\mathscr{B} n_{1}^{I}$ increase with $\mathscr{B}$. I first look at the case where $d q=q^{C}-q^{R}$ is held constant to isolate the franchise value channel, I then analyze the impact through the change in $q^{C}-q^{R}$. One can rewrite $S S, R S, S R, R R$ as follows:

$$
\begin{aligned}
S S\left(X, k^{C}\right) & =\frac{1}{\mathscr{B}^{1-\gamma}} u\left[(1+\rho) X+\alpha \cdot *\left(\bar{K}-X d q^{-1}\right) * X d q^{-1}\right] \\
R S\left(X, k^{C}\right) & =\frac{1}{\mathscr{B}^{1-\gamma}}(1-\lambda)^{\gamma} u\left[(1+\rho) X+\mathscr{B} \alpha \cdot *\left(\frac{\bar{K}-\frac{(\mathscr{B}-1)}{\mathscr{B}} \cdot * X d q^{-1}}{2}\right)^{2}\right] \\
S R\left(n, k^{C}\right) & =\frac{1}{\mathscr{B}^{1-\gamma}} u\left[(1+\rho) X+\mathscr{B} \alpha \cdot *\left(\bar{K}-X d q^{-1}\right) *\left(X d q^{-1}-(\mathscr{B}-1) k^{I}\right)\right] \\
R R(n) & =\frac{1}{\mathscr{B}^{1-\gamma}}(1-\lambda)^{\gamma} u\left[(1+\rho) X+\mathscr{B} \alpha \cdot *\left(\frac{\bar{K}}{\mathscr{B}+1}\right)^{2}\right]
\end{aligned}
$$

with $\quad X=\mathscr{B} n$

Let's start by showing that $X_{1}=\mathscr{B} n_{1}^{C}$ should increase when $\mathscr{B}$ go up holding $d q$ constant. One can show that $\mathscr{B} \alpha \cdot *\left(\frac{\bar{K}-\frac{(\mathscr{B}-1)}{\mathscr{B}} \cdot * X d q^{-1}}{2}\right)^{2}$ is increasing in $\mathscr{B}$ for $X \in\left[0, d q \frac{\mathscr{B}}{\mathscr{B}+1}\right]$. This is necessary and sufficient for $N S$ to shift down at the point $n_{1}^{C}$ (the derivative of NS with respect to $1 / \mathscr{B}^{1-\gamma}$ is zero at the point where $N S=0$ ). This implies that $\mathscr{B} n_{1}^{C}$ should increase to maintain $N S=0$ since NS is increasing in $X$ for $X \in[0, d q \mathscr{\mathscr { K }} \bar{K}]$.

I now show that $X_{2}=\mathscr{B} n_{1}^{I}$ should increase when $\mathscr{B}$ go up holding $d q$ constant. The derivative of $N R$ with respect to $\mathscr{B}$ holding $d q$ constant is given by

$$
\begin{aligned}
& \frac{\partial N R}{\partial \mathscr{B}}=\frac{\partial S R}{\partial \mathscr{B}}-\frac{\partial R R}{\partial \mathscr{B}} \\
& =\frac{1}{\mathscr{B}}{ }^{1-\gamma} \alpha\left[(1-\lambda)^{\gamma} \bar{K}^{2} \frac{\mathscr{B}-1}{(\mathscr{B}+1)^{2}} u^{\prime}\left[(1+\rho) X+\mathscr{B} \alpha \cdot *\left(\frac{\bar{K}}{\mathscr{B}+1}\right)^{2}\right]\right. \\
& \left.-\left((\bar{K}-X / d q) *\left((2 \mathscr{B}-1) k^{I}-X / d q\right)\right) u^{\prime}\left[(1+\rho) X+\mathscr{B} \alpha \cdot *(\bar{K}-X / d q) *\left(X / d q-(\mathscr{B}-1) k^{I}\right)\right]\right]
\end{aligned}
$$

Given that $u$ is concave, and $\mathscr{B}\left(\frac{\bar{K}}{\mathscr{B}+1}\right)^{2}>\mathscr{B}\left(\bar{K}-X d q^{-1}\right) *\left(X d q^{-1}-(\mathscr{B}-1) k^{I}\right)$, we 
have that

$$
u^{\prime}\left[(1+\rho) X+\mathscr{B} \alpha \cdot *\left(\frac{\bar{K}}{\mathscr{B}+1}\right)^{2}\right]<u^{\prime}\left[(1+\rho) X+\mathscr{B} \alpha \cdot *\left(\bar{K}-X d q^{-1}\right) *\left(X d q^{-1}-(\mathscr{B}-1) k^{I}\right)\right] .
$$

A sufficient condition for the derivative to be negative is that

$$
\begin{aligned}
\left(\left(\bar{K}-X d q^{-1}\right) *\left((2 \mathscr{B}-1) k^{I}-X d q^{-1}\right)\right)>(1-\lambda)^{\gamma} \bar{K}^{2} \frac{\mathscr{B}-1}{(\mathscr{B}+1)^{2}} \\
\Longleftrightarrow\left(\mathscr{B}+1-X d q^{-1} / k^{I}\right)\left(2 \mathscr{B}-1-X d q^{-1} / k^{I}\right)>(1-\lambda)^{\gamma}(\mathscr{B}-1)
\end{aligned}
$$

A sufficient condition for this inequality to hold is that

$$
2 \mathscr{B}^{2}-\frac{X d q^{-1}}{k^{I}}\left[3 \mathscr{B}-2-\frac{X d q^{-1}}{k^{I}}\right]>0 \Longleftrightarrow\left(\frac{\frac{X d q^{-1}}{\mathscr{B}}}{k^{I}}\right)^{2}-\frac{\frac{X d q^{-1}}{\mathscr{B}}}{k^{I}}\left[3-\frac{2}{\mathscr{B}}\right]+2>0
$$

I then study the polynomial $P(x)=x^{2}-\left[3-\frac{2}{\mathscr{B}}\right] x+2$. It is decreasing until $\left[3-\frac{2}{\mathscr{B}}\right]$ and then increasing. The point at which the minimum is reached is always higher than $13-\frac{2}{\mathscr{B}}>1$ for $\mathscr{B}>1$. Since $x \in[0,1]$, we therefore know that $P(x)>P(1)=\frac{2}{\mathscr{B}}>0$ for all $x \in[0,1]$. Hence the result $\frac{\partial N R}{\partial \mathscr{B}}<0$. Using again the argument that $N R$ is increasing in $X$ for a given $d q^{-1}$, we find that $X$ should increase to maintain $N S\left(X_{2}\right)=0$. This ends the proof that $\mathscr{B} n_{1}^{I}$ is increasing in $\mathscr{B}$.

Price-drop effect. I now show that the partial effect of $\mathscr{B}$ on $\mathscr{B} n_{k}$ for $k=1,2$ through the drop in asset prices $d q$ amplifies the franchise value effect, i.e. that

$$
\frac{\partial \mathscr{B} n_{k}}{\partial d q} \frac{\partial d q}{\partial \mathscr{B}}>0 \quad \forall k=1,2
$$

From lemma 1, $\frac{\partial d q}{\partial \mathscr{B}}>0$. We have shown earlier that $\frac{\partial N S\left(n, k^{C}\right)}{\partial k^{C}}>0$ and $\frac{\partial N R\left(n, k^{C}\right)}{\partial k^{C}}>0$ over the relevant range of $k^{C} \in\left[0, k^{I}\right]$. I rely on the same argument here, since $k^{C}=$ $n d q^{-1}$, to get that $\frac{\partial N R\left(n, k^{C}\right)}{\partial d q}<0$ and $\frac{\partial N S\left(n, k^{C}\right)}{\partial d q}<0$. Hence we obtain $\frac{\partial N R\left(n, k^{C}\right)}{\partial d q} \frac{\partial d q}{\partial \mathscr{B}}<0$ and $\frac{\partial N S\left(n, k^{C}\right)}{\partial d q} \frac{\partial d q}{\partial \mathscr{B}}<0$. Since $N R\left(n, k^{C}(n)\right)$ and $N S\left(n, k^{C}(n)\right)$ are increasing in $\mathscr{B} n$ as shown before, it should be that $\mathscr{B} n_{1}^{C}$ and $\mathscr{B} n_{1}^{I}$ increase to maintain $N R=N S=0$. This ends the proof. 


\section{B Proofs}

\section{B.1 F.O.C HH and pricing equations}

It is immediate that the first order conditions when the households are risk-neutral gives the following no-arbitrage conditions $\dot{q}+z-f^{\prime}\left(k_{h}\right)=-\lambda \Delta q^{R}-\zeta(z) \Delta q^{z}+\rho q$ and $\forall b \quad r_{b}=-\lambda\left(\psi_{b}-1\right)+\rho$.

\section{B.2 Derivation of the law of motion for a bank's net worth}

After substituting out for deposits using the definition of net worth, one gets:

$$
\dot{n}_{b}=r n_{b}+\left(\dot{q}+z-r_{b} q\right) k_{b}-d_{b}
$$

where it appears clearly that the net excess return to an investment of one unit of capital if no run occurs is $\dot{q}+z-r_{b} q$. By the Household F.O.C together with

the market clearing condition for the capital market, and denoting $K=\sum_{j}^{\mathscr{B}} k_{j}$ the aggregate capital investment of banks, the net excess return is equal to:

$R(K)=R\left(\sum_{j}^{\mathscr{B}} k_{j}\right)=\dot{q}+z-r_{b} q=f^{\prime}\left(\beta-\sum_{j}^{\mathscr{B}} k_{j}^{b}\right)-\lambda_{b} \Delta q_{b}^{R}+\lambda_{b} q\left(\psi_{b}-1\right)-\zeta(z) \Delta q^{z}$

which shows how the net return on capital depends on the choice of capital by the individual banker through the aggregate $K$. Replacing into the law of motion for net worth one gets

$$
\begin{aligned}
\dot{n} & =r n+(\dot{q}+z-r q) k-d \\
& =\left(\lambda_{b}+\rho-\lambda_{b} \psi_{b}\right) n+\left(f^{\prime}\left(\beta-\sum_{j}^{\mathscr{B}} k_{j}^{b}\right)-\lambda_{b} \Delta q_{b}^{R}+\lambda_{b} q\left(\psi_{b}-1\right)-\zeta(z) \Delta q^{z}\right) k-d
\end{aligned}
$$


Finally, I use the definition of $\psi_{b}=\frac{q_{b}^{R} k_{b}}{\delta_{b}}=\frac{q_{b}^{R} k_{b}}{q k_{b}-n_{b}}$ :

$$
\begin{aligned}
\dot{n} & =\left(\lambda_{b}+\rho-\lambda_{b} \psi_{b}\right) n+\left(f^{\prime}\left(\beta-\sum_{j}^{\mathscr{B}} k_{j}^{b}\right)-\lambda_{b} \Delta q_{b}^{R}+\lambda_{b} q\left(\psi_{b}-1\right)-\zeta(z) \Delta q^{z}\right) k-d \\
& =\left(\lambda_{b}+\rho\right) n+\left(f^{\prime}\left(\bar{K}-\sum_{j}^{\mathscr{B}} k_{j}\right)-\zeta(z) \Delta q^{z}\right) k-d
\end{aligned}
$$

In the particular case without productivity shock, the law of motion becomes:

$$
\dot{n}=\left(\lambda_{b}+\rho\right) n+\left(f^{\prime}\left(\bar{K}-\sum_{j}^{\mathscr{B}} k_{j}\right)\right) k-d
$$

\section{B.3 Proof of proposition 2.1 in the dynamic setting}

The rule for choosing between the interior vs the corner solution is:

$\max \left[\lambda(\mathbf{k}, \mathbf{n})\left(n-\frac{v\left(n, \mathbf{n}_{-b}\right)-v^{R}}{v_{n}\left(n, \mathbf{n}_{-b}\right)}\right)+R\left(k^{I}, \mathbf{k}_{-b}\right) k^{I}, R\left(k^{C}\left(n, \mathbf{k}_{-b}, \mathbf{n}_{-b}\right), \mathbf{k}_{-b}\right) k^{C}\left(n, \mathbf{k}_{-b}, \mathbf{n}_{-b}\right)\right]$

Definitions of payoffs in equilibrium and deviations I are now ready to check for deviations. Define $P_{i}^{j}\left(k^{C}\right)$ is the profit of playing $j$ (Interior or Corner) if the banks are supposed to play $i$ and the corner solution is $k^{C}$.

$$
\begin{aligned}
& k^{I}=\frac{\bar{K}}{\mathscr{B}+1} \quad k^{C *}=\frac{n}{-\Delta q^{R}} \quad k^{C}=\frac{\mathscr{B} n}{-\Delta q^{R}}-\sum_{j \neq b} k_{j}=\mathscr{B} k^{C *}-\sum_{j \neq b} k_{j} \\
& P_{C}^{C}\left(k^{C *}\right)=\alpha\left(\bar{K}-\mathscr{B} k^{C *}\right) k^{C *} \quad P_{C}^{I}\left(k^{C *}\right)=\alpha\left(\frac{\bar{K}-(\mathscr{B}-1) k^{C *}}{2}\right)^{2} \\
& P_{I}^{I}\left(k^{C *}\right)=\alpha\left(\frac{\bar{K}-(\mathscr{B}-1) k^{I}}{2}\right)^{2} \quad P_{I}^{C}\left(k^{C *}\right)=\alpha\left(\bar{K}-\mathscr{B} k^{C *}\right)\left(\mathscr{B} k^{C *}-(\mathscr{B}-1) k^{I}\right) \\
& F_{I}\left(k^{C *}\right)=P_{I}^{I}\left(k^{C *}\right)-P_{I}^{C}\left(k^{C *}\right) \quad F_{C}\left(k^{C *}\right)=P_{C}^{I}\left(k^{C *}\right)-P_{C}^{C}\left(k^{C *}\right)
\end{aligned}
$$

where the last two lines define the net payoff from deviating from the interior equilibrium and playing the safe one $F_{I}$, and the net payoff from the deviating from the safe equilibrium and playing the risky one $F_{C}$. 


\section{Existence of $n_{1}$}

Lemma 5. 1. The four functions $P_{I}^{I}, P_{C}^{I}, P_{I}^{C}, P_{C}^{C}$ of $k^{C}$ are parabolas

2. For all $k^{C} \backslash\left\{\frac{\bar{K}}{\mathscr{B}+1}\right\}, P_{C}^{C}\left(k^{C}\right)<P_{C}^{I}\left(k^{C}\right)$ and $P_{I}^{C}\left(k^{C}\right)<P_{I}^{I}\left(k^{C}\right)$

3. The functions $F_{I}, F_{C}$ are strictly decreasing for $k^{C *} \in\left[0, k^{I}\right]$ and strictly increasing for $k^{C *}>k^{I}$. They are equal to 0 at $k^{C *}=k^{I}$

4. And at $k^{C}=\frac{\bar{K}}{\mathscr{B}+1}, P_{C}^{C}\left(\frac{\bar{K}}{\mathscr{B}+1}\right)=P_{C}^{I}\left(\frac{\bar{K}}{\mathscr{B}+1}\right)$ and $P_{I}^{C}\left(\frac{\bar{K}}{\mathscr{B}+1}\right)=P_{I}^{I}\left(\frac{\bar{K}}{\mathscr{B}+1}\right)$

5. $\forall k^{C *} \in\left[0, k^{I}\right] F_{I}\left(k^{C *}\right)>F_{C}\left(k^{C *}\right)$ with equality for $k^{C *}=k^{I}$.

Proof. All proofs are immediate except the last one.

$$
\begin{aligned}
F_{C}(x)-F_{I}(x) & =\alpha\left(\bar{K}-\mathscr{B} k^{C *}\right)\left(\mathscr{B} k^{C *}-(\mathscr{B}-1) k^{I}\right)-\alpha\left(\frac{\bar{K}-(\mathscr{B}-1) k^{I}}{2}\right)^{2} \\
& -\alpha\left(\bar{K}-\mathscr{B} k^{C *}\right) k^{C *}+\alpha\left(\frac{\bar{K}-(\mathscr{B}-1) k^{C *}}{2}\right)^{2} \\
& =\alpha\left(\bar{K}-\mathscr{B} k^{C *}\right)(\mathscr{B}-1)\left(k^{C *}-k^{I}\right)+\frac{\alpha}{2}(\mathscr{B}-1)\left(k^{I}-k^{C *}\right)\left(\bar{K}-(\mathscr{B}-1) \frac{k^{I}+k^{C *}}{2}\right) \\
& =\frac{\alpha}{2}(\mathscr{B}-1)\left(k^{C *}-k^{I}\right)\left(2(\mathscr{B}+1) k^{I}-2 \mathscr{B} k^{C *}-\bar{K}+(\mathscr{B}-1) \frac{k^{I}+k^{C *}}{2}\right) \\
& =-\frac{\alpha}{2}(\mathscr{B}-1)\left(k^{C *}-k^{I}\right)^{2}\left(\mathscr{B}+1+\frac{\mathscr{B}-1}{2}\right) \\
& <0
\end{aligned}
$$

I now redefine all functions in terms of net worth. Since I have assumed that $k^{C}(n)$ was a bijection and increasing in $n$ with first derivatives bounded away from 0 , there exists $n^{I}$ such that $k^{C}$ is increasing over $\left[0, n^{I}\right]$ with $k^{C}(0)=0, k^{C}\left(n^{I}\right)=k^{I}$. I can also redefine the function $F_{I}(),. F_{C}($.$) as functions of n$ over the interval $\left[0, n^{I}\right]$.

I now prove the existence and uniqueness of the two cutoff points. Define for $k=I, C, \tilde{P}_{k}^{C}(n)=P_{k}^{C}(n)+F^{*}(n)$. The following is true:

Lemma 6. If $v^{R}=0$ and $F^{*}$ is differentiable with $\left(F^{*}\right)^{\prime}>0$, there exists a unique $\left\{n_{1}^{I}, n_{1}^{C}\right\} \in\left[0, n^{I}\right]$ such that

$$
\tilde{P}_{C}^{C}\left(n_{1}^{C}\right)=P_{C}^{I}\left(n_{1}^{C}\right) \quad \text { and } \quad \tilde{P}_{I}^{C}\left(n_{1}^{I}\right)=P_{I}^{I}\left(n_{1}^{I}\right)
$$


Proof. Furthermore, I also have that $v^{*}(0) \geq 0$ for $n \geq 0$, hence $F^{*}(0) \geq 0$, which combined with $\left(F^{*}\right)^{\prime}>0$ gives $F^{*}(n)>0$ for $n>0$.

Define now $H_{I}(n)=F_{I}(n)-F^{*}(n) \quad H_{C}(n)=F_{C}(n)-F^{*}(n)$

Case 1: $H_{I}(0)>H_{C}(0)>0$ Gathering all the properties I have established and the one I just assumed, I have that

1. $H_{I}(0)>H_{C}(0)>0$

2. $H_{I}\left(n^{I}\right)=H_{C}\left(n^{I}\right)<0$

3. $H_{I}, H_{C}$ are continuous and strictly decreasing for $n \in\left[0, n^{I}\right]$

4. $H_{I}(n)>H_{C}(n)$ for $n \in\left[0, n^{I}\right)$

From the first three properties, there exists a unique pair $\left\{n_{1}^{I}, n_{1}^{C}\right\} \in\left[0, n^{I}\right]$ such that $H_{I}\left(n_{1}^{I}\right)=0=H_{C}\left(n_{1}^{C}\right)$ with $n_{1}^{C}<n_{1}^{I}$ where the latter comes from the third property.

Case 1: $H_{I}(0)>0>H_{C}(0) \quad$ In this case I conventionally set $n_{1}^{C}=0$.

Case 1: $0>H_{I}(0)>H_{C}(0) \quad$ In this case I conventionally set $n_{1}^{C}=n_{1}^{I}=0$.

Proof of the Corollary I only need to establish that $n_{1}>0$. I show that in the equilibrium I are constructing, if $n_{1}=0$ then $v^{*}(0)=0$ and that this is is a contradiction.

For a contradiction assume $n_{1}=0$. Then all banks play safe for $n \geq 0$. For $n=0$, the banks cannot invest at all if it plays the safe strategy and its profit will be zero, forever. Therefore $v^{*}(0)=0$. But $v^{*}(0)$ implies that $H_{C}(0)>0$, and hence that it optimal to deviate from the safe strategy for 0 net worth. This is a contradiction with the assumed Cournot equilibrium at $n=0$. Hence $n_{1}>0$.

\section{B.4 Dividend policy and steady-state: lemma 2 and 3}

When there is no aggregate shock, $\zeta(z)=0$, assuming the solution for dividends is interior - and it will be under the CRRA assumption for the instanteneous utility - 
the F.O.C and envelop theorem in the safe zone is

$$
\begin{aligned}
& u_{d}(d)=v_{n}\left(n, \mathbf{n}_{-b}\right) \Rightarrow-\gamma \frac{\dot{d}}{d}=\frac{v_{n n}\left(n, \mathbf{n}_{-b}\right) \dot{n}+\sum_{j \neq b} v_{n n_{j}}\left(n, \mathbf{n}_{-b}\right) \dot{n}_{j}}{v_{n}\left(n, \mathbf{n}_{-b}\right)} \\
& \rho v_{n}\left(n, \mathbf{n}_{-b}\right)= v_{n n}\left(n, \mathbf{n}_{-b}\right) \dot{n}+\sum_{j \neq b} v_{n n_{j}}\left(n, \mathbf{n}_{-b}\right) \dot{n}_{j} \\
& \quad+v_{n}\left(n, \mathbf{n}_{-b}\right)\left(\rho+k_{n}^{C}\left(n, \mathbf{n}_{-b}\right) \alpha\left(\bar{K}-(\mathscr{B}+1) k^{C}\left(\left(n, \mathbf{n}_{-b}\right)\right)\right)\right) \\
& \Rightarrow 0=\frac{v_{n n}\left(n, \mathbf{n}_{-b}\right) \dot{n}+\sum_{j \neq b} v_{n n_{j}}\left(n, \mathbf{n}_{-b}\right) \dot{n}_{j}}{v_{n}\left(n, \mathbf{n}_{-b}\right)}+k_{n}^{C}\left(n, \mathbf{n}_{-b}\right) \alpha\left(\bar{K}-(\mathscr{B}+1) k^{C}\left(n, \mathbf{n}_{-b}\right)\right)
\end{aligned}
$$

where the second line uses the CRRA assumption for utility and the third line uses the Cournot assumption that a banker takes $\dot{n}_{-b}$ as given. Combining both gives

$$
\gamma \frac{\dot{d}}{d}=k_{n}^{C}\left(n, \mathbf{n}_{-b}\right) \alpha\left(\bar{K}-(\mathscr{B}+1) k^{C}\left(n, \mathbf{n}_{-b}\right)\right)
$$

When the capital investment is interior, the solution is different because the marginal effect of net worth on capital is null:

$$
\gamma \frac{\dot{d}}{d}=k_{n}^{C}\left(n, \mathbf{n}_{-b}\right) \alpha(\bar{K}-(\mathscr{B}+1) k)=0
$$

Moreover by continuity of the dividend policy rule, it has to be that $d(n)=d\left(n_{1}\right)$ for $n_{-1}<n<n_{1}$ where $n_{-1}=\frac{d\left(n_{1}\right)-R\left(\mathbf{k}^{I}\right) k^{I}}{\rho+\bar{\lambda}}$

is the level of net worth below which distributing the level of dividends $d\left(n_{1}\right)$ is no longer sustainable without making net worth decrease over time. Consequently, below $n_{-1}$ - and this applies only if $n_{-1}>0$-, the only way to keep dividends constant is to set it such that net worth is constant over time: $d(n)=(\rho+\bar{\lambda}) n+R^{I} k^{I}$

If dividends are set higher, then net worth will decrease and reach 0 in finite time. If dividends are set lower, net worth will increase and reach $n_{-1}$ in finite time at which point dividends would have to discontinuously jump to $d\left(n_{1}\right)$ which contradicts the continuity of the dividends path and the concavity of the utility function.

Steady-state. Setting equation 24 to $0, \dot{d}=0$ give the steady-state level of capital: $k^{S S}=\frac{\bar{K}}{\mathscr{B}+1}$. Using the asset price equation 17 with $\dot{q}=0$ solves for the steady-state asset price as a function of $k^{S S}$. Since the steady-state capital investment is also safe, it has to be that $n^{S S}=\left(q^{S S}-q^{R}\right) k^{S S}$ and finally one finds $d^{S S}$ by equating $\dot{n}=0$. 


\section{B.5 Proof of proposition 3.2}

Suppose for a contradiction that with immediate entry, an equilibrium of the type described in proposition 3.1 with $0 \leq n_{1}<+\infty$ exists. Then $\forall n \in\left[0, n_{1}\right), \lambda(n)=\bar{\lambda}$ and $k^{*}(n)=k^{I}$

By the assumption that $\eta \rightarrow+\infty$, I have that the run price is the price when the system is at 0 net worth and $\mathscr{B}$ banks are operating, i.e. $q^{R}=q(0)$.

For $n=0$, I have $q(n)=q(0)$, hence $q(n)=q^{R}$ and $\frac{n}{q(n)-q^{R}}$ is infinitely large and therefore larger than $k^{I}, \lim _{n \rightarrow 0^{+}} \frac{n}{q(n)-q^{R}}=+\infty$ therefore greater than $k^{I}$

Hence the corner investment $\frac{n}{q(n)-q^{R}}$ is larger than the interior solution $k^{I}$ at 0 . And by continuity it is larger in a neighborhood of zero. Hence the interior investment doesn't imply a risk of runs and $\lambda(n)=0$ for $n$ in a neighborhood of 0 . This contradicts the properties of the assumed equilibrium.

Let's now check that when $\eta \rightarrow+\infty, \forall n \geq 0$

$$
\lambda(n)=0 \quad k^{*}(n)=k^{I} \quad d(n)=\rho n+\alpha\left(k^{I}\right)^{2} \quad q(n)=\frac{z-\alpha k^{I}}{\rho}
$$

is an equilibrium.

First, I have that $q(n)-q^{R}=q(n)-q(0)=0$ hence that $\frac{n}{q(n)-q^{R}}$ is infinitely large and therefore that $k^{I}$ is always safe. Hence, the optimal capital investment of banks is always $k^{I}$. This implies $\lambda(n)=0$. From the optimal conditions for dividends, I have that $\dot{d}=0$, i.e. that $d(n)=\rho n+\alpha\left(k^{I}\right)^{2}$. Finally, given the optimal investment of banks $k^{*}(n)=k^{I}$ and $\lambda(n)=0$, the P.D.E. for asset prices is $\dot{q}=\alpha k^{I}-z+\rho q$ with final condition $q(n)=q^{S} S$. This has only one stable solution, which is $q(n)=\frac{z-\alpha k^{I}}{\rho}=q^{S S}$ for all $n \geq 0$. The proof for the individual bank run case is exactly the same.

\section{B.6 Proof of lemma 4}

Global analysis For the first part of lemma 4, I provide a graphical proof. First I derive a simplified version of the system of differential equations 22 in terms of $(d, k, \tilde{q})$ 
where $\tilde{q}=q-q^{R}$. From $k=\frac{n}{q-q^{R}}=\frac{n}{\tilde{q}}$, one gets

$$
\begin{aligned}
\dot{k} & =\frac{1}{\tilde{q}}(\dot{n}-k \dot{\tilde{q}})=\frac{1}{\tilde{q}}\left(\rho n+\alpha(\bar{K}-\mathscr{B} k) k-d-k\left[\rho \tilde{q}+\rho q^{R}-z+\alpha(\bar{K}-\mathscr{B} k)\right]\right) \\
& =\frac{1}{\tilde{q}}\left(k\left(z-\rho q^{R}\right)-d\right) \\
& =\frac{1}{\tilde{q}}(k \alpha \bar{K}-d) \quad \text { if } \eta=0
\end{aligned}
$$

Then I use the following system

$\dot{k}=\frac{1}{\tilde{q}}\left(k\left(z-\rho q^{R}\right)-d\right) \quad \dot{q}=\rho \tilde{q}+\rho q^{R}-z+\alpha(\bar{K}-\mathscr{B} k) \quad \gamma \frac{\dot{d}}{d}=k_{1} \alpha(\bar{K}-(\mathscr{B}+1) k)$

to draw the associated phase diagram 9 in the $(d, k, \tilde{q})$ plane. The $\dot{k}=0$ locus is strictly increasing because $\tilde{q}^{R}<\frac{z}{\rho}$. To gain intuition I first focus on the representation in the $(d, k)$-plane in figure 8 , fixing $\tilde{q}$ for the time being.

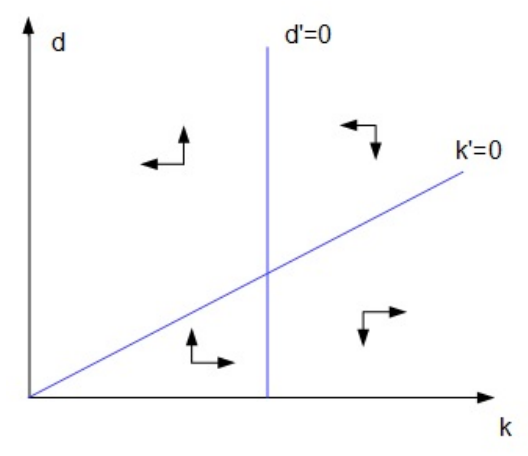

Figure 8: Phase diagram in the $(k, d)$ dimension

The steady-state, the $\dot{k}=\dot{d}=0$ loci and, importantly, the direction of the arrows are independent of $\tilde{q}$. The steady-state is the point at which the two lines cross. Under the assumption that $k_{1}>0$, the saddle path - if it exists - has to feature $d$ and $k$ moving in the same direction - either both increasing or both decreasing, depending on where the system starts. Since I will consider cases in which net worth starts below its steady-state value, $k$ is necessarily lower than its steady-state value, it has to be that both are increasing over time. Since $k$ is increasing over time until $k^{S S}$, profits are increasing over this range of $k$ and $d$ is increasing over time, $\dot{n}$ has to be increasing too. This confirms that in equilibrium $k_{1}>0$. Also note that if $k_{1}<0$ then all arrows in the $d$-dimension are reversed and no saddle path could exist. 
I now draw the full phase diagram in three dimensions in figure 9 . The $x$-axis corresponds to capital while the $y$-axis corresponds to dividends. The third dimension, the $z$-axis is for $\tilde{q}$. The $\dot{q}=0$ locus is a fully vertical plane - i.e. orthogonal to the d-dimension -, from the back-left of the cube to the front right. The $\dot{d}=0$ plane is coming from the vertical line in the back plane towards us, orthogonal to both the $q$ and the $d$-dimension. Finally the $\dot{k}=0$ plane is the ramp starting on the $q$-axis and increasing from the bottom left to the top right. Their intersection - the red point is the steady-state of the system. I have drawn the same arrows as in the previous graph and added arrows in the $(q, k)$-plane to indicate the direction for $q$.

From the first part of the proof, if a saddle-path exists, it must be to the left of the $\dot{d}=0$ plane and below the $\dot{k}=0$ plane. Furthermore, the saddle-path must lie in the zone where all arrows, including those in the $\tilde{q}$ dimension, point towards the steadystate. I have delimited and colored this zone: the figure with the hatched triangular basis, the blue triangular faces, the purple triangular back and the transparent roof has to contain the saddle-path.

Finally the green line lying in the $(k, \tilde{q})$ plane, is the line on which the system should start, as commanded by the initial condition, $k\left(t_{0}\right) \tilde{q}\left(t_{0}\right)=n_{1}$. This shows that $\tilde{q}$ has to be increasing over time along the equilibrium path.

Figure 9: Phase Diagram

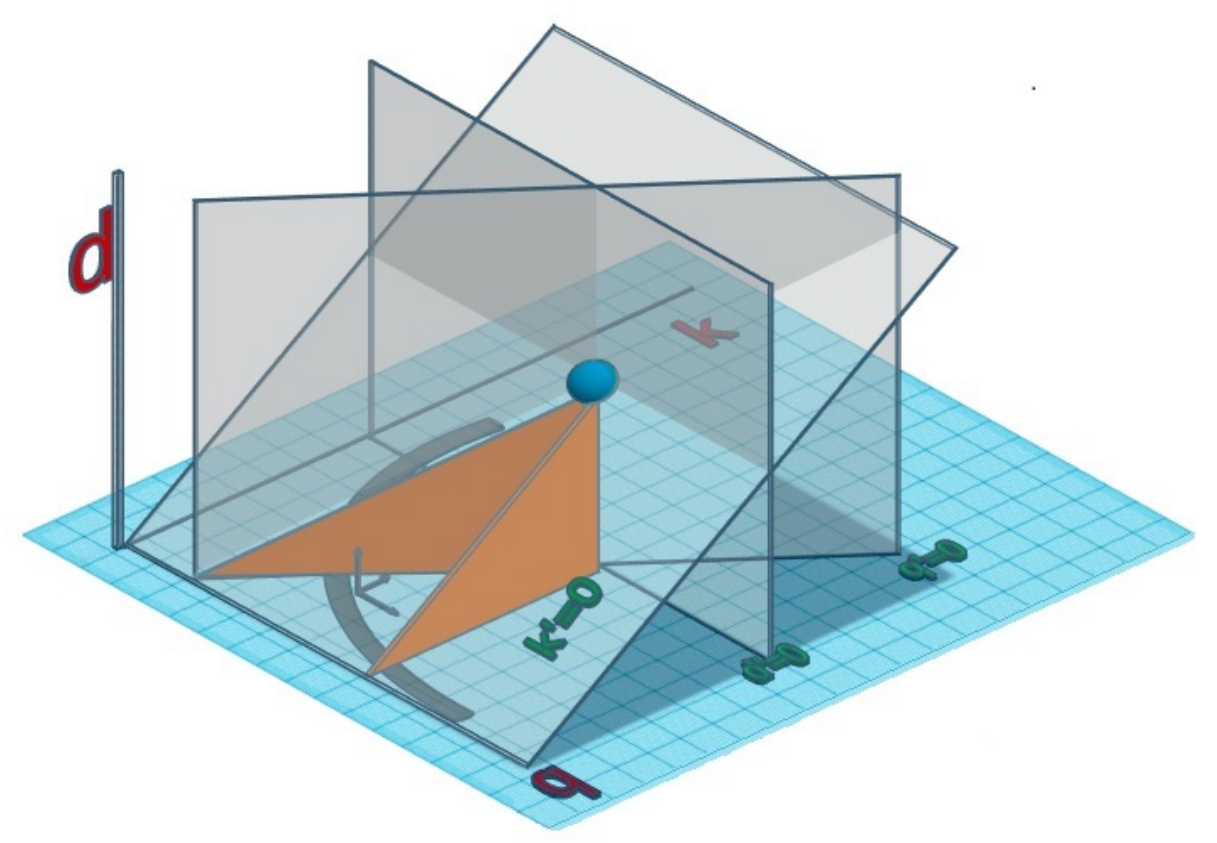


Local determinacy I now prove that the linear approximation of the system 22 around the point $\left(d^{S S}, n^{S S}, q^{S S}\right)$ admits one and only one solution satisfying the initial and terminal conditions. I linearize the following system

$$
\dot{n}=\rho n+\alpha(\bar{K}-\mathscr{B} k) k-d \quad \dot{q}=\rho \tilde{q}+\rho q^{R}-z+\alpha(\bar{K}-\mathscr{B} k) \quad \gamma \frac{\dot{d}}{d}=k_{1} \alpha(\bar{K}-(\mathscr{B}+1) k)
$$

around the steady-state. In matrix form, the system is

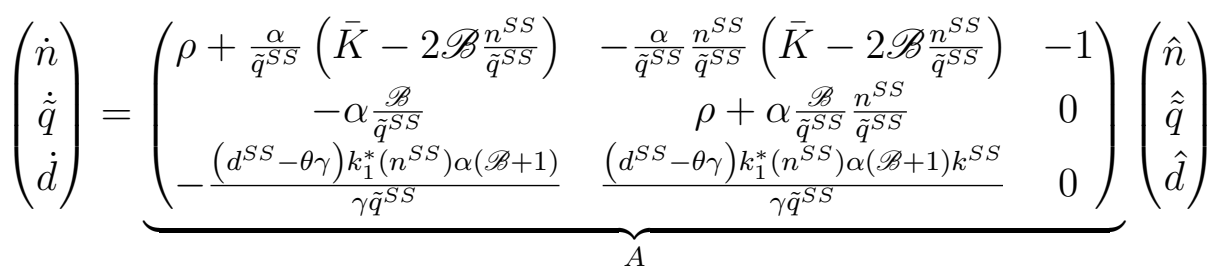

where "^" stands for deviation from their steady-state values $\left(d^{S S}, n^{S S}, q^{S S}\right)$. Notice that in steady-state $q_{1}^{*}\left(n^{S S}\right)>0$ as I have proved ealier. Although not needed for the proof, I provide an explicit expression for it below. Denote the three eigenvalues of $A$, $l_{1}, l_{2}, l_{3}$. From the properties of eigenvalues,

$$
\begin{aligned}
\operatorname{Tr} A & =2 \rho+\frac{\alpha}{\tilde{q}^{S S}}\left(\bar{K}-\mathscr{B} k^{S S}\right)=l_{1}+l_{2}+l_{3} \\
\operatorname{det} A & =-\rho \frac{\left(d^{S S}-\theta \gamma\right) k_{1}^{*}\left(n^{S S}\right)(\mathscr{B}+1) \alpha}{\gamma \tilde{q}^{S S}}=l_{1} \times l_{2} \times l_{3}
\end{aligned}
$$

Hence one gets the following restrictions on the signs of eigenvalues: $l_{1}+l_{2}+l_{3}>0$ and $l_{1} \times l_{2} \times l_{3}<0$. The last inequality implies that either 1 or 3 eigenvalues are negative. The first inequality implies that at least one eigenvalue is strictly positive. This establishes that 1 eigenvalue is negative and 2 are positive. Since my system has two jump variables with a terminal condition and one initial condition for $n$, this implies that the system admits one and only one saddle path solution.

Speed of convergence To compute the speed of convergence of capital around the steady-state, I use the same linearized model but in the $(k, d)$ space.

$$
\dot{k}=\frac{1}{\tilde{q}^{S S}}\left(\hat{k}\left(z-\rho q^{R}\right)-\hat{d}\right) \quad \dot{d}=\frac{k_{1}^{S S} d^{S S} \alpha}{\gamma}(\bar{K}-(\mathscr{B}+1) \hat{k})
$$


In matrix form it is

$$
\left(\begin{array}{l}
\dot{k} \\
\dot{d}
\end{array}\right)=\underbrace{\left(\begin{array}{cc}
\frac{z-\rho q^{R}}{\tilde{q}^{S S}} & -\frac{1}{\tilde{q}^{S S}} \\
\frac{-\left(d^{S S}-\theta \gamma\right) k_{1}^{S S} \alpha}{\gamma}(\mathscr{B}+1) & 0
\end{array}\right)}_{A}\left(\begin{array}{c}
\hat{k} \\
\hat{d}
\end{array}\right)
$$

It is easy to check that the system admits one negative and one positive eigenvalue:

$\operatorname{Tr} A=\frac{z-\rho q^{R}}{\tilde{q}^{S S}}=\ell_{1}+\ell_{2}>0 \quad \operatorname{det} A=\frac{-\left(d^{S S}-\theta \gamma\right) k_{1}^{S S} \alpha}{\gamma \tilde{q}^{S S}}(\mathscr{B}+1)=\ell_{1} \ell_{2}<0$

Denoting $\ell_{-}$the negative root - the only that matters for the convergence rate one has:

$$
\ell_{-}=\frac{z-\rho q^{R}-\sqrt{\left(z-\rho q^{R}\right)^{2}+\frac{4}{\gamma}\left(1-k^{S S} q_{1}^{S S}\right)\left(d^{S S}-\theta \gamma\right)(\mathscr{B}+1) \alpha}}{2\left(q^{S S}-q^{R}\right)}
$$

Expression for $k_{1}^{*}\left(n^{S S}\right)$ In this paragraph, I show how to find the solution for $k_{1}^{*}\left(n^{S S}\right)$. It is not directly needed to establish the previous results, but it shows how one should use the equilibrium conditions to derive the derivatives of asset prices with respect to a bank's own net worth.

From the expression $k_{1}^{*}(n)=\frac{1-k^{C *}(n) q_{1}^{*}(n)}{q(n)-q^{R}}$ I see that the challenge is indeed to compute $q_{1}^{*}\left(n^{S S}\right)$. I start by using the equilibrium condition for the dynamics of asset prices

$$
\begin{aligned}
\dot{q}(\mathbf{n}) & =\rho q(\mathbf{n})-z+\alpha\left(\bar{K}-\mathscr{B} k^{C}(\mathbf{n})\right) \\
\Rightarrow \mathscr{B} q_{1}(n) \dot{n} & =\rho q(n)-z+\alpha\left(\bar{K}-\mathscr{B} k^{C}(n)\right) \Rightarrow q_{1}(n)=\frac{\dot{q}(n)}{\mathscr{B} \dot{n}(n)}
\end{aligned}
$$

where the second line takes the total derivative of $\dot{q}$ with respect to the net worth of every bank and then uses the property of symmetry along the equilibrium path. The next step consists in using L'Hospital rule to find an expression for this ratio who takes an indeterminate form in the limit where $n \rightarrow n^{S S}$ :

$$
\lim _{n \rightarrow n^{S S}} q_{1}(n)=\lim _{n \rightarrow n^{S S}} \frac{\dot{q}(n)}{\mathscr{B} \dot{n}(n)}=\lim _{n \rightarrow n^{S S}} \frac{\rho \mathscr{B} q_{1}(n)-\alpha \mathscr{B} \frac{1-k^{C *}(n) \mathscr{B} q_{1}^{*}(n)}{q(n)-q^{R}}}{\mathscr{B}\left(\rho+\frac{1-k^{C *}(n) \mathscr{B} q_{1}^{*}(n)}{q(n)-q^{R}} \alpha\left(\bar{K}-2 \mathscr{B} k^{C *}(n)\right)-d_{n}(n)\right)}
$$


The expression for the limit will depend on $d_{n}\left(n^{S S}\right)$ the derivative of dividends with respect to net worth in equilibrium. In a similar fashion, one can use:

$$
\lim _{n \rightarrow n^{S S}} d_{n}(n)=\lim _{n \rightarrow n^{S S}} \frac{\dot{d}(n)}{\dot{n}(n)}=\frac{d^{S S} \frac{1-k^{C *}(n) q_{1}(n)}{q(n)-q^{R}}\left(-(\mathscr{B}+1) \frac{1-k^{C *}(n) q_{1}(n)}{q(n)-q^{R}}\right)}{\rho+\frac{1-k^{C *}(n) \mathscr{B} q_{1}^{*}(n)}{q(n)-q^{R}} \alpha\left(\bar{K}-2 \mathscr{B} k^{C *}(n)\right)-d_{n}(n)}
$$

These two equations have two unknowns $d_{n}\left(n^{S S}\right), q_{1}\left(n^{s s}\right)$ that can be solved for numerically. In general, there is no closed-form solution. In the monopoly case $\mathscr{B}=1$, one can simplify a little bit the expression. From the first and second equation, one gets:

$$
q_{1}\left(n^{S S}\right)=\frac{1}{k^{I}} \frac{\rho}{\rho+d_{n}} \quad d_{n}\left(n^{S S}\right)\left(\rho-d_{n}\left(n^{S S}\right)=-2 d^{S S}\left(\frac{1-k^{I} q_{1}\left(n^{S S}\right)}{q\left(n^{S S}\right)-q^{R}}\right)^{2}\right.
$$

Using the first one to substitute for $k^{I} q_{1}$ in the second, gives

$$
\begin{aligned}
d_{n}\left(\rho-d_{n}\right) & =-2 d^{S S}\left(\frac{d_{n}}{\left(q\left(n^{S S}\right)-q^{R}\right)\left(\rho+d_{n}\right)}\right)^{2} \\
\frac{\left(\rho-d_{n}\right)\left(\rho+d_{n}\right)^{2}}{d_{n}} & =-2 d^{S S}\left(\frac{1}{q\left(n^{S S}\right)-q^{R}}\right)^{2}
\end{aligned}
$$

This polynomial of degree 3 in $d_{n}$ has exactly one solution with $d_{n}>\rho$

Existence and uniqueness of solution to non-linear system It turns out to be rather difficult to prove existence and even more difficult to show uniqueness of a solution to the non linear system 22. Using the Cauchy-Peano theorem for existence and Picard-Lindelöf for uniqueness could give us restrictions such that a local solution around the steady-state exists and is unique. However, my problem is slightly different because I have both an initial condition for $n$ and a terminal conditions for the other variables.

\section{B.7 Proof of proposition 3.1}

I start the proof with the middle zone $n_{-1}<n_{0}<n_{1}$.

1. At $n_{-1}<n_{0}<n_{1}$, I know it is optimal to invest at the optimal interior $k=k^{I}$ 
from corollary 1. I need to establish that the bank has strictly positive saving in the run zone.

I have established in lemma 4 that capital, prices, net worth and dividends were growing in the safe zone. So this means that the limit of dividends from the right of $n_{1}$ is low enough so that the bank is saving. Moreover at $n_{1}$, it has to be the case that the limit of profits from the right is stricter smaller that the limit of profits from the left (there is a discontinuity). Since dividends are continuous at $n_{1}$, it has to be that the bank that net worth is accumulating on the left limit of $n_{1}$. This establishes only that the property holds locally. It might still be that $n_{-1}$ is strictly positive, i.e. $n_{-1} \in\left(0, n_{1}\right)$ where I have defined $n_{-1}$ such that $\rho n_{-1}+R^{I} k^{I}=d\left(n_{1}\right)$. I treat this case in the following bullet point.

2. If $n_{-1} \in\left(0, n_{1}\right)$, and $n \in\left[0, n_{-1}\right)$ then by lemma 3 , I know that dividends should be constant and set such that net worth is constant. Hence, the system is in steady-state and banks wait for a certain death. Given that saving are strictly positive and not going to zero as the bank approaches $n_{1}$, the bank reaches $n_{1}$ in finite time.

3. This is an implication of lemma 4 .

\section{Immediate}

I now need to check that the assumptions in 1 hold in the equilibrium I have characterized. The function $k^{C}(n)$ is positive, continuous, strictly increasing as shown in lemma 4 with a derivative with respect to $n$ bounded away from 0 . I need to check that $q-q^{R}$ is always well-defined for $n>0$, and strictly positive. $q^{R}$ is given by $q^{R}=\frac{\eta}{\rho+\eta} q(0)+\frac{z-\alpha \bar{K}}{\rho+\eta}$. I know that in the safe zone, $q-q^{R}>0$. I need to establish the same property in the run zone. Either $q$ is increasing or decreasing in the run zone. If it is increasing, since

$$
q(n)-q^{R} \geq q(0)-q^{R}=\frac{\rho}{\rho+\eta} q(0)-\frac{z-\alpha \bar{K}}{\rho+\eta}=\rho \frac{q(0)-\frac{(z-\alpha \bar{K})}{\rho}}{\rho+\eta}>0
$$

where the second line comes from the definition of $q(0)$ and the last line comes from the fact that $\frac{(z-\alpha \bar{K})}{\rho}$ is the smallest price possible, when no banks never operate. If prices are decreasing in the run zone, then for $n \in\left[0, n_{1}\right], q(n)-q^{R} \geq q\left(n_{1}\right)-q^{R}>0$, where the second line stems from the property established in lemma 4 as well as the continuity of prices at $n_{1}$. Hence $-\Delta q^{R}$ is well defined and strictly positive. 
I finally establish that the assumptions regarding $F^{*}$ and the value function in lemma 1 hold. I admit that the value is twice differentiable.

$$
\begin{aligned}
\left(F^{*}\right)^{\prime} & =\frac{v_{1}^{*}(n) \sum_{b} v_{n_{b}}^{*}(\mathbf{n})-\left(v^{*}(n)-v^{R}\right) \sum_{b} v_{1, n_{b}}^{*}(n)}{\left(v_{1}^{*}(n)\right)^{2}}-1 \\
\left(F^{*}\right)^{\prime} & =\frac{v_{1}^{*}(n) \sum_{j \neq b} v_{n_{b}}^{*}(\mathbf{n})-\left(v^{*}(n)-v^{R}\right) \sum_{b} v_{1, n_{b}}^{*}(n)}{\left(v_{1}^{*}(n)\right)^{2}}
\end{aligned}
$$

From the point of view of a bank, the net worth of another bank increases the value because it allows to increase the pool of equity the system can rely on. And the returns of this equity are diminishing at the margin. Hence $v_{n_{b}}^{*}(\mathbf{n})>0$ and $v_{1, n_{b}}^{*}(n)<0$ for all $b$. This proves that $\left(F^{*}\right)^{\prime}>0$.

\section{Additional Figures}

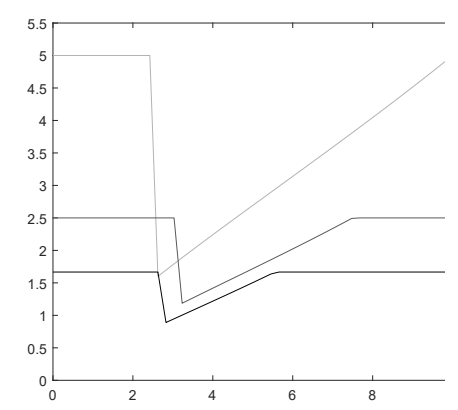

(a) Ind Bank Investment

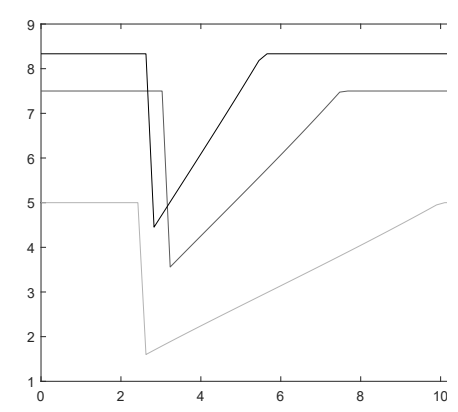

(b) All Bank Investment

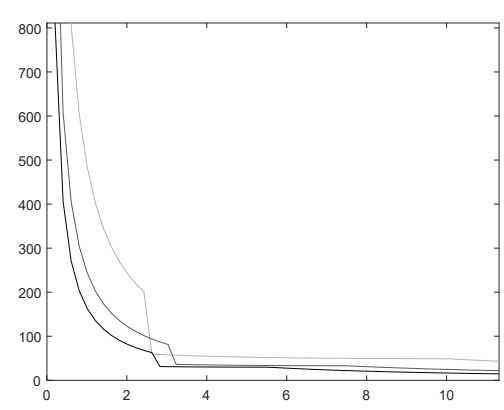

(c) Leverage

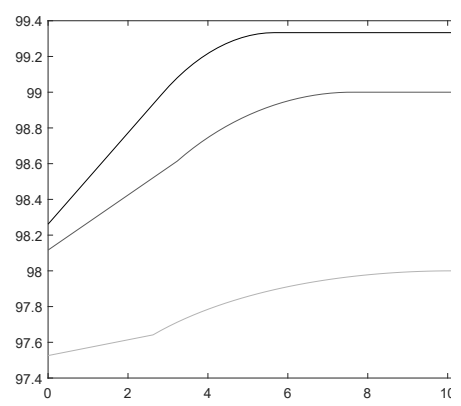

(d) Asset Price

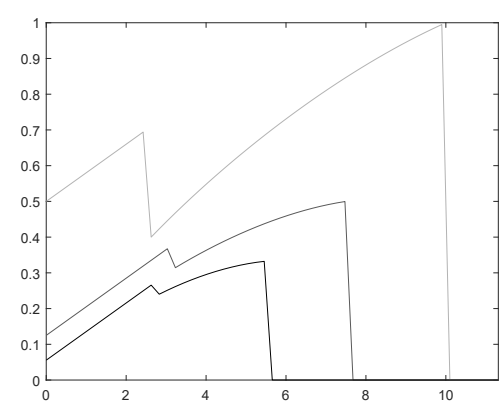

(e) Saving

Figure 10: Policy rules and asset price as a function of net worth in benchmark model for $\mathscr{B}=1,3,5$ 


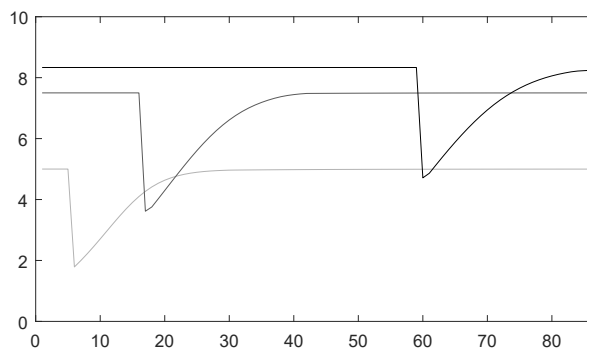

(a) All Bank Investment

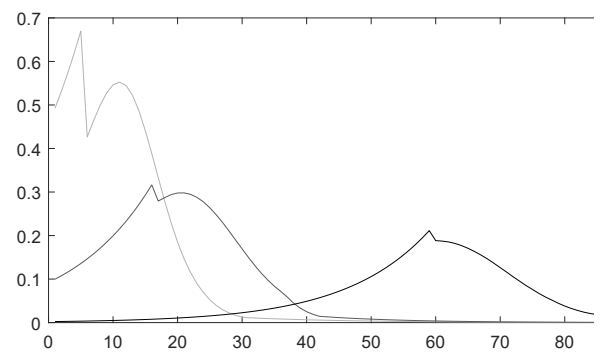

(c) Saving

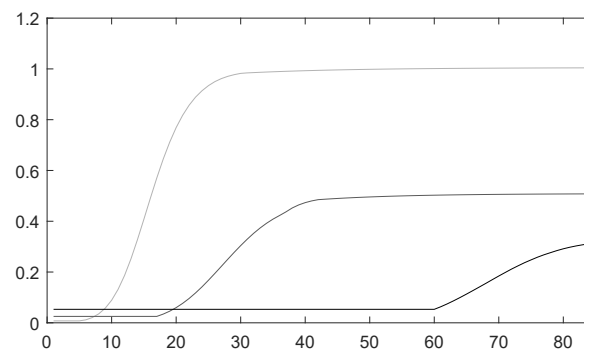

(e) Dividends

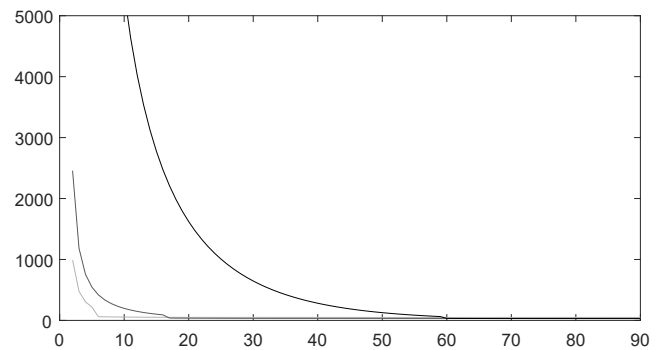

(b) Leverage

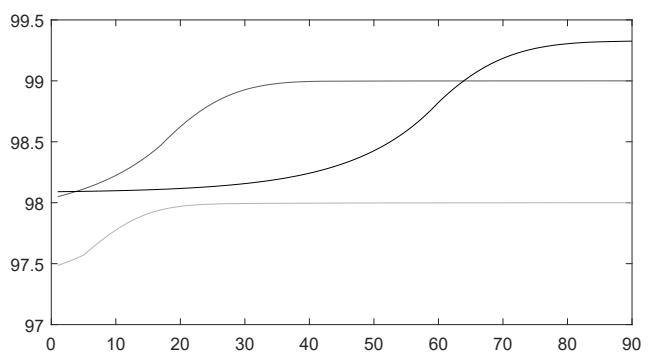

(d) Asset Price

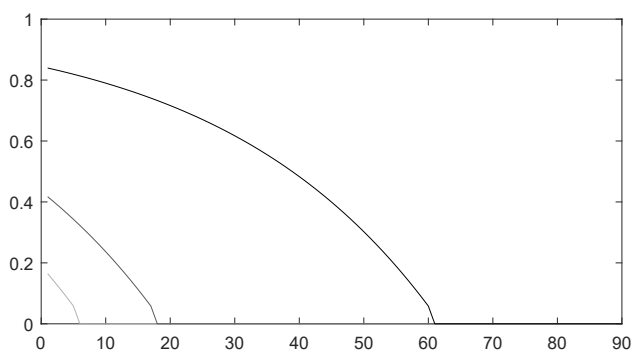

(f) CumProbRun

Figure 11: Transition path as a function of time for $\mathscr{B}=1,3,5$ 


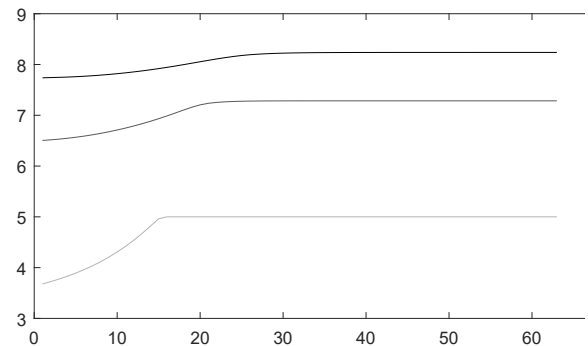

(a) All Bank Investment

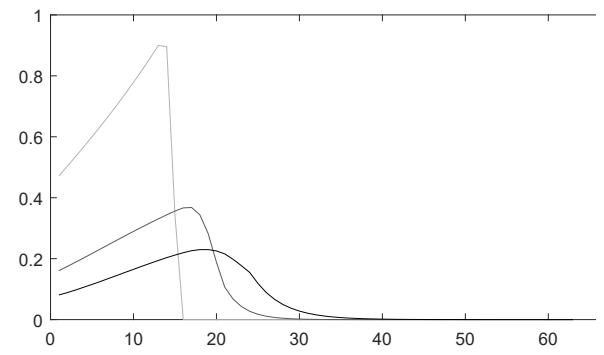

(c) Saving

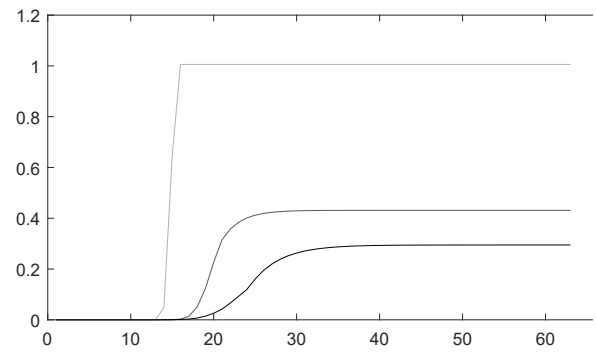

(e) Dividends

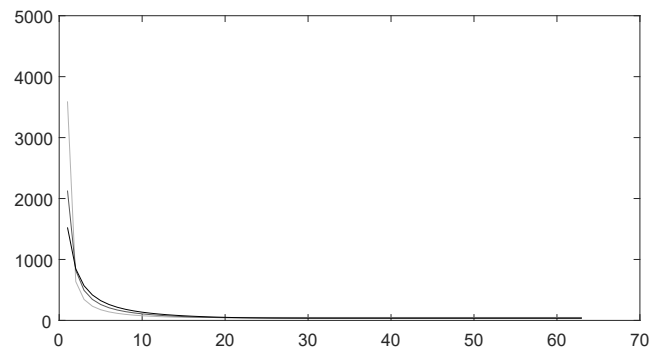

(b) Leverage

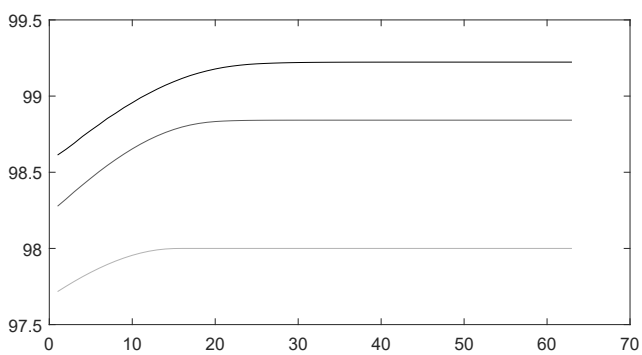

(d) Asset Price

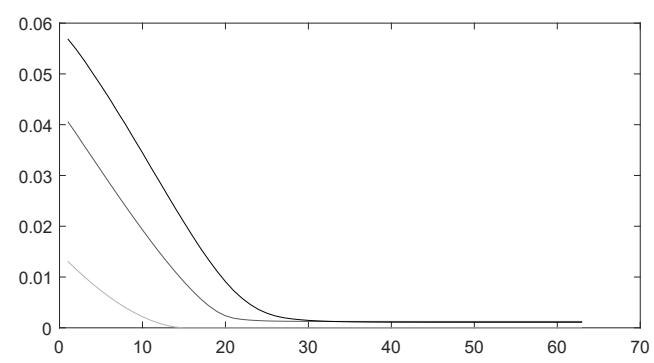

(f) $\lambda$

Figure 12: Transition path as a function of time for $\mathscr{B}=1,3,5$ 


\section{A Dual System of Regulated and Shadow Banks}

In modern financial systems, most intermediaries benefit from public deposit insurance schemes and access to the Central Bank discount window, which - if not totally at least to a large extent-protect them from the risk of a run. In exchange from this public insurance, they have to abide by capital and liquidity requirements that impose constraints on the composition of their balance-sheets.

In the past three decades, the landscape of the shadow and traditional banking sector has experienced significant changes in terms of concentration and regulation. Firstly since the Great Recession, three of the big five investment banks have disappeared: two large investment banks have been absorbed by former competitors-Bear Stern by JP Morgan Chase and Merril Lynch by Bank of America - and Lehman Brothers has been liquidated. Secondly, many of the remaining investment banks converted to traditional bank holding companies in order to benefit from TARP and are now therefore subject to stricter rules and supervision. Furthermore, the last three decades have seen a significant movement of concentration in the traditional banking industry as well as a toughening of capital requirements since the Great Recession.

In this section, I ask three questions. In a world in which only the shadow banking sector is subject to systemic runs, how does the interactions with the traditional banking sector modify the previously established results? What are the implications of stronger regulations and higher level of concentration in the traditional banking sector for the overall stability of the financial system?

A Model with Regulated and Unregulated Banks I set up a generalized version of the model in section 3 that includes both an unregulated shadow banking system subject to systemic runs and a regulated traditional banking system that is subject to a leverage ratio rule and benefits from the public deposit insurance scheme or access to the discount window of a lender of last resort. Figure 13 summarizes the different actors and financial relationships across parts of the financial system with shadow and regulated banks.

There is a finite number $\mathscr{R}$ (resp. $\mathscr{S}$ ) of regulated (resp. unregulated) banks. The total number of institutions is $\mathscr{S}+\mathscr{R}=\mathscr{B}$. Both types of banks invest in the same asset. 


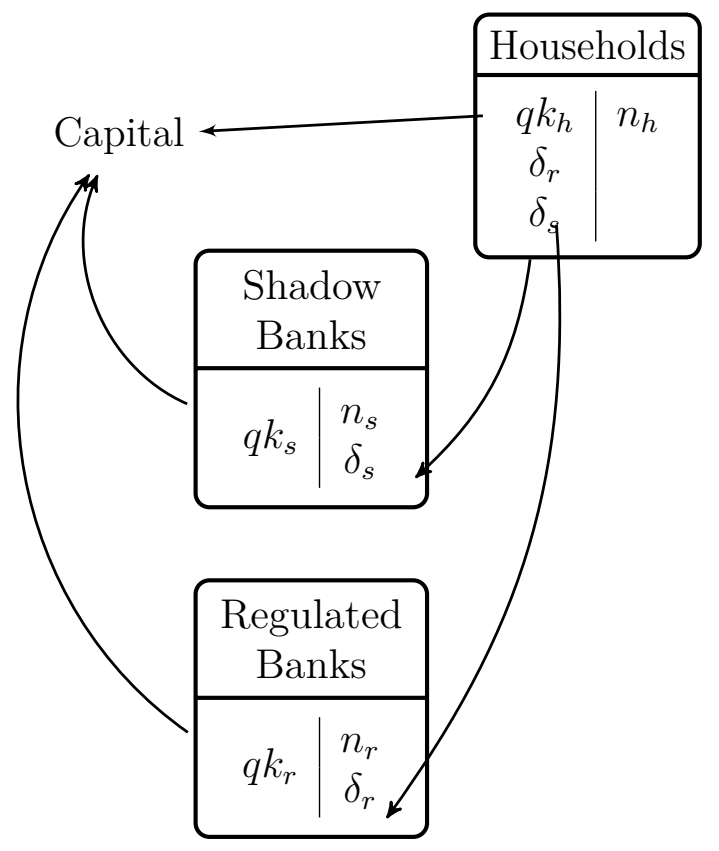

Figure 13: Schema of Financial System

Regulated Banks. Regulated banks choose their capital investment, their stream of dividends and net worth a) subject to a capital requirement constraint 25 and b) benefiting from deposit insurance either in the form of a federal deposit insurance scheme or because the depository institution has access to the discount window of the Lender of Last Resort.

$$
\begin{aligned}
k_{r} & =\kappa n_{r} \\
\lambda_{r} & =1
\end{aligned}
$$

for all $r=1 \ldots \mathscr{R}$. I do not specify the capital requirement rule 25 in terms of market value of asset, but instead adopt a specification more consistent with the Bales III rules in terms of the book value of the banks' asset. ${ }^{16}$ Throughout this paper I will assume that $\kappa<\frac{1}{-\Delta q^{R}}$ so that if a run occurs, the net worth of regulated banks always remains positive. The relevant aggregate state variables of the economy are the vectors of net worth of regulated and unregulated banks, productivity and the number of each type of financial intermediaries. Because in equilibrium, $\mathscr{R}$ will remain fixed over time,

\footnotetext{
${ }^{16}$ Basel Committee on Banking Supervision, "Basel III leverage ratio framework and disclosure requirements"
} 
I omit it when no confusion results. The problem of a regulated bank is:

Taking $\mathbf{k}_{-r}, \mathbf{k}_{s}, \dot{\mathbf{n}}_{-r}, \dot{\mathbf{n}}_{s}$ as given, a regulated bank $r$ HJB equation is:

$$
\begin{aligned}
\rho v\left(n, \mathbf{n}_{-r}, \mathbf{n}_{s}, \mathscr{S}\right) & =\max _{d, k} u(d)+v_{n}((\dot{q}+z) k-r \delta-d)+\sum_{j \neq r}^{\mathscr{R}} v_{n_{j}} \dot{n}_{j}+\sum_{s}^{\mathscr{S}} v_{n_{s}} \dot{n}_{s} \\
& \left.+\lambda\left(v\left(n+\Delta q^{R} k, \mathbf{n}_{-r}+\Delta q^{R} \mathbf{k}_{-r}, 0,0\right)\right)-v\left(n, \mathbf{n}_{-r}, \mathbf{n}_{s}, \mathscr{S}\right)\right)
\end{aligned}
$$

s.t. $\quad k_{r}=\kappa n_{r}$

Shadow banks. Shadow banks solve the same problem as before but now taking also the investment of regulated banks as given. Taking $\mathbf{k}_{-s}, \mathbf{k}_{r}, \dot{\mathbf{n}}_{-s}, \dot{\mathbf{n}}_{r}$ as given, a shadow bank $s$ HJB equation is:

$$
\begin{aligned}
\rho v\left(n, \mathbf{n}_{-s}, \mathbf{n}_{r}, \mathscr{S}\right) & =\max _{d, k} u(d)+v_{n}((\dot{q}+z) k-r \delta-d) \\
& +\sum_{j \neq s}^{\mathscr{S}} v_{n_{j}} \dot{n}_{j}+\sum_{r}^{\mathscr{R}} v_{n_{r}} \dot{n}_{r}+\lambda\left(v^{R}-v\left(n, \mathbf{n}_{-b}, \mathbf{n}_{r}, \mathscr{S}\right)\right)
\end{aligned}
$$

Market clearing. The goods, deposits and capital markets must clear. By Walras law, it is sufficient that the deposit and capital markets clear. The market clearing condition for deposits is the same as previously. The market clearing for capital is:

$$
\sum_{s=1}^{\mathscr{S}} k_{s}+\sum_{r=1}^{\mathscr{R}} k_{r}+\int k_{h} d h=\bar{K}
$$

Entry and run price. Given the results I have established earlier, I will focus here on the case with no entry - corresponding to $\eta=0$ - where after a run on the shadow banking system, the system stays forever after only populated by regulated banks.

$$
\begin{aligned}
& \mathscr{S}^{\prime}=0 \\
& \mathscr{R}^{\prime}=\mathscr{R}
\end{aligned}
$$

Finally, the run price should be consistent with the post-run macroeconomic condition:

$$
q^{R}\left(\mathbf{n}_{s}, \mathbf{n}_{r}, \mathscr{S}\right)=q\left(0, \mathbf{n}_{r}+\Delta q^{R} \mathbf{k}\left(\mathbf{n}_{r}\right), 0\right)
$$

where $q\left(0, \mathbf{n}_{r}+\Delta q^{R} \mathbf{k}\left(\mathbf{n}_{r}\right), 0\right)$ denotes the price of the asset when no shadow banks is operating, all the capital stock is held by regulated banks and households and when 
no shadow banks may enter consistently with 28 .

Symmetric Equilibrium and Transition Dynamics I assume symmetry among regulated banks on the one hand and among shadow banks on the other, but allow for asymmetry between the two groups.

Run game. During the second stage of an instant, depositors might run. The condition for a run on the shadow banking sector is

$$
N_{\mathscr{S}}+\Delta q^{R} K_{\mathscr{S}}<0
$$

where $N_{\mathscr{S}}=\mathscr{S} n_{s}$ and $K_{\mathscr{S}}=\mathscr{S} k_{s}$. The condition is independent of the regulated banks' net worth and capital investment because regulated banks' deposits are insured and they cannot transfer liquidity to the shadow banking system in times of run because their leverage constraint is already binding. No pooling of liquidity is possible between the two parts of the financial system. ${ }^{17}$

Behavior of regulated and shadow banks. Investment by regulated banks is strictly tied to their net worth given by 25 , so that aggregate investment by regulated banks is

$$
K_{\mathscr{R}}=\kappa N_{\mathscr{R}}=\kappa \mathscr{R} n_{\mathscr{R}}
$$

They accumulate net worth until they reach the optimal Cournot interior:

$$
k^{S S}=\frac{\bar{K}}{\mathscr{S}+\mathscr{R}+1}
$$

The behavior of shadow banks is the same as the one described in the equilibrium without regulated banks where $\bar{K}$ should be replaced by

$$
\tilde{K}\left(n_{\mathscr{R}}\right)=\bar{K}-\mathscr{R} \min \left(\kappa n_{\mathscr{R}}, k^{S S}\right)
$$

\footnotetext{
${ }^{17}$ The following condition

$$
N_{\mathscr{S}}+N_{\mathscr{R}}+\Delta q^{R}\left(K_{\mathscr{S}}+K_{\mathscr{R}}\right)<0
$$
}

would entail more than mere pooling of liquidity, and would require pooling of equity and would mean that when a run hits, the entire shadow banking system is acquired by the regulated sector. Although I focus on the case described in 30, the failure of Lehman Brothers and the acquisition of Bear Sterns and Merrill Lynch by JP Morgan and Bank of America respectively suggests that there was partial pooling of equity during the Great Recession and that I are looking at an extreme case. 
Competition Policies in the Regulated Sector To illustrate the impact of increasing the degree of competition in the shadow and in the regulated banking sector, I do two counterfactuals. In the first one, I decrease the number of regulated banks from 3 to 2, keeping the number of shadow banks to 2 . In the second, I keep the former at 3 but decrease the number of shadow banks to 1 . Figure 14 plots the transition path of an economy unexpectedly hit by a shock that brings the net worth of shadow banks to 0 . The transition path in the original economy is depicted in black, the first counterfactual in dark gray and the second in light gray. On (a) and (b), the solid line (dashed line) represents shadow banks (regulated banks). On (c), the solid line (dashed line) represents the asset price (run price).

The decrease in competition in the regulated sector has a slight stabilizing effect in my example by increasing profits of shadow banks. The franchise value channel and the recapitalization channels indeed favor less risk-taking and a faster travel speed through the crisis zone thanks to higher profits as may be seen on (b). But the price-drop effect severely dampens their impact: less regulated banks implied that the drop in prices is more severe after a run on the entire shadow banking system as may be seen on (c). This contributes to making the crisis zone larger. This larger drop is not only caused by the market power channel according to which less banks implies lower output and lower asset prices but also caused by the large drop in regulated banks' net worth caused by their relatively larger exposure.

Decreasing the number of shadow banks and keeping the number of regulated banks constant- $(\mathscr{R}, \mathscr{S})=(3,1)$ - has the already-described stabilizing effect through the franchise value channel, the recapitalization channel and the price-drop channel.

Macroprudential Policies in the Regulated Sector To illustrate the impact of making regulation tighter for regulated banks, I simulate the transition path of two economies, $\kappa=1$ and $\kappa=.25$, unexpectedly hit by a shock that brings the net worth of shadow banks to 0 . Because regulated banks are better capitalized, their starting level of net worth on the transition path is strictly positive. The black lines represent the benchmark case $\kappa=1$.

In my example, a more tightly regulated banking sector implies a more stable overall financial system. The main reason is that regulated banks are better capitalized. Should a run occur and the shadow banks disappear, capital investment by financial intermediaries would drop by less. This maintains a higher run-price when $\kappa=.25$ as 


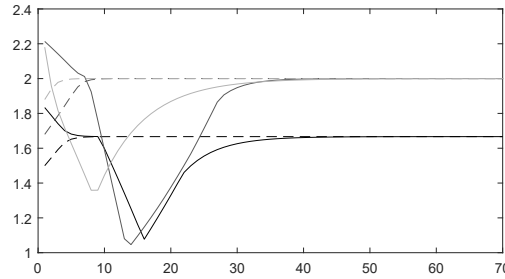

(a) Ind Bank Investment

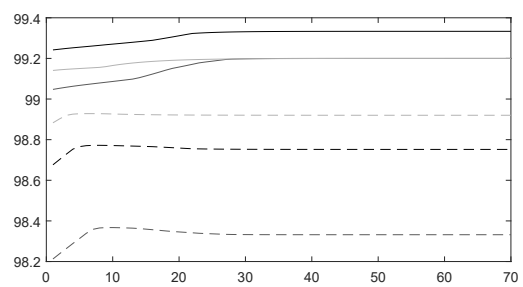

(c) Asset Price

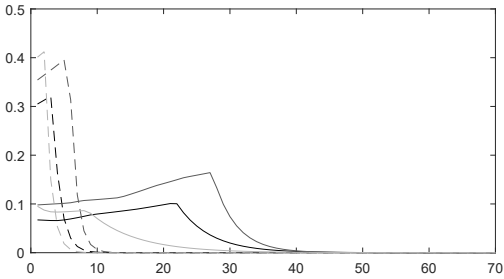

(b) Saving

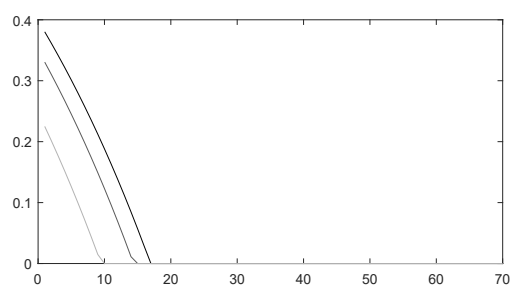

(d) CumProbRun

Figure 14: Transition path as a function ot time for $(\mathscr{R}, \mathscr{B})=(3,2),(2,2),(3,1)$

may be seen on (c).

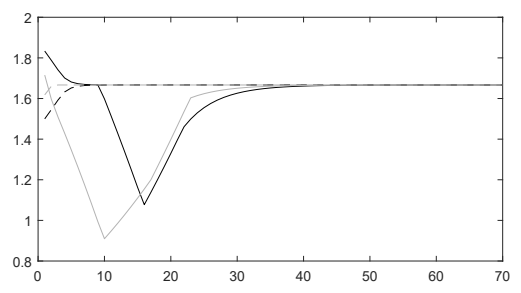

(a) Ind Bank Investment

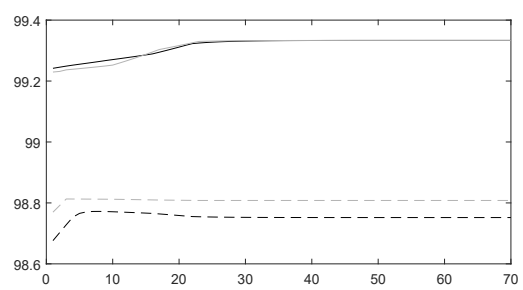

(c) Asset Price

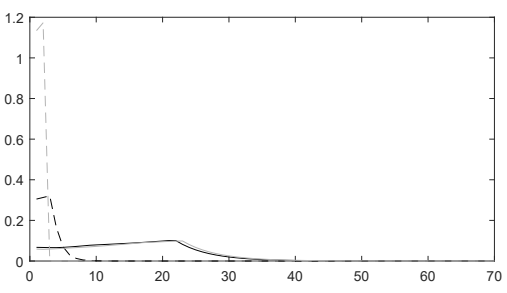

(b) Saving

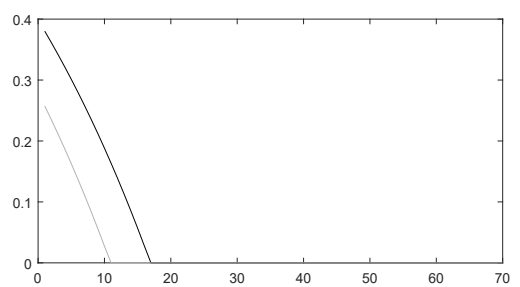

(d) CumProbRun

Figure 15: Transition path as a function ot time for $\kappa=1$ and .25

I now do the same experiment but assuming that before the unexpected shock hit both economy were at the steady-state where the regulated sector was subject to the same capital requirement, $\kappa=.25$. After the shock hits, one economy experiences a tightening of its capital requirement to $\kappa=1$. This counterfactual is closer to what happened in the aftermath of the Great Recession. 
Interestingly, the more tightly regulated system is characterized by a higher probability of a run. The effect described previously doesn't apply anymore because both economies start from the same point in the state-space after the productivity shock hits. There are two key mechanisms. The larger price-drop in the more tightly regulated system stems from the fact that it takes much longer for the regulated banking system to recapitalize which depresses asset price should they be the only ones left to intermediate funds. This makes the run zone with the more tightly regulated system larger. The recapitalization channel dampens this first effects: from the point of view of shadow banks, stricter capital requirements for regulated banks means less competition and therefore higher profits, higher savings and quicker recovery along the transition path. In this example, the first effect dominates.

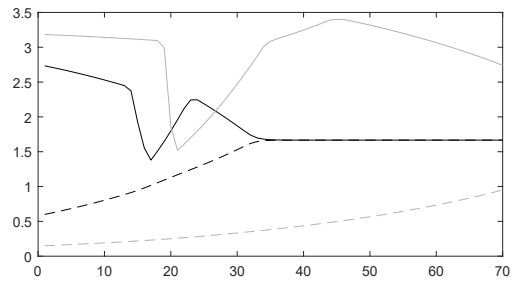

(a) Ind Bank Investment

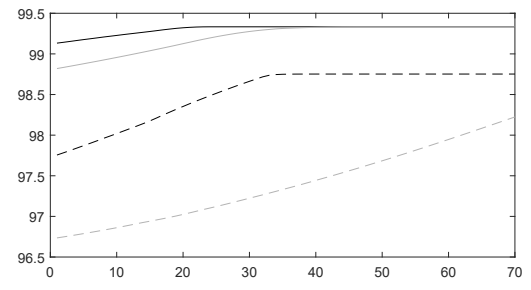

(c) Asset Price

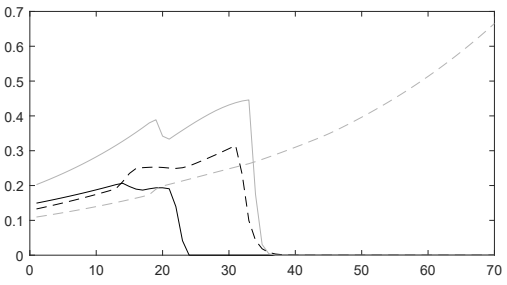

(b) Saving

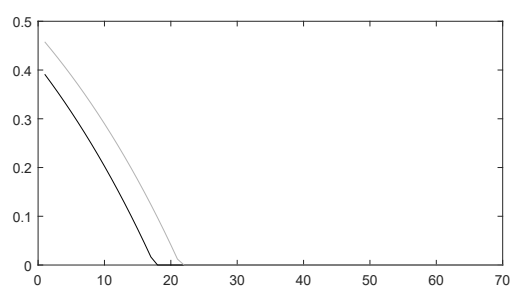

(d) CumProbRun

Figure 16: Transition path as a function ot time for $\kappa=1, .25$ and common starting net worth 